Aus dem Institut für Neuro- und Sinnesphysiologie

(Prof. Dr. Silvio O. Rizzoli)

im Zentrum Physiologie und Pathophysiologie

der Medizinischen Fakultät der Universität Göttingen

\title{
Die präzise Ultrastruktur der Organellen der dendritischen Spines
}

\author{
INAUGURAL-DISSERTATION \\ zur Erlangung des Doktorgrades \\ der Medizinischen Fakultät der \\ Georg-August-Universität zu Göttingen
}

vorgelegt von

Vanessa Salimi

aus

Sydney 
Dekan:

Prof. Dr. rer. nat. H.K. Kroemer

\section{Betreuungsausschuss}

Betreuer/in

Prof. Dr. rer. nat. S. O. Rizzoli

Ko-Betreuer/in:

Prof. Dr. P. Lingor

\section{Prüfungskommission}

Referent/in Prof. Dr. rer. nat. S. O. Rizzoli

Ko-Referent/in: i.V. PD Jan C. Koch

Drittreferent/in: Prof. Dr. Rainer Mausberg

Datum der mündlichen Prüfung: 19.11.2018 
Hiermit erkläre ich, die Dissertation mit dem Titel "Die präzise Ultrastruktur der Organellen der dendritischen Spines" eigenständig angefertigt und keine anderen als die von mir angegebenen Quellen und Hilfsmittel verwendet zu haben.

Göttingen, den 


\section{Inhaltsverzeichnis}

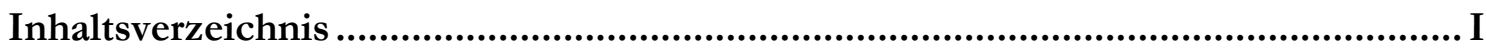

Abbildungsverzeichnis ..........................................................................................II

Tabellenverzeichnis ............................................................................................... III

Abkürzungsverzeichnis...............................................................................IV

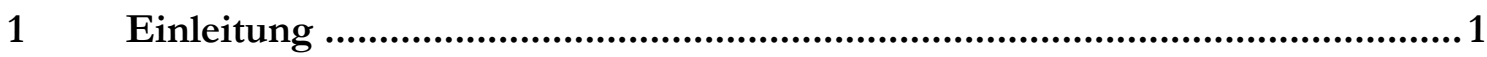

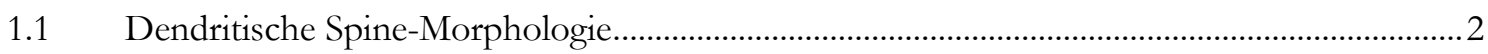

1.2 Synaptische Plastizität..................................................................................................

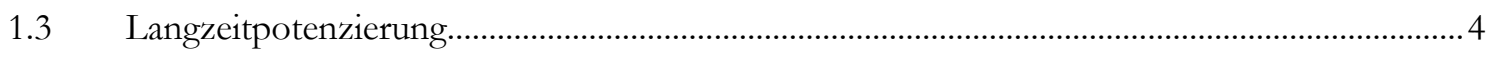

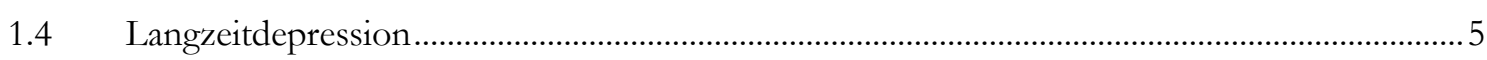

1.5 Dendritische Spine-Zusammensetzung .........................................................................

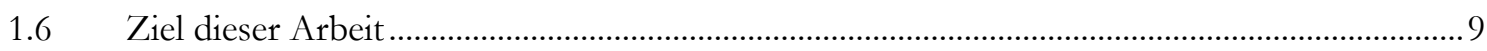

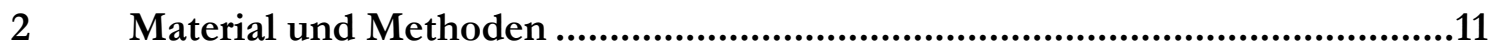

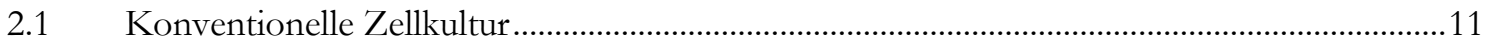

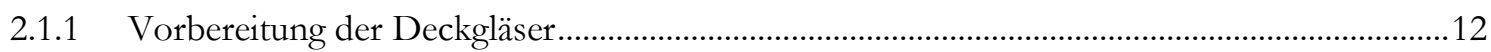

2.1.2 Zerteilung und enzymatische Verarbeitung von Hippocampi ................................................13

2.1.3 Mechanische Zerteilung von Zellen aus dem Gewebe .............................................................14

2.2 Fixation, EM-Methode, Adobe Photoshop CS6, Matlab .........................................................15

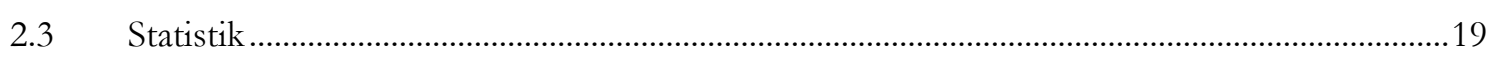

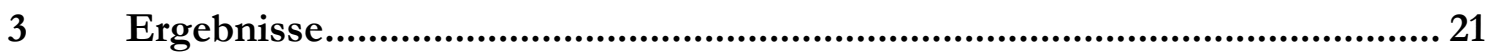

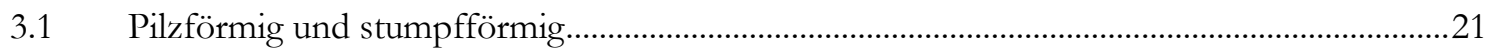

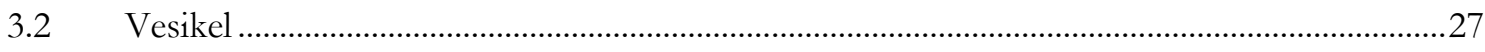

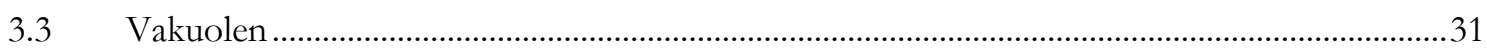

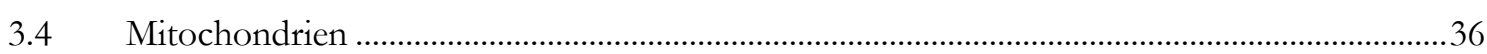

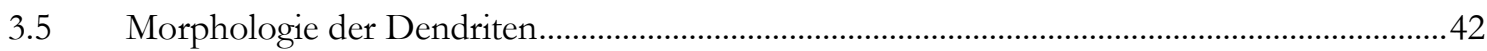

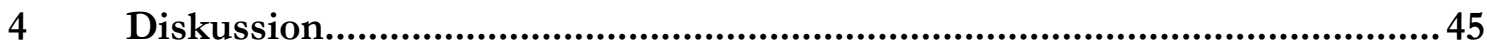

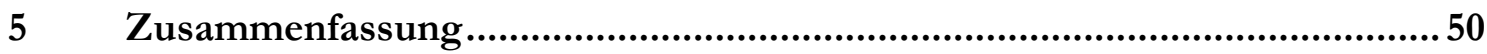

5.1 Limitationen der wissenschaftlichen Arbeit .........................................................................

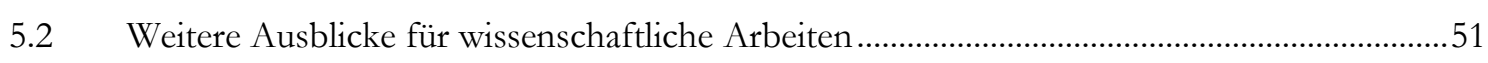

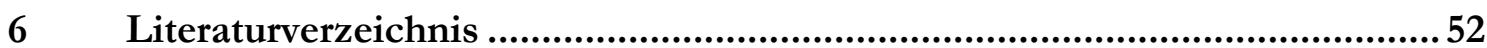




\section{Abbildungsverzeichnis}

Abbildung 1: A) Darstellung eines Dornenfortsatzes einer Purkinjezelle, Originalzeichnung von Cajal (Yuste 2015). B) Transversalschnitt durch einen Dendriten (Gray 1959)................1

Abbildung 2: Beispiele der Klassifikation der dendritischen Spines (Schema)........................................2

Abbildung 3: Elektronenmikroskopie von Dornenfortsätzen zur Verdeutlichung der

Klassifikation der dendritischen Spines (Harris und Kater 1994).................................................

Abbildung 4: Überblick einiger Organellen der dendritischen Spines....................................................6

Abbildung 5: Darstellung einer Spine im EM-Bild .................................................................................

Abbildung 6: Weiterer Schnitt der Postsynapse ……………............................................................16

Abbildung 7: Darstellung eines Arbeitsprozesses, der zeigt, dass die Spines rotiert wurden...............16

Abbildung 8: Manuelle Umzeichnung der Postsynapse.............................................................................

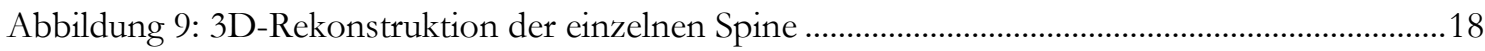

Abbildung 10: Darstellung aller Dendriten, die morphologisch in die Gruppierung pilzförmig

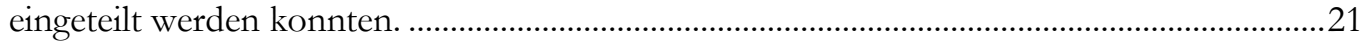

Abbildung 11: Darstellung aller Dendriten, die morphologisch in die Gruppierung stumpfförmig eingeteilt werden konnten..................................................................................22

Abbildung 12: Darstellung eines pilzförmigen dendritischen Dornenfortsatzes ..................................23

Abbildung 13: Darstellung eines pilzförmigen Dendritens mit einer Anhäufung von Vesikeln........23

Abbildung 14: Dreidimensionale Darstellung einer pilzförmigen dendritischen Spine ........................24

Abbildung 15: Darstellung eines Dendriten mit klassischen Charakteristika für eine pilzförmige Morphologie

Abbildung 16: Darstellung einer stumpfförmigen Synapse nach dem Plotting mit Matlab als

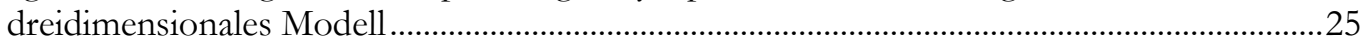

Abbildung 17: Darstellung einer stumpfförmigen Postsynapse als 3D-Modell ....................................25

Abbildung 18: Stumpfförmige Postsynapse mit mehreren postsynaptisch dichten Bereichen ..........26

Abbildung 19: Säulendiagramm zur Veranschaulichung der Vesikelanzahl in pilz- und stumpfförmigen Dendriten ...................................................................................................2

Abbildung 20: Punktdiagramm zur Veranschaulichung der Vesikelanzahl in pilz- und

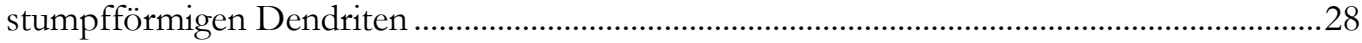

Abbildung 21: Darstellung der Anzahl der Spines, die überhaupt Vesikel haben ................................29

Abbildung 22: Darstellung der Korrelation der Entfernung zum Spine-Zentrum (x-Achse) und die Entfernung zum Zentrum der aktiven Zone (y-Achse) in $\mu \mathrm{m}$...........................................30

Abbildung 23: Säulendiagramm zur Darstellung der Anzahl der Vakuolen in pilzförmigen und stumpfförmigen Dendriten ........................................................................................................ 31

Abbildung 24: Darstellung, wieviel Dendriten mit der Morphologie pilzförmig und stumpfförmig eine gewisse Anzahl an Vakuolen haben...............................................................31

Abbildung 25: Säulendiagramm zur Darstellung des Volumens der Vakuolen $\left(\mu \mathrm{m}^{3}\right)$ für pilzförmige und stumpfförmige Dendriten

Abbildung 26: Darstellung der Entfernung zur Mitochondrienmembran in Abhängigkeit von der Entfernung zum Zentrum der Mitochondrien in $\mu \mathrm{m}$ der Vakuolen in jeweils pilzsowie stumpfförmigen Dendriten

Abbildung 27: Säulendiagramm zur Darstellung des Volumens der Mitochondrien in $\mu \mathrm{m}^{3}$................36

Abbildung 28: Verlaufsdiagramm zur Übersicht der Mitochondienanzahl und die jeweiligen Volumina in Dendriten

Abbildung 29: Punktdiagramm zur Darstellung der Distanz der Mitochondrien zum Zentrum der aktiven Zone in $\mu \mathrm{m}$ und zur aktiven Zone in $\mu \mathrm{m}$.. 
Abbildung 30: Darstellung der Entfernung von den Mitochondrien zum Spine-Zentrum in Abhängigkeit zur Entfernung der aktiven Zone in $\mu \mathrm{m}$

Abbildung 31: Darstellung der Distanzen der Mitochondrien zur aktiven Zone auf der und zum Mitochondrienzentrum in $\mu \mathrm{m}$

Abbildung 32: Die Graphen zeigen die Mitochondrien in Bezug zur Entfernung zur Membran und die Entfernung zum Zentrum des Dendriten in $\mu \mathrm{m}$.

Abbildung 33: Darstellung der Form der Dendriten durch Gegenüberstellung der jeweiligen Achsen.

Abbildung 34: Gegenüberstellung der gesamten Membranoberfläche zum durchschnittlichen Schnittvolumen von stumpf- und pilzförmigen Dendriten

Abbildung 35: Stark vereinfachte Skizze dreier pilzförmiger Synapsen, die verdeutlichen soll, dass die Distanzen von der aktiven Zone (A) zu den Mitochondrien (M) aufgrund der komplexen und teils unterschiedlichen Form der Dendriten inkonsistent sind.

Abbildung 36: Skizze einer Ellipse mit Werten, um das Verhältnis der kleineren Achse gegen die größere Achse zu verdeutlichen.

\section{Tabellenverzeichnis}

Tabelle 1: Aufstellung der verwendeten Materialien und ihre nähere Erläuterung 


\section{Abkürzungsverzeichnis}

\begin{tabular}{|c|c|}
\hline AMPA & a-amino-3-bydroxy-5-methyl-4-isoxazolepropionic acid receptor \\
\hline $\mathrm{DAB}$ & 3,3'-Diaminobenzidin \\
\hline $\mathrm{ddH}_{2} \mathrm{O}$ & Doppelt destilliertes Wasser, Reinstwasser \\
\hline DMEM & Dulbecco's Modified Eagle Medium \\
\hline EDTA & Ethylendiamintetraacetat \\
\hline EM & Elektronenmikroskopie \\
\hline EPSP & Exzitatorisches postsynaptisches Potenzial \\
\hline FCS & Fetal Calf Serum (Fetales Kälberserum) \\
\hline FIT & Regressionsanalyse \\
\hline FUDR & 5-Fluoro-2'-deoxyuridine \\
\hline HBSS & Hank’s Balanced Salt Solution \\
\hline LTD & Long Term Depression, Langzeitdepression \\
\hline LTP & Long Term Potential, Langzeitpotenzierung \\
\hline MEM & Minimal's Eagle Medium \\
\hline NMDA & N-Methyl-D-Aspartat \\
\hline PBS & Polybutylensuccinat \\
\hline PLL & Poly-L-Lysin \\
\hline PSD & Postsynaptische Dichte \\
\hline STED & Stimulated Emission Depletion Microscopy \\
\hline
\end{tabular}




\section{Einleitung}

Das Gehirn ist das komplexeste Organ im menschlichen Körper. Es besteht aus über 80 Milliarden Neuronen (Azevedo et al. 2009), die die Grundlage für Bewusstsein, Gedächtnis und Lernen bilden. Synapsen sind der Kontaktpunkt zwischen zwei Neuronen, sie ermöglichen die Signalübertragung vom präsynaptischen Teil in die Postsynapse. Die Dornenfortsätze der Postsynapse haben eine besondere Verdichtung, in der sich Ionenkanäle und Transmitterrezeptoren befinden. Diese sind zur Signalübertragung von immenser Bedeutung. Die Morphologie des postsynaptischen Dornenfortsatzes variiert dynamisch und kann in einige Formen unterteilt werden.

Santiago Ramón y Cajal gilt als Wegbereiter für die Forschung an Synapsen. Obwohl seine Arbeit und seine Ideen rund 100 Jahre alt sind, sind sie immer noch Grundlage für zahlreiche Neurowissenschaftler (Sotelo 2003). Ramón y Cajal hat 1903 eine Methode gefunden, mit der sich Neurofibrillen und Axone zuverlässiger färben lassen als mit der zuvor verwendeten Golgi-Färbung. Er veröffentlichte eine modifizierte Golgi-Färbung, um das neuronale Zytoskelett darzustellen (Sotelo 2003). Auch noch über 100 Jahre nach seiner besonderen Darstellung der Dornenfortsätze ist diese Methode von hoher Signifikanz und wird von zahlreichen Wissenschaftlern thematisiert (Yuste 2015).

A

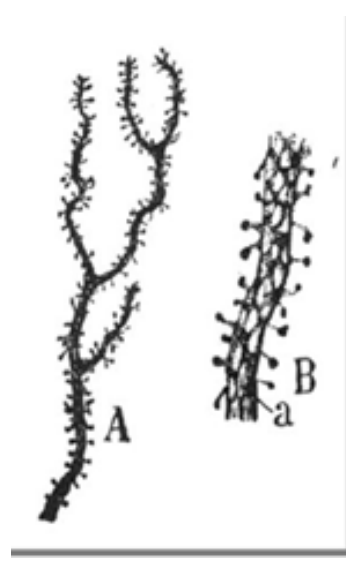

$\mathrm{B}$

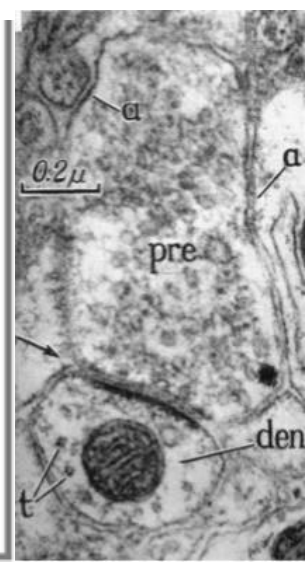

Abbildung 1: A) Darstellung eines Dornenfortsatzes einer Purkinjezelle, die Dornen sind hier deutlich zu erkennen, Originalzeichnung von Cajal (Yuste 2015). B) Transversalschnitt durch einen Dendriten, der Pfeil zeigt die postsynaptisch dichte Stelle (Gray 1959). 


\subsection{Dendritische Spine-Morphologie}

Anhand der Elektronenmikroskopie lässt sich die Morphologie der Spines gut charakterisieren. Bereits seit ihrer Entdeckung zur Jahrhundertwende wurden dendritische Dornenfortsätze durch ihre vielfältigen Formen klassifiziert (Chicurel und Harris 1992).

Spines haben eine durchschnittliche Länge von 0,5-6 $\mu \mathrm{m}$ und ihr Volumen variiert von $0,01 \mu \mathrm{m}^{3}$ bis $0,8 \mu \mathrm{m}^{3}$ (Chicurel und Harris 1992). Die gesamte Länge einer dünnen Spine ist größer als der Halsdurchmesser, der in einem knolligen Kopf endet und einen Durchmesser von 0,6 mm aufweist. Stumpfförmige Spines sind kurz und breit und ohne eine Verengung in der Kopfregion. Pilzförmige Spines haben einen eingeschnürten Hals und einen großen Kopf (0,6 mm im größten Querschnitt) (Sorra und Harris 2000).

Dendritische Spines werden in pilzförmig, dünn, stumpfförmig, dünnhälsig und verzweigt klassifiziert (Jones und Powell 1969). Bedeutend dabei ist hingegen, dass diese Klassifizierung nicht strikt vorgenommen wird, da, wie die Zweiphotonenmikroskopie nachgewiesen hat, die Spines dynamisch sind und über eine gewisse Zeit ihre Morphologie und Struktur verändern (Dunaevsky et al. 1999). Die Zweiphotonenmikroskopie der freibeweglichen Dornenfortsätze zeigte, dass $50 \%$ der observierten Spines in ihrer morphologischen Klassifizierung verblieben, während die andere Hälfte die Klassifizierung wechselte (Hering und Sheng 2001).

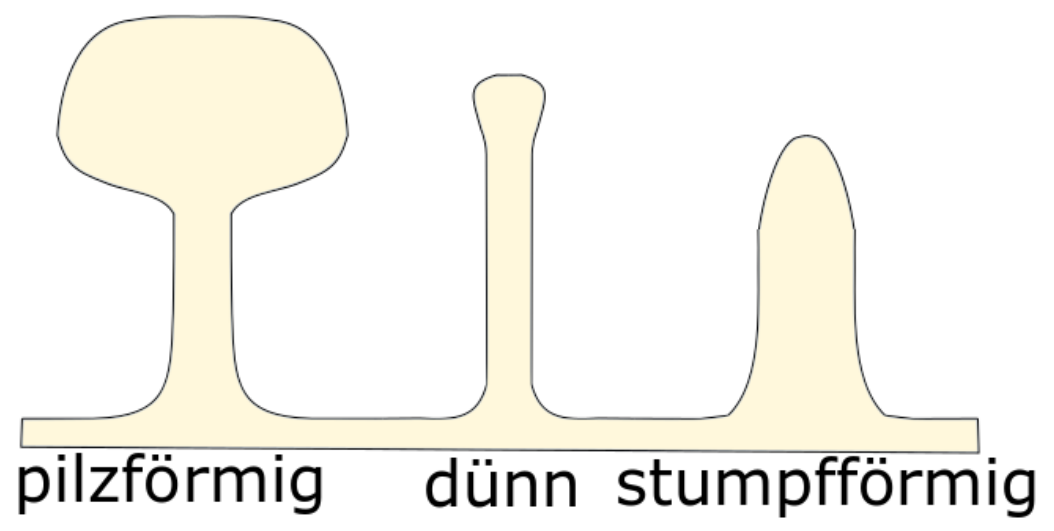

Abbildung 2: Diese Grafik zeigt einige Beispiele der Klassifikation der dendritischen Spines als Schema.

Die Dynamik der Spine-Form zeigt, dass die Klassifikation der Spines auf statischen Bildern beruht und dass sich die Morphologie einer einzelnen Spine zeitweilig verändern 
kann. (Dunaevsky et al. 1999). Die Form der dendritischen Dornenfortsätze kommt durch das Zytoskelett zustande. Während der Hals der Dendriten meistens Mikrotubuli und weitere intermediäre Filamente beinhaltet, ist nichts dergleichen in den Dornenfortsätzen zu finden. Nur in wenigen Fällen waren Mikrotubuli in großen dendritischen Dornenfortsätzen auszumachen (Chicurel und Harris 1992).

Mit der großen kopfartigen Struktur und dem vergleichsweise dünnen Hals kann ein anderes Milieu als im Shaft geschaffen werden, was besonders bedeutsam für den Kalziumeinstrom nach Stimulierung der Synapse ist. Es gibt ungefähr 1-20 Kalziumkanäle auf dem Kopf des Dornenfortsatzes (Sabatini et al. 2001). Diese verhältnismäßig geringe Anzahl reicht bereits für das kleine Volumen der Spine aus, um einen Konzentrationsunterschied zu bewirken. Zudem ist die Morphologie der Spines für die Schnelligkeit der Kalziumantwort entscheidend: Spines mit einem kürzeren Hals haben eine längere Latenzzeit verglichen mit Spines mit einem längeren Hals (Majewska et al. 2000). Ein Dornenfortsatz kann diese Eigenschaft verwenden, um die postsynaptische Kalziumgeschwindigkeit zu modifizieren. Außerdem kann die Anzahl der jeweiligen Spines auf einem Dendriten reguliert werden. Dementsprechend hat eine abnormale SpineMorphologie diverse neurologische Krankheiten zur Folge, bspw. das Down-Syndrom oder Epilepsie (Ferrer und Gullotta 1990).

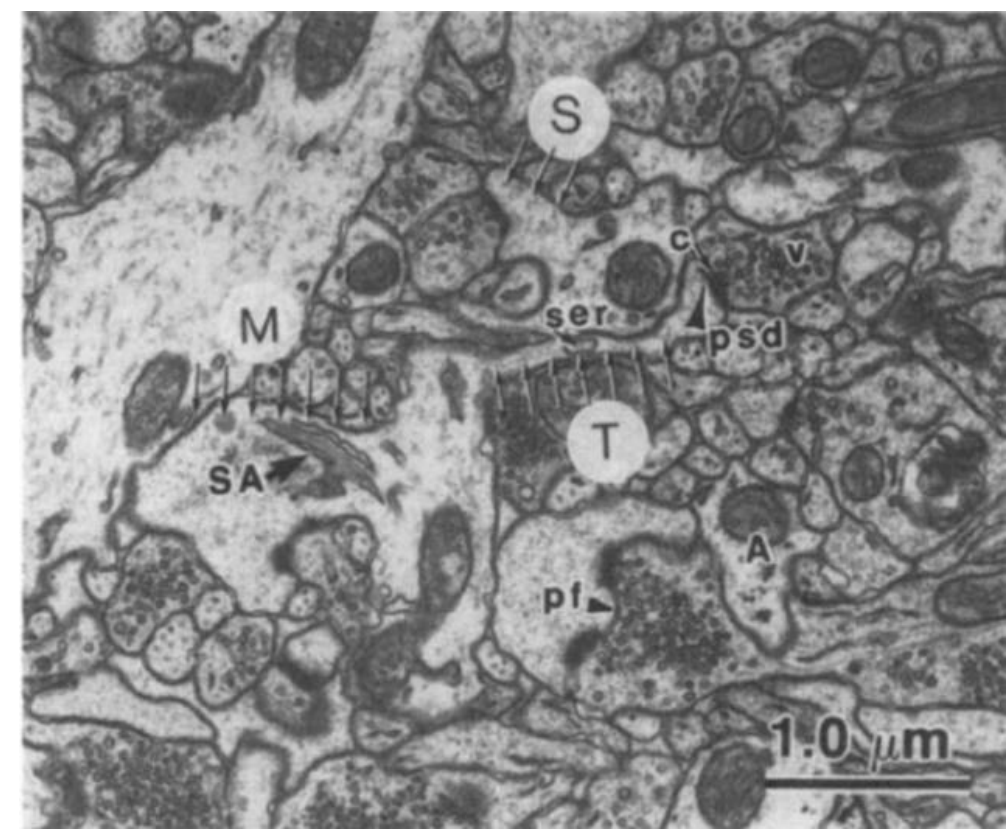

Abbildung 3: Elektronenmikroskopie von Dornenfortsätzen, entnommen aus Neuronen des Hippocampus. Hier wurden drei Spines parallel zu ihrer Längsachse geschnitten, die verschiedene Morphologien darstellen: stumpfförmig (S), pilzförmig (M, von Mushroom) und dünn ( $\mathrm{T}$, von Thin). Der dünne Dornenfortsatz $(\mathrm{T})$ beinhaltet ein glattes endoplasmatisches Retikulum (sEr), und in 
dem pilzförmigen Dornenfortsatz ist ein Dornenapparat (Sa, von Spine aparat) zu erkennen. Eine perforierte postsynaptische Dichte ist mit „pf“ gekennzeichnet (Harris und Kater 1994).

\subsection{Synaptische Plastizität}

Der Ausdruck ,Plastizität ${ }^{\star}$ wurde in der Gehirnforschung über ein Jahrhundert lang verwendet, um auf die Wechsel der neuronalen Organisation hinzuweisen, die für verschiedene Arten des Verhaltens begründet wurden. Die Arten des Verhaltens können sowohl kurzanhaltend oder langanhaltend sein als auch eine spezifische oder unspezifische Art des Lernens beinhalten (Berlucchi und Buchtel 2009).

Die Plastizität beschreibt die Veränderung in der Anzahl der dendritischen Dornenfortsätze. Die Art und der Grad der Plastizität ändern sich mit der Reife der Gehirnregion und experimentellen Gegebenheiten (Sorra und Harris 2000).

Eine Synapse ist keine statische Struktur, sondern sie adaptiert sich kontinuierlich an verschiedene Stimuli. Dieser, Synaptische Plastizität' genannte Prozess resultiert in einer Stärkung oder Schwächung der Synapse und ihrer Fähigkeit, Signale zu übermitteln - der Hauptmechanismus des Gedächtnisses und Lernens. Die bekannteste Form dieser Mechanismen ist die Langzeitpotenzierung (Long Term Potential, LTP), die auf der postsynaptischen Seite abläuft.

\section{$1.3 \quad$ Langzeitpotenzierung}

Unter LTP ist die Verstärkung der synaptischen Übertragung eines Neurons als Reaktion auf eine vermehrte Bildung von Aktionspotenzialen zu verstehen. Zwei signifikante langzeitige Plastizitätsmechanismen wurden in dendritischen Dornenfortsätzen identifiziert: die oben genannte LTP und ihr Gegenstück, die Langzeitdepression (Long Term Depression, LTD). Diese beinhalten die Wechsel sowohl in der Dornenfortsatzmorphologie als auch in ihrer molekularen Zusammensetzung. Die LTP verändert die Anzahl der Spines, ihre Gestalt und auch ihre subzelluläre Zusammensetzung (Bourne und Harris 2008).

Der sich in der postsynaptischen Membran befindliche AMPA-Rezeptor wird bei einem Aktionspotenzial durch das Glutamat geöffnet und lässt somit Natriumionen durchströmen. Dieser Einstrom bewirkt ein exzitatorisches postsynaptisches Potenzial (EPSP). Durch weitere Aktionspotenziale, also bei länger anhaltender Erregung, wird die postsynaptische Membran stärker depolarisiert, woraus die Öffnung der N-Methyl-D- 
Aspartat-Rezeptoren (NMDA) resultiert, da das Magnesium diese nicht mehr blockiert. Durch die geöffneten NMDA-Rezeptoren kann das Kalzium nun ungehindert eindringen und Schlüsselenzyme aktivieren, wozu unter anderem Stickstoffmonoxid, CalciumCalmodulin-Kinase II, Adenylatcyclase etc. gehören.

Stickstoffmonoxid führt dazu, dass in der Präsynapse mehr Transmitter pro Aktionspotenzial ausgeschüttet werden, was wiederum eine bessere Übertragung des Aktionspotenzials bewirkt. Dadurch kann im Schnitt mehr Kalzium eindringen, sodass das Stickstoffmonoxid häufiger aktiviert werden kann. Die Transmittermenge pro Aktionspotenzial steigt also.

Die Calcium-Calmodulin-Kinase II wird durch Kalzium aktiviert und führt zu einem gehäuften Auftreten von Natriumkanälen in der postsynaptischen Membran. So wird jedes Aktionspotenzial besser übertragen.

Die LTP resultiert typischerweise aus einer kurzen, starken NMDA-Rezeptoraktivität, während die LTD aus schwächeren und längeren Aktivitäten hervorgeht. (Dudek und Bear 1992).

Studien, die den Effekt der Langzeitpotenzierung verwendeten, ergaben gemischte Ergebnisse. Die Elektronenmikroskopie zeigte ein Wachstum der Dornenfortsätze (Fifkova und Anderson 1981), während andere Resultate deutlich machten, dass es keine Veränderung in der Spine-Morphologie gibt (Chang und Greenough 1984). Außerdem wurde berichtet, dass die LTP die Dichte der Spines erhöht (Engert und Bonhoeffer 1999), aber es gibt mindestens eine Studie, die keinen Anstieg der Anzahl der Spines beobachten konnte (Sorra und Harris 1998).

Das Problem an diesen Studien ist, dass nur an einem kleinen Teil der analysierten stimulierten Synapsen LTP angewendet wurde und es dadurch nicht möglich war, ebendiese zu identifizieren. Darüber hinaus mussten die Autoren die zwei Populationen (stimuliert und nicht stimuliert) vergleichen, was jedoch ein schwieriges Unterfangen sein kann, da in jeder einzelnen Gruppe eine große strukturelle Heterogenität besteht.

\subsection{Langzeitdepression}

Die Langzeitdepression (LTD) wird wie ein paralleler, gegenläufiger Prozess zur Langzeitpotenzierung betrachtet (Segal 2016). Darunter ist eine Abschwächung des Aktionspotenzials zu verstehen. Die LTD vermindert die Anzahl der involvierten Spines und ihre Größe (Bourne und Harris 2008). Die Quellen des einströmenden Kalziums sind 
dabei verschieden. Die LTP in der Ca1-Region des Hippocampus beinhaltet den Kalziumeinstrom durch den NMDA-Rezeptor, wohingegen bei der LTD im Cerebellum der Kalziumeinstrom durch spannungsgeleitete Kalziumkanäle gesteuert wird (Bolshakov und Siegelbaum 1994).

\subsection{Dendritische Spine-Zusammensetzung}

Dendritische Dornenfortsätze beinhalten eine große Varietät und Anzahl an Organellen und Proteinen (Abbildung 4).

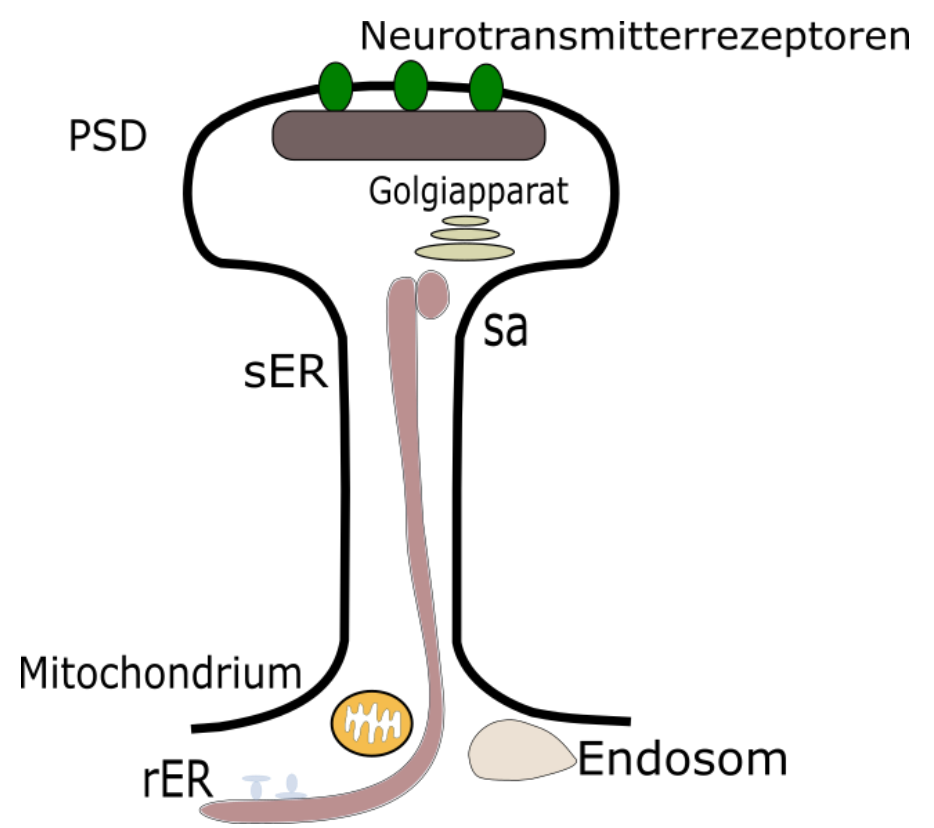

Abbildung 4: Überblick einiger Organellen der dendritischen Spines. RER: raues endoplasmatisches Retikulum, sER: glattes endoplasmatisches Retikulum, sa: Dornenapparat, PSD: postsynaptische Dichte.

Die postsynaptische Dichte

Die postsynaptische Dichte (PSD) ist eine spezifische elektronenmikroskopisch dichte Organelle, die an der postsynaptischen Seite der exzitatorischen Synapse lokalisiert ist, wo NMDA und AMPA, die zwei Hauptarten der Rezeptoren, gehäuft auftreten (Stewart et al. 2014).

Die PSD ist dem synaptischen Junction-Komplex benachbart, der die Proteine beinhaltet, die eine Adhäsion zwischen der Prä- und Postsynapse vermitteln (Cho et al. 1992). Für die PSD wurden einige Funktionen vorgeschlagen, unter anderem die Regulation der postsynaptischen Rezeptoren, die Stabilisierung der synaptischen Verbindungen (Siekevitz 
1985), die Signaltransduktion als Antwort auf Membranrezeptoren und die Abspeicherung der Informationen (Lisman und Goldring 1988).

Die PSD beträgt ungefähr $10 \%$ der Gesamtoberfläche der Spine und ist exakt zur präsynaptischen Zone ausgerichtet. Da die Größe des Spine-Kopfes proportional zum Bereich der PSD, der Anzahl der postsynaptischen Rezeptoren und der Anzahl der präsynaptischen angedockten Vesikel ist, korreliert das Wachstum des Spine-Kopfes wahrscheinlich mit einer Verstärkung der synaptischen Übertragung (Hering und Sheng 2001). Es wurden multiple Formen der PSD beobachtet: von einer einfachen, kontinuierlichen Erscheinung über eine diskontinuierliche bis hin zu einer perforierten Struktur, die weiterhin in „fenestriert“, „hufeisenförmig“ oder „segmentiert“ klassifiziert werden kann (Hering und Sheng 2001). Perforierte Strukturen sind entweder eine vorübergehende Form während der Teilung der Spines oder das Ergebnis einer erhöhten Rezeptoraktivität nach einer starken Stimulation, wie es bei der Langzeitpotenzierung vorkommt (Sorra und Harris 1998). Dies ist auch durch die Beobachtung gestützt, dass stimulierte Spines eine größere PSD haben (Toni et al. 2001).

Neurotransmitterrezeptoren:

Neurotransmitterrezeptoren können in verschiedene Klassen unterteilt werden, bspw. die inhibitorische $\gamma$-Aminobuttersäure (GABA) und Glycinrezeptoren oder exzitatorische Acetylcholin- oder Glutamatrezeptoren. Auf einer dendritischen Spine können nur exzitatorische Rezeptoren gefunden werden, wohingegen hemmende GABAR- oder Glycinrezeptoren sich immer direkt auf dem Hals oder auf Zellkörpern befinden (Choquet und Triller 2013).

Glutamatrezeptoren werden klassifiziert in ionotrope Glutamatrezeptoren (AMPA-, NMDA-, Kainat-Rezeptoren) oder metabotrope Glutamatrezeptoren. AMPA-Rezeptoren sind zuständig für die Depolarisation der postsynaptischen Dichte, nachdem sich Glutamat gebunden hat. Sie sind permeabel für Natrium- und Kalziumionen. Die NMDARezeptoren sind liganden- und spannungsabhängig und permeabel für Natrium, Kalium und Kalzium. Beim Ruhemembranpotenzial sind diese Kanäle durch extrazelluläres Magnesium blockiert, das nur herausgeschleust wird, wenn die Postsynapse über $-40 \mathrm{mV}$ depolarisiert wird (Nikolaev et al. 2012). Ist dieser Zustand erreicht, öffnet sich der NMDA-Rezeptor und Kalzium strömt in die Zelle hinein.

Kainat-Rezeptoren sind durchlässig für Natrium und Kalium und nur zum Teil auch für Kalzium (Nakanishi und Masu 1994). 
Ionenkanäle:

Spannungsgesteuerte Ionenkanäle sind für die De- und Repolarisation des Dendriten verantwortlich, ausgelöst durch Neurotransmitterrezeptoren. Dendriten besitzen verschiedene Kalzium- und Kaliumkanäle, wohingegen Natriumkanäle nur in einer geringen Anzahl aufzufinden sind (Lorincz und Nusser 2010). Dies ist eine mögliche Erklärung dafür, dass die Aktionspotenziale nur im Axon und nicht im Dendriten generiert werden können.

Endosomen:

In dendritischen Spines können Endosomen gefunden werden, während noch nicht erschlossen ist, ob sich solche auch in der Präsynapse befinden (Spacek und Harris 1997). Sie besitzen meist eine tubuläre Struktur und sind mit Vesikeln assoziiert. Endosomen dienen als Speicher für Neurotransmitterrezeptoren (Bourne und Harris 2008) und sind daher signifikant, da sie Proteine und Lipide zu verschiedenen Zielen, bspw. zur Zelloberfläche oder zum Golgi-Komplex, senden (Cooney et al. 2002; Murk, J. L. A. N. et al. 2003).

Endoplasmatisches Retikulum und Golgi-Apparat:

Das endoplasmatische Retikulum kann durch Ribosomen in zwei Arten unterschieden werden: Das glatte endoplasmatische Retikulum besitzt keine Ribosomen. Das raue endoplasmatische Retikulum weist jedoch zahlreiche Ribosomen auf seiner Oberfläche auf, und seine Hauptaufgaben sind die Proteinbiosynthese und Membranproduktion.

Das glatte endoplasmatische Retikulum spielt in der dendritischen Spine eine größere Rolle und stellt ein Netzwerk im Hals des Dornenfortsatzes dar. Es erstreckt sich mitunter bis kurz vor die PSD (Spacek und Harris 1997) und erscheint als eine abgeflachte, zisternenartige Struktur im Elektronenmikroskop. Größere Spines enthalten auch mehr glatte endoplasmatische Retikula als kleinere Spines (Gray 1959). Das glatte endoplasmatische Retikulum hat die Funktion, die Kalziumkonzentration zu regulieren, und fungiert so als ein intrazellulärer Speicher. Es ist darüber hinaus mit Vesikeln verbunden. In $5 \%$ der dendritischen Dornenfortsätzen ist das endoplasmatische Retikulum im Dornenapparat organisiert (Spacek und Harris 1997), der primär als Kalziumspeicher fungiert. Dies ist bei der LTP von erheblicher Bedeutung, da es sonst zu einem geringeren Kalziumeinstrom in die Synapse kommen kann. 
Mitochondrien:

Mitochondrien sind Energieträger der Nervenzellen, da sie Adenosintriphosphat (ATP) generieren. Sie sind in ausgestülpten Fortsatzspitzen reichhaltig vorhanden. Das von ihnen produzierte ATP diffundiert in den Dendriten, um Energie für die Signaltransduktion zu erzeugen. Im Gegensatz dazu befinden sich Mitochondrien eher selten in dendritischen Dornenfortsätzen und sind meistens in komplexen, großen Spines zu finden (Chicurel und Harris 1992). Aufgrund der eher eingeschränkten Diffusion von den ausgestülpten Fortsatzspitzen zu den Dornenfortsätzen ist es unwahrscheinlich, dass das von den Mitochondrien produzierte ATP die PSD in ausreichender Menge erreichen kann.

Ferner wurde gezeigt, dass die PSD in der Lage ist, selbst eine Glykolyse durchzuführen, und dass diese Art der Energiegewinnung wahrscheinlich die Quelle von ATP für die Synapse ist (Wu et al. 1997).

\subsection{Ziel dieser Arbeit}

Die Synapse ist die bedeutendste Komponente für die neuronale Kommunikation. Die Organellen der Präsynapse sind bekannt, wie z. B. die synaptischen Vesikel. Allerdings ist dies auf der postsynaptischen Seite nicht der Fall. Die Postsynapse wird zwar seit Jahrzehnten weitgehend untersucht, jedoch wurde bisher mit hippocampalen Gehirnschnitten geforscht. Für diese Forschung wurden die Zellen aus dem Hippocampus gefiltert und eine Zellkultur angelegt. Aus dieser wurden Schnitte gefertigt und mithilfe eines Elektronenmikroskops abgebildet. Diese Elektronenmikroskopbilder wurden mithilfe der MATLAB-Software analysiert und in ein 3D-Modell umgewandelt.

Um die Funktions- und Wirkungsweise der Postsynapse nachvollziehen zu können, müssen zunächst die Organellen verstanden werden. Es gibt mehrere Morphologien der dendritischen Dornenfortsätze (filopodienförmig, stumpfförmig, pilzförmig und dünn). In dieser Arbeit werden zwei dieser Morphologien, nämlich pilzförmig und stumpfförmig, genauer untersucht und einander gegenübergestellt. Im Verlauf der Arbeit wird untersucht, ob die einzelnen Zellorganellen dieser Synapsen wie z. B. Mitochondrien hinsichtlich ihrer Größe, Anzahl und Struktur Unterschiede zu der zweiten Morphologie aufweisen. Es kann zudem davon ausgegangen werden, dass eine unterschiedliche Form der Dornenfortsätze auch auf eine unterschiedliche Funktion hinweist. 
Wenn die Morphologie bekannt ist, können darauf basierend die Funktionen der einzelnen Zellorganellen besser untersucht werden. Denkprozesse werden besser verstanden und Pathologien können besser erkannt und sogar verhindert werden (Alzheimer). 


\section{$2 \quad$ Material und Methoden}

Die Beschaffung der Ratten erfolgte entweder von spezialisierten Laboren oder von kommerziellen Anbietern. Alle Tiere wurden gemäß den Vorschriften der Universität Göttingen und des Landesamts für Verbraucherschutz in Braunschweig behandelt. Die Präparate und Bilder wurden von Prof. Dr. Thomas Schikorski, Universidad Central Del Caribe, Bayamón, Puerto Rico, gemacht.

Das Aktenzeichen der Tötungsantragsnummer lautet: T.9-08.

\subsection{Konventionelle Zellkultur}

Im Folgenden wird die Prozedur der Herstellung einer konventionellen Zellkultur näher erläutert. Die verwendeten Materialien sind in Tabelle 1 aufgeführt.

Tabelle 1: Aufstellung der verwendeten Materialien und ihre nähere Erläuterung

\begin{tabular}{|c|c|}
\hline Lösung & Bestandteile der Lösung \\
\hline Aussaatmedium (Plating Medium) & $\begin{array}{l}111 \mathrm{ml} \text { MEM } \\
66 \mathrm{mg} \text { Glucose }(3,3 \mathrm{mM}) \\
11 \mathrm{ml} \text { Horse-Serum }(10 \%) \\
1,1 \mathrm{ml} \text { Glutamin }(2 \mathrm{mM})\end{array}$ \\
\hline Boratpuffer pH 8,5 $100 \mathrm{Mm}$ & $\begin{array}{l}\text { 1. Lösung - Base ( } 500 \mathrm{ml}) \text { : } \\
\mathrm{Na}_{2} \mathrm{~B}_{4} \mathrm{O}_{7} * 10 \mathrm{H}_{2} \mathrm{O} 19,07 \mathrm{~g} \text { längere Zeit umrühren } \\
\text { 2. Lösung - Säure }(500 \mathrm{ml}) \text { : } \\
\mathrm{H}_{3} \mathrm{BO}_{3} \text { (Borsäure) } 3,09 \mathrm{~g} \\
\text { 3. Mit Reinstwasser mischen } \\
\text { Zweite Lösung (Säure) in ein Becherglas geben, der pH-Wert } \\
\text { von } 8,5 \text { wird erreicht, indem die erste Lösung (Base) } \\
\text { hinzugegeben wird. }\end{array}$ \\
\hline
\end{tabular}




\begin{tabular}{|c|c|}
\hline Enzymlösung & $\begin{array}{l}2 \mathrm{mg} \text { Cystein } \\
10 \mathrm{ml} \text { DMEM (Dulbecco's Modified Eagle's Medium, ein } \\
\text { standardisiertes Nährmedium für die Zellkultur) } \\
0.1 \mathrm{ml} \mathrm{CaCl} 2(100 \mathrm{mM})) \\
0.1 \mathrm{ml} \text { EDTA }(50 \mathrm{mM})) \\
20-25 \text { Einheiten Papain/ml Enzymlösung } \\
\text { Carbogengas sieden für 10-20 Minuten } \\
\text { Lösung bis zum Gebrauch im Wasserbad aufbewahren }\end{array}$ \\
\hline Inaktivierungslösung & $\begin{array}{l}25 \mathrm{mg} \text { Albumin } \\
25 \mathrm{mg} \text { Trypsin-Inhibitor } \\
5 \mathrm{ml} 10 \% \text { FCS-Medium (Fetales Kälber-Serum) } \\
\text { Steril filtriert und auf } 37^{\circ} \mathrm{C} \text { erwärmt }\end{array}$ \\
\hline $10 \%$ FCS- Medium & $\begin{array}{l}437 \mathrm{ml} \text { DMEM } \\
50 \mathrm{ml} \text { FCS } \\
10 \mathrm{ml} \text { Glutamin } \\
3 \mathrm{ml} \text { Pen/Strep }\end{array}$ \\
\hline Neurobasal-A-Medium & $\begin{array}{l}500 \mathrm{ml} \text { Neurobasal-A } \\
10 \mathrm{ml} \text { B-27-Supplement } \\
5 \mathrm{ml} \text { Glutamax l-Stock } \\
1.000 \mu \mathrm{l} \text { Penicillin/Streptomycin }\end{array}$ \\
\hline
\end{tabular}

\subsubsection{Vorbereitung der Deckgläser}

Die Deckgläser (18 mm Durchmesser) mussten über Nacht mit Salpetersäure in bestimmten Haltern gewaschen werden. Die Halter müssen säurebeständig sein, dafür eignet sich am besten Teflon oder Keramik. Einen Tag später wurden die Deckgläser mit doppelt destilliertem Wasser in den Haltern gewaschen und so lange gespült, bis ein $\mathrm{pH}$ Wert von 7 erreicht wurde. 
Daraufhin wurden die Deckgläser in den Haltern mit Tüchern getrocknet, um das überschüssige Wasser aufzusaugen. Weiterhin wurden sie in einem mit Alufolie abgedeckten Becherglas für 30 Minuten bei $37^{\circ} \mathrm{C}$ in einen Wärmeschrank gestellt, um sicherzustellen, dass die Deckgläser beim Autoklavieren trocken bleiben. Die Coverslips kamen in den Autoklav, dort wurden die Deckgläser bei einer Temperatur von $121^{\circ} \mathrm{C}$ und unter Druck sterilisiert und somit von allen eventuellen Bakterien und Viren befreit. Anschließend wurden sie in Zellkultur-Schalen mit einem Durchmesser von $15 \mathrm{~cm}$ gelegt. Hierbei war zu beachten, dass sich zum einen die Deckgläser und zum anderen die Wände der Schale nicht berührten. In einer Schale konnten 20 Deckgläser untergebracht werden.

Die Deckgläser wurden mit $1 \mathrm{ml}$ Poly-L-Lysin (PLL) und Boratpuffer bedeckt. PLL hat eine Konzentration von $1 \mathrm{mg}$ Poly-L-Lysin pro $1 \mathrm{ml}$ Boratpuffer. Üblicherweise ist $1 \mathrm{ml}$ PLL ausreichend für drei bis vier Deckgläser. Sobald diese vollständig mit den Lösungen bedeckt waren, wurden sie über Nacht bei $37^{\circ} \mathrm{C}$ in den Autoklav gestellt. Dabei musste beachtet werden, dass sie vollständig mit Alufolie bedeckt waren.

Das PLL wurde anschließend wieder von den Deckgläsern entfernt und bei $-20{ }^{\circ} \mathrm{C}$ aufbewahrt. Die Deckgläser wurden mit doppelt destilliertem Wasser bedeckt und in 12Well-Platten transferiert, die ebenfalls mit doppelt destilliertem Wasser gespült wurden (1 $\mathrm{ml}$ pro Well reichte dabei aus).

Nach dem letzten Waschen wurde so viel Wasser wie möglich wieder entnommen und $1 \mathrm{ml}$ Aussaatmedium auf die Deckgläser gegeben. Die 12-Well-Platten wurden nun für mindestens drei Tage bei $37^{\circ} \mathrm{C}$ in den Inkubator gegeben.

\subsubsection{Zerteilung und enzymatische Verarbeitung von Hippocampi}

Bevor die Zerteilung begonnen wird, sollten $10 \mathrm{ml}$ der Enzymlösung vorbereitet und bei $37^{\circ} \mathrm{C}$ in einem Wasserbad erwärmt werden. Hierbei war zu beachten, dass die Enzymlösung sterilisiert wird, bevor diese in das Gewebe gegeben wird.

Die Gehirne der neugeborenen Ratten (P1) wurden komplett entfernt und in eine Petrischale mit kalter Hank's Balanced Salt Solution (HBSS) gelegt, sodass der Hypothalamus nach oben zeigte. Das Gehirn sollte mit einer Pinzette zwischen der Hirnstamm- und Kleinhirn-Region positioniert werden, gemeinsam mit den beiden Lappen der zerebralen Kortizes. 
Jede Seite der Kortizes sollte in einem Winkel von der vorderen Mittellinie zu dem seitlichen hinteren Ende der Kortizes mit einem Skalpell zerteilt werden, sodass ein keilförmiger Abschnitt des verbleibenden Gehirns übrigbleibt.

Die zerteilten Hemisphären wurden auf eine neue Petrischale mit neuer HBSS übertragen.

Die Hippocampi waren am häufigsten von der medialen flachen geschnittenen Seite der Hemisphäre sichtbar. Die zerlegten Teile wurden umgedreht, sodass die flachen Seiten nach unten zeigten. Die vaskularisierte Hirnhaut sollte von der abgerundeten Außenseite der Hemisphäre abgezogen werden. Sobald die Hirnhaut von der Kortikalis vollständig entfernt worden war, konnte die ganze Sektion wieder umgedreht werden, damit der Hippocampus wieder nach oben weist.

Dann wurde die Hirnhaut weiter entfernt und konnte anschließend in einem Spalt des Hippocampus verbunden werden. Mit einer scharfen Pinzette konnte nun ein gerader Schnitt an jedem Ende der Struktur gemacht werden, um wieder eine Drehung vorzunehmen. So konnte über den Streifen des Gewebes entlang der Seite des Hippocampus geschnitten werden, um es vom Kortex zu lösen. Dabei sollte nah beim Hippocampus geblieben werden, um nicht das Gewebe aus dem Subiculum aufzunehmen. Jetzt sollten alle Teile in eine sterile Enzymlösung übergeführt und 60 Minuten unter kontinuierlichem Rühren inkubiert werden.

\subsubsection{Mechanische Zerteilung von Zellen aus dem Gewebe}

Nach 60 Minuten wurde die Enzymlösung verworfen und $5 \mathrm{ml}$ der Inaktivierungslösung den Hippocampi hinzugefügt.

Es wurde weitere 15 Minuten pausiert und anschließend auch die Inaktivierungslösung wieder verworfen. Danach folgte dreimal eine Waschung mit $5 \mathrm{ml}$ Neurobasal-A-Medium. Es wurden $3 \mathrm{ml}$ Neurobasal-A-Medium mit einer 10-ml-Pipette zu den Hippocampi dazu pipettiert. Beim Auf- und Abpipettieren war zu beachten, dass sich die Pipette am Boden des Gefäßes befand, damit das Gewebe resuspendiert. Anschließend wurden $2 \mathrm{ml}$ Neurobasal-A-Medium zur Lösung hinzugegeben, und die Zellen wurden mit einer Neubauer Counting Chamber gezählt. In jedes Well kamen 80.000 Zellen mit Aussaatmedium, und die Neurone wurden für mindestens zwei Stunden in den Inkubator gestellt.

Daraufhin wurde das Aussaatmedium vollständig entfernt und 1,25 ml von Neurobasal-AMedium zu den Neuronen hinzugefügt. Nach zwei Tagen wurde das Medium der Zellkulturen ausgewechselt, indem $1 \mathrm{ml}$ des alten Mediums gegen frisches ausgetauscht wurde. Für den Fall, dass sich zu viele Mikroglia in der Kultur befinden, können diese mit 5-Fluoro-2'-deoxyuridine (FUDR) gehemmt werden. Nach vier bis fünf Tagen wurden $20 \mu \mathrm{m}$ pro 
Well zu den Neuronen hinzugefügt.

\subsection{Fixation, EM-Methode, Adobe Photoshop CS6, Matlab}

Fixation:

Die Präparate wurden in 2,5 \% Glutaraldehyd in Polybutylensuccinat (PBS) für 30 Minuten auf Eis gelegt. Die weitere Fixation erfolgte bei Raumtemperatur für 30 Minuten bis eine Stunde in 2,5\% Glutaraldehyd. Alle verbleibenden Schritte wurden bei $4{ }^{\circ} \mathrm{C}$ durchgeführt. Die Präparate wurden mit PBS gewaschen und mit $100 \mathrm{mM}$ Ammoniumchlorid in PBS abgekühlt. Nach dem Ausspülen mit PBS wurden die Proben in $1,5 \mathrm{mg} / \mathrm{ml}$ Diaminobenzidin (DAB) für 30 bis 45 Minuten inkubiert.

Postfixation und Färbung:

Nach der Prozedur mit PBS wurden die Präparationen in 1\% Osmiumtetroxid bei Raumtemperatur behandelt und anschließend für ungefähr eine Stunde mit einer aufsteigenden Reihe von Ethanolen und Propylenoxid ebenfalls bei Raumtemperatur dehydriert. Das Osmiumtetroxid diente hierbei sowohl zur Färbung als auch zur Postfixation.

Weiterhin wurden die Proben in 50\% Epoxidharz (Epon) in Propylenoxid für 12 bis 18 Stunden unter kontinuierlichem Rühren inkubiert. Damit das Propylenoxid verdunsten kann, wurden die Proben für acht Stunden in $100 \%$ Epon in offenen Injektionsfläschchen inkubiert und schließlich erneut für 36 Stunden bei $60^{\circ} \mathrm{C}$.

Die Schnitte, die aus den Blöcken geschnitten wurden, waren $70 \mathrm{~nm}$ dick. Die Elektronenmikroskopbilder wurden mit dem Mikroskop ZEISS EM 902 A erworben, das mit einem 1,024 x 1,024 CCD-Detektor (Proscan CCD HSS 512/1024, Proscan Electronic Systems) ausgestattet ist.

Adobe Photoshop CS6:

Um die Elektronenmikroskopbilder der Spines auf eine Ebene zu bringen und sie übereinanderzulegen, wurde Adobe Photoshop CS6 verwendet. Dazu wurden die Bilddateien als .tif (Abbildung 5, Abbildung 6) geöffnet und die verschiedenen Ebenen übereinandergelegt. Die dendritischen Dornenfortsätze wurden aus dem Elektronenmikroskopbild geschnitten und in einem neuen Fenster geöffnet. Nun wurde die Opazität reduziert, um zu sehen, in welchem Winkel das neue ausgeschnittene Spinebild rotiert werden muss (Abbildung 7), um ein zufriedenstellendes Ergebnis zu 
erzielen. ,Ein zufriedenstellendes Ergebnis‘ bedeutet in diesem Fall, dass die Postsynapsen nahtlos übereinandergelegt werden, ohne dass sie Diskrepanzen hinsichtlich ihrer Rotation und Form zum Bild zuvor aufweisen.

Nachdem eine optimale Überlagerung eingestellt worden war, wurde die Opazität wieder auf 100 \% erhöht. Auf diese Weise entstand eine Bildserie, mit der die Dornenfortsätze gut weiterführend in der MATLAB-Software bearbeitet werden konnten.

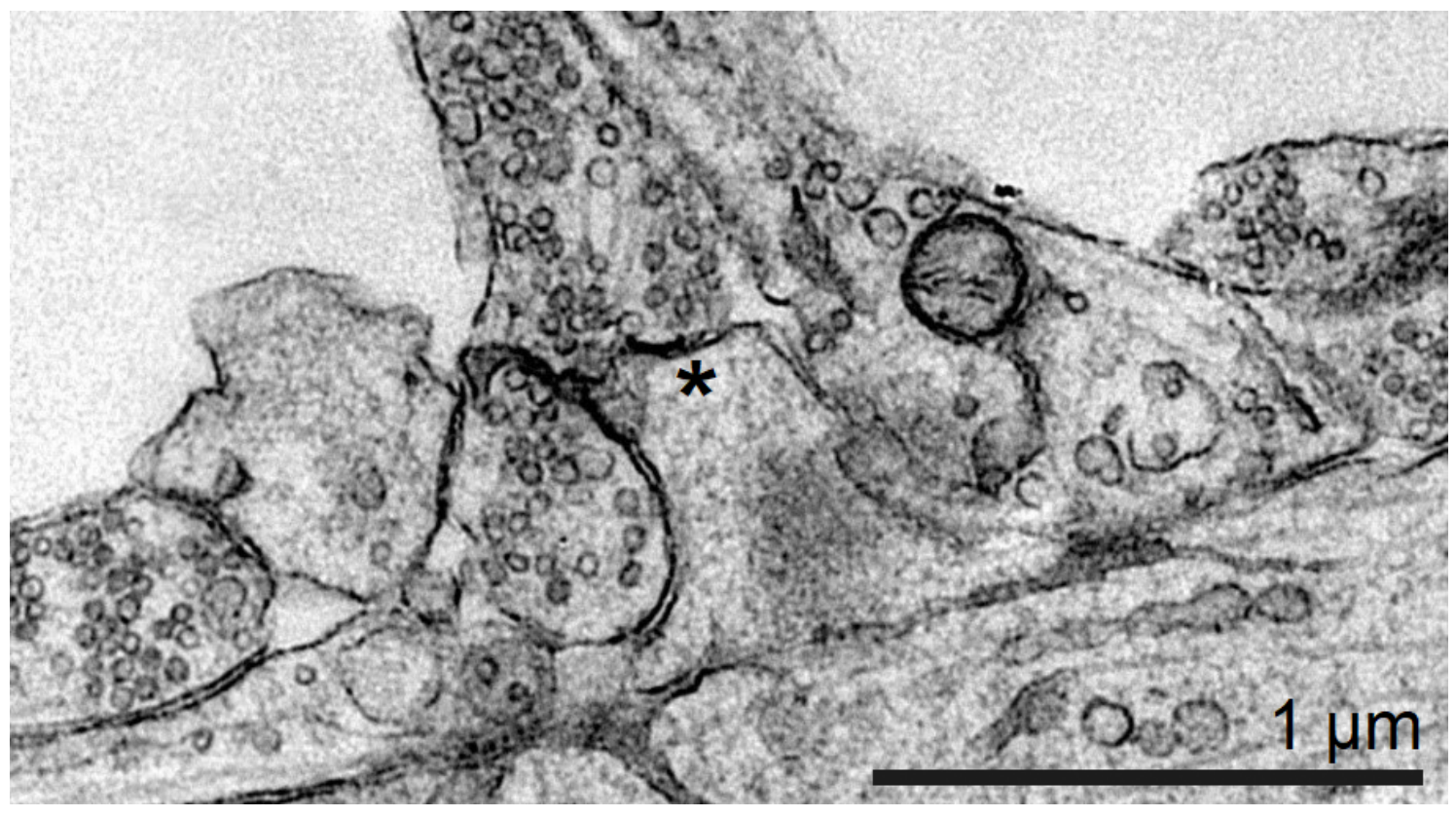

Abbildung 5: Darstellung einer Spine im EM-Bild. Es ist deutlich zu sehen, dass der Dornenfortsatz an der Basis aus dem Neuron entspringt. Die PSD $\left(^{*}\right)$ ist als dunkle Verdickung zu erkennen. Auf der präsynaptischen Seite sind zahlreiche Vesikel zu sehen.

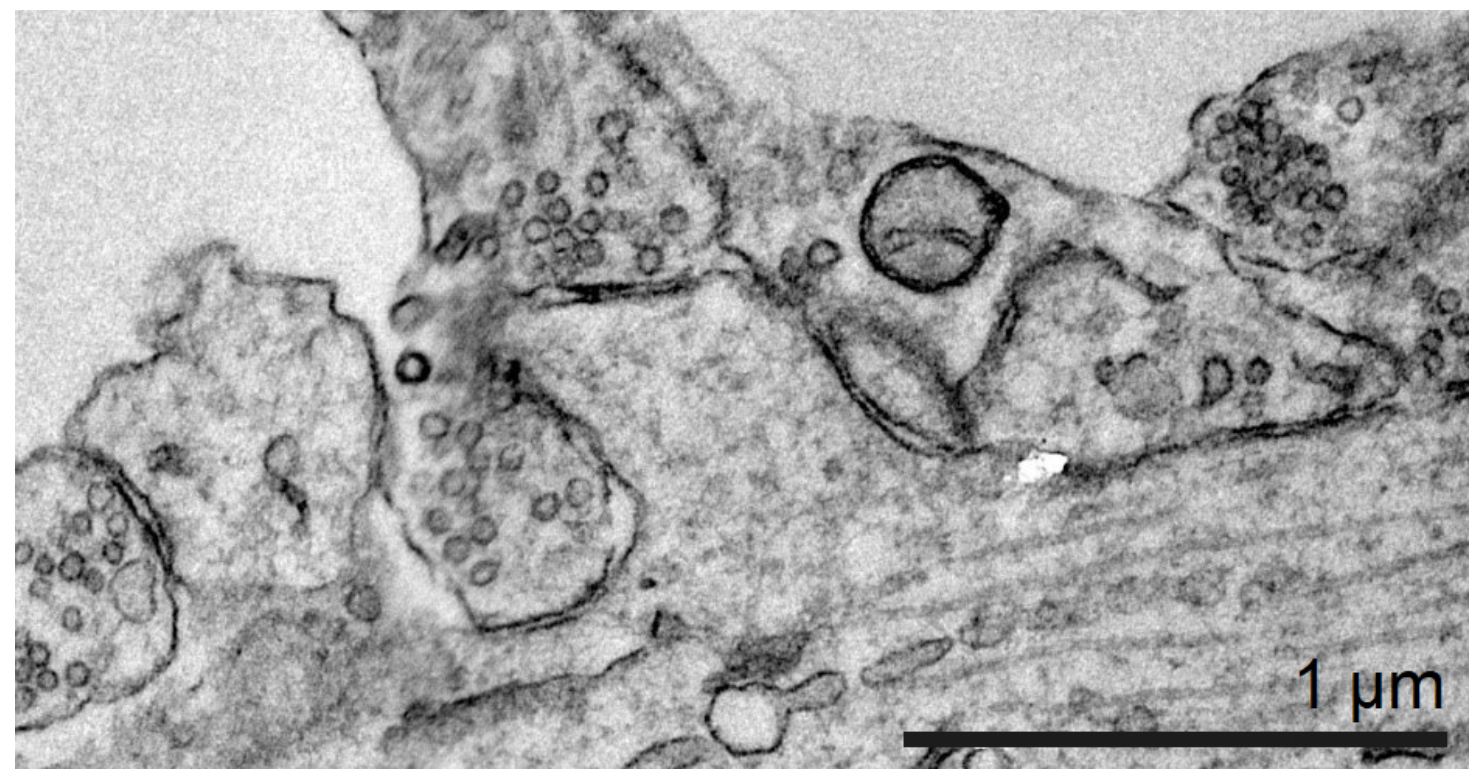


Abbildung 6: Auf diesem Bild ist der nächste Schnitt (70 nm Schnittdicke) derselben Postsynapse erkennbar. Die PSD hat sich etwas verjüngt, hebt sich jedoch immer noch deutlich von dem Rest der Membran ab.

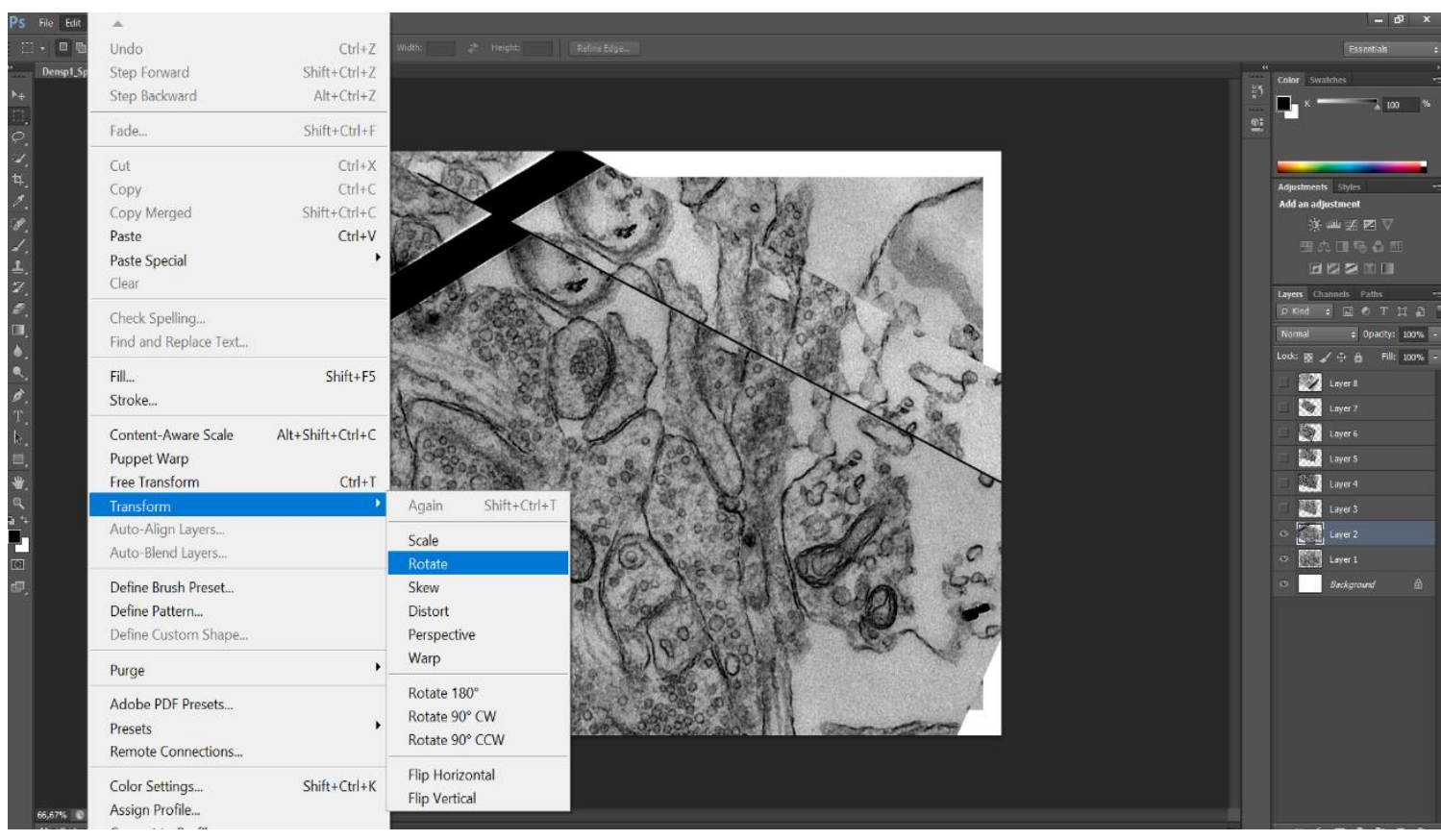

Abbildung 7: Darstellung eines Arbeitsprozesses, der zeigt, dass die Spines rotiert wurden. Rechts im Bild sind die verschiedenen Ebenen zu sehen, hier Layer 1 bis 8 genannt.

Elektronenmikroskop-Datenanalyse:

Die Bildanalyse wurde mit der Software MATLAB hergestellt. Die mit Photoshop bearbeiteten EM-Bilder wurden mittels MATLAB in ein 3D-Bild umgewandelt, was mit einer von Professor Silvio O. Rizzoli programmierten Software geschah.

Zunächst wurden die EM-Bilddateien (63 Postsynapsen in verschiedenen Schnitten) mit einem Zeichentool von MATLAB geöffnet. Mithilfe eines ,Dell Inspiron 13 7000'Touchscreen wurden die Bestandteile der Postsynapse manuell eingezeichnet (Abbildung 8). Der erste Schritt ist das Anzeichnen der PSD in Rot. Anschließend wurde die Kontur der Membran mit Gelb skizziert. Die Zeichnung der Vakuolen erfolgte in Grün und die der Mitochondrien in Dunkelblau. Die Vesikel sind punktförmig in Türkis dargestellt. 
Das Programm MATLAB wurde gewählt, da es als Datentyp Matrizen verwendet. Es können mehrdimensionale Matrizen hergestellt werden, daher eignet sich diese Software für die Bildbearbeitung und dreidimensionale Plots. Zwar verfügen auch andere Programme über diese Funktion, das Einlesen der Matrix in MATLAB ist jedoch wesentlich praktikabler.

Bilder sind zweidimensional und bestehen aus bestimmten Werten von Graustufen. In MATLAB wird dieses zweidimensionale Bild als Matrix eingelesen und kann dann als dreidimensionales Bild geplottet werden (Abbildung 9). Hier ist zu erkennen, dass die Postsynapse in Beige, die aktive Zone nach wie vor in Rot, die Vesikel in Grau und die Mitochondrien in Violett dargestellt wurden.

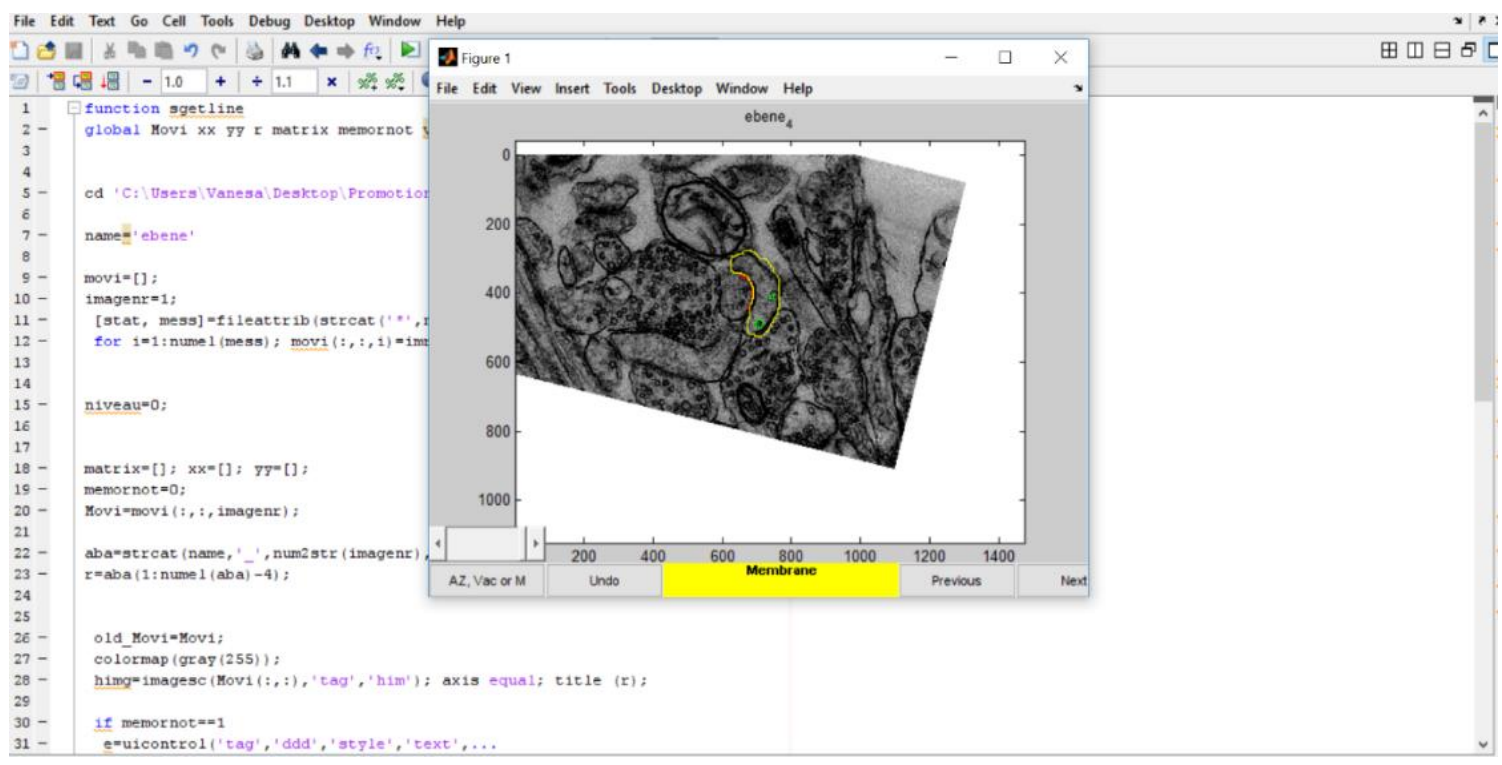

Abbildung 8: Der Screenshot zeigt die manuelle Zeichnung der Postsynapse. Die PSD (rot), die Membran (gelb) und die Vakuolen (grün) wurden eingezeichnet. In dieser Abbildung sind keine Vesikel und Mitochondrien zu sehen. 


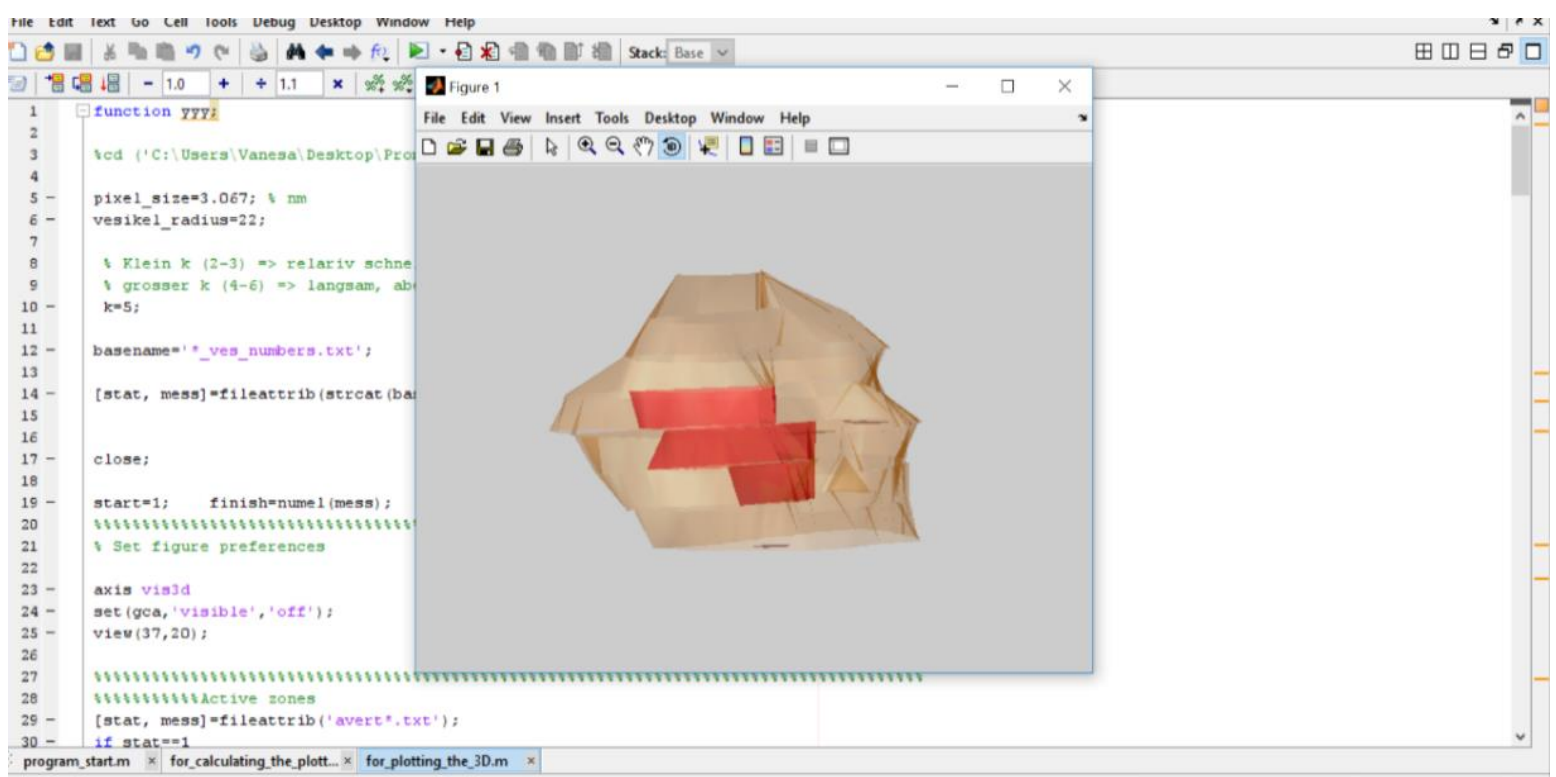

Abbildung 9: Diese Abbildung stellt eine 3D-Rekonstruktion der einzelnen Spine dar. Die Darstellung ist am Computer rotierbar, so dass alle Elemente besser betrachtet werden können. In Rot ist die PSD abgebildet, diese erstreckt sich über mehrere Ebenen.

\subsection{Statistik}

Pearson-Korrelationskoeffizient:

Der Pearson-Korrelationskoeffizient $(\mathrm{R})$ ist durch einen Wert definiert, der den Grad einer linearen Beziehung zwischen zwei Werten aufzeigt und der zwischen -1 und 1 liegen kann. Dieses Maß ist dimensionslos. Liegt R bspw. bei 1, so hängen die Merkmale positiv linear voneinander ab. Sollte $\mathrm{R}=-1$ sein, besteht zwar auch ein linearer Zusammenhang, jedoch ist dieser dann negativ. Beträgt der Wert 0 , so besteht keine lineare Abhängigkeit zwischen den zwei Merkmalen. Bei $\mathrm{R}=-1$ ist der Graph abfallend, bei $\mathrm{R}=1$ steigend. Die Neigung des Graphen zeigt also, ob ein Zusammenhang eine lineare Abhängigkeit aufweist oder nicht.

Nicht alle Korrelationskoeffizienten, die eine positive lineare Abhängigkeit darstellen, bedeuten, dass eine solche auch vorherrscht. Deshalb kann der PearsonKorrelationskoeffizient nur angewendet werden, wenn einige Rahmenbedingungen gegeben sind. Die zentralste ist hierbei die Signifikanzbedingung. Wenn der Wert p kleiner als 0,05 ist, ist der Korrelationskoeffizient signifikant. Damit wird dargestellt, dass dieser Wert $\mathrm{R}$ eine Wahrscheinlichkeit von $95 \%$ hat, nicht zufällig entstanden zu sein. P ist also ein Wert für die Wahrscheinlichkeit eines Ergebnisses. Die Grenze von signifikant zu insignifikant ist bei $\mathrm{p}=0,05$ gelegt worden. Wenn $\mathrm{p}>0,05$ ist, dann ist der Wert der positiven bzw. negativen linearen Abhängigkeit nicht signifikant. 
t-Test:

Der t-Test überprüft, ob zwei Mittelwerte sich statistisch unterscheiden. Die Nullhypothese besagt, dass die Differenz zwischen den Mittelwerten rein zufällig entstanden und somit kein Unterschied zwischen den untersuchten Gruppen vorzufinden ist. Ist $\mathrm{p}<0,05$, so besagt dies, dass die Differenz signifikant und nicht rein zufällig entstanden ist. Der Wert von $\mathrm{p}<0,05$ bedeutet, dass es eine 95-prozentige Wahrscheinlichkeit gibt, dass diese Werte nicht zufällig erschienen. 


\section{Ergebnisse}

In dieser Arbeit werden bestimmte Zellorganellen der stumpfförmigen Postsynapsen mit Zellorganellen aus pilzförmigen Postsynapsen hinsichtlich ihrer Größe, Anzahl und Lokalisation im dendritischen Dornenfortsatz verglichen. Bei diesen Zellorganellen handelt es sich um Vesikel, Mitochondrien und Vakuolen. Die dreidimensionalen Modelle wurden mit MATLAB erstellt und mithilfe der Software SigmaPlot konnten verschiedene Grafiken erstellt werden. Diese visualisieren die Ergebnisse und konkretisieren sie zusätzlich durch spezielle Statistikmethoden.

\subsection{Pilzförmig und stumpfförmig}

Nach der Konstruktion aller 63 Dornenfortsätze wurde eine Einteilung vorgenommen, um pilzförmige und stumpfförmige Dendriten voneinander zu differenzieren.

Bei der Einteilung wurde darauf geachtet, dass die Morphologien der Dornenfortsätze ihren typischen Charakteristika entsprechen; dies bedeutet, dass die pilzförmigen Dendriten eine Verjüngung im Halsbereich aufweisen und insgesamt einen voluminösen Kopf haben. Die stumpfförmigen Dornenfortsätze haben einen kurzen Hals, der sich wenig bis gar nicht von der Art der Ausprägung des Kopfes differenziert.

Dabei konnten 30 pilzförmige dendritische Spines (Abbildung 10) und 33 stumpfförmige Dendriten (Abbildung 11) mithilfe von Professor Silvio O. Rizzoli identifiziert werden. Die Übergänge zwischen den zwei Arten der Postsynapse sind fließend, es gab aber auch eindeutige Beispiele für pilzförmige und stumpfförmig dendritische Dornenfortsätze (Abbildung 12, Abbildung 13). 

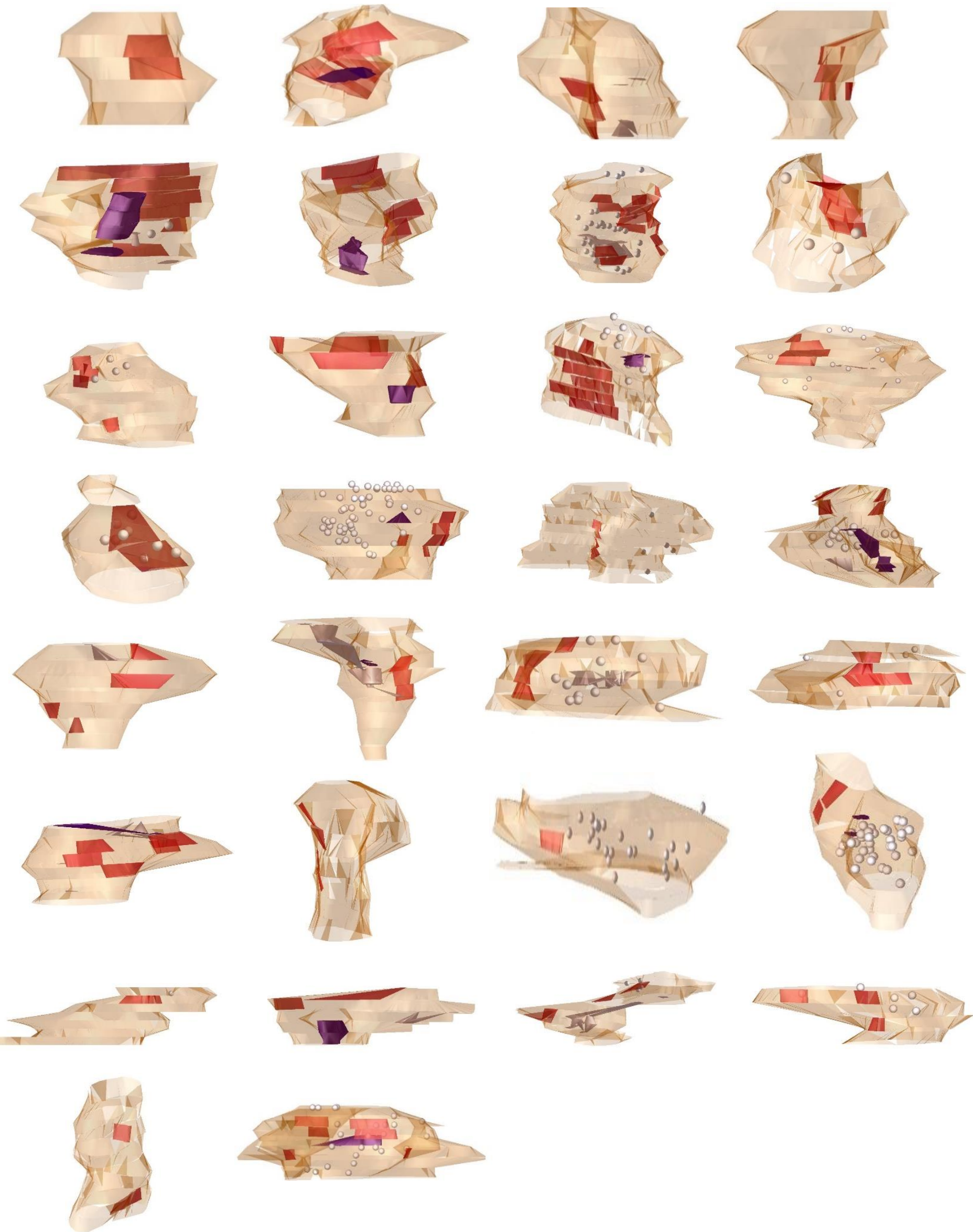

Abbildung 10: Darstellung aller Dendriten, die morphologisch in die Gruppierung ,pilzförmig“ eingeteilt werden konnten. 

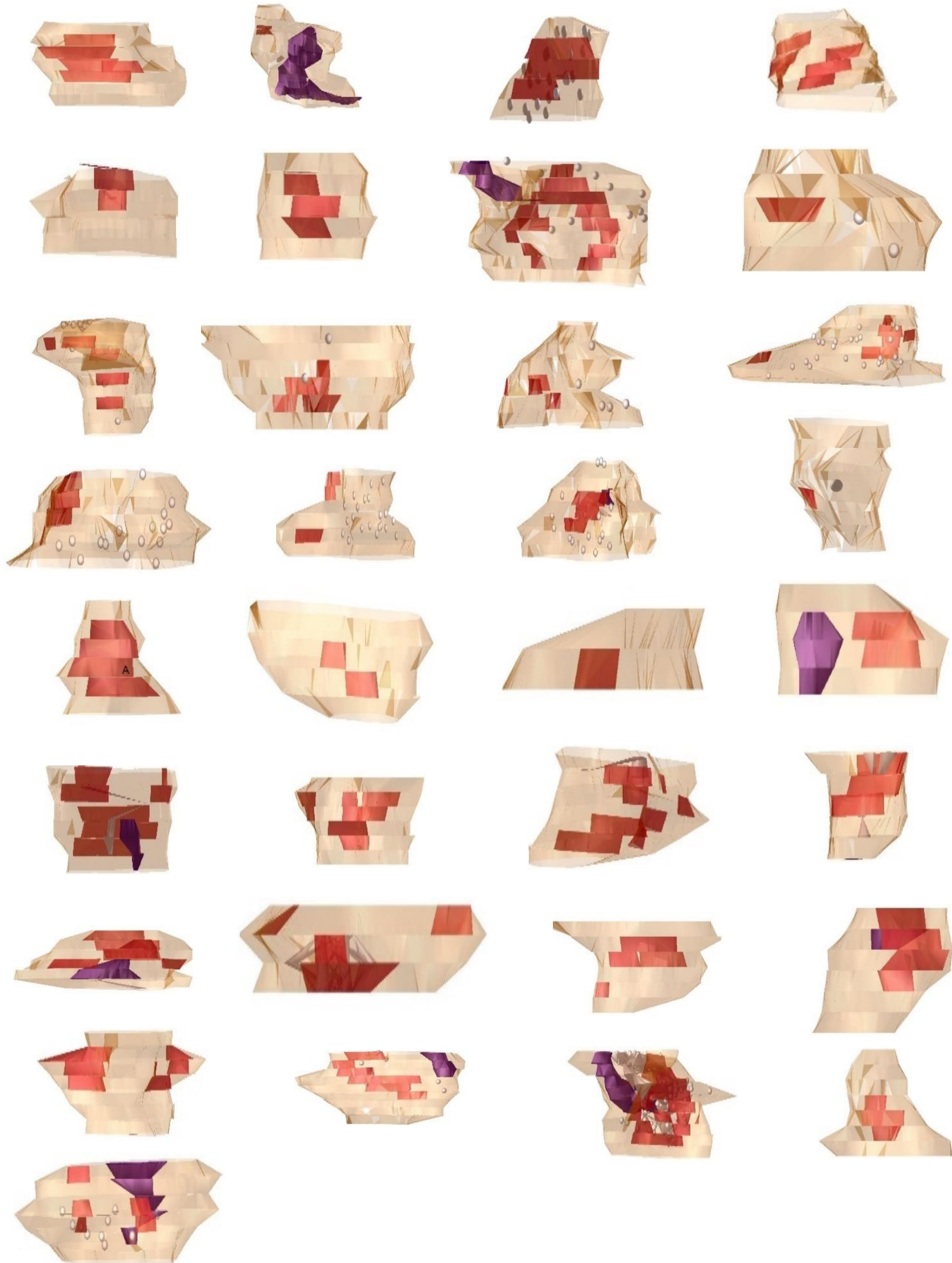

Abbildung 11: Die Abbildung zeigt alle dendritischen Dornenfortsätze, die morphologisch in die Gruppierung ,stumpfförmig' eingeteilt werden konnten. 


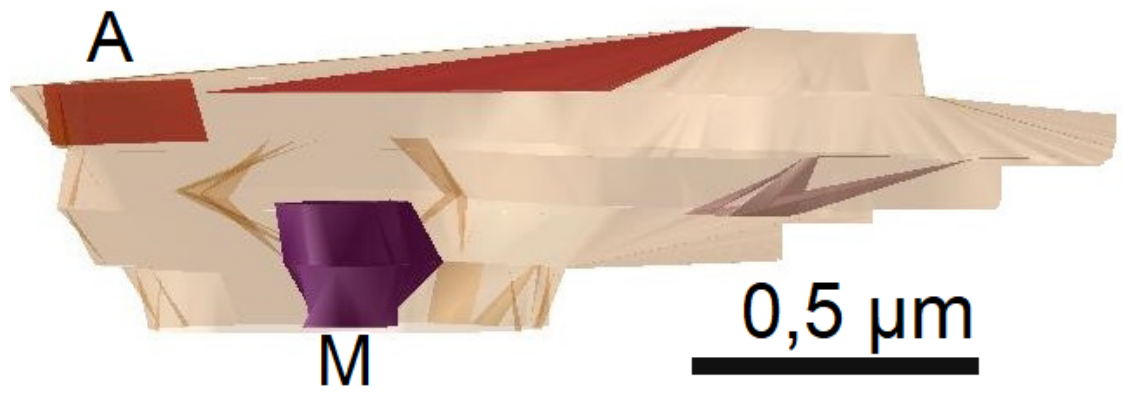

Abbildung 12: Darstellung eines pilzförmigen dendritischen Dornenfortsatzes. Die pilzförmigen Spines sind charakterisiert durch einen schmalen Hals und einen voluminösen, kugeligen Dendritenkopf. Die PSD (A) ist in zwei Hälften aufgeteilt. An der Basis des Dendriten ist ein Mitochondrium $(M)$ zu sehen, das sich über ungefähr drei Ebenen erstreckt.

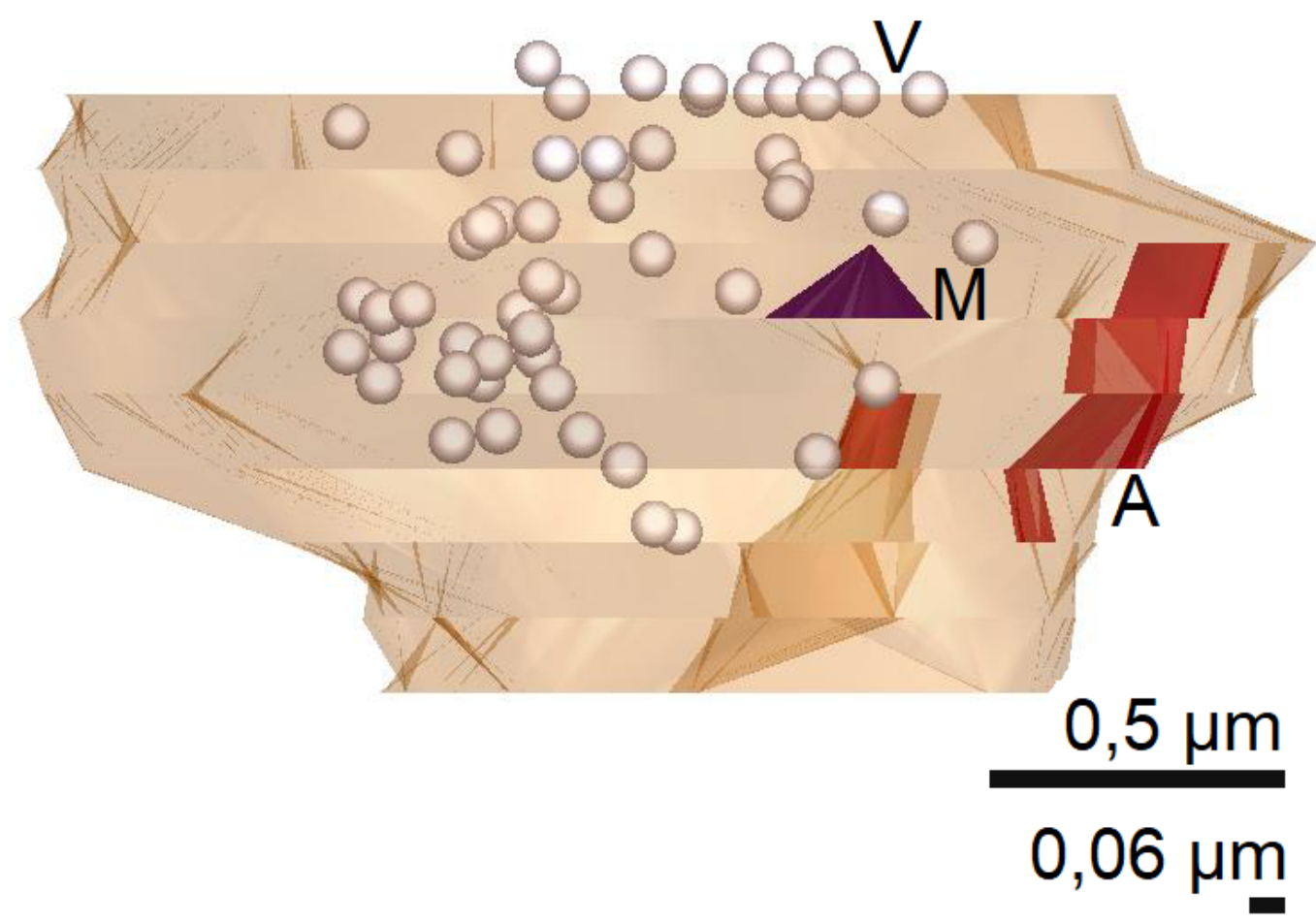

Abbildung 13: Hier ist ein pilzförmiger Dendrit dargestellt, der besonders viele Vesikel (V) besitzt. Diese zahlreiche Anhäufung von Vesikeln wurde in den restlichen dreidimensionalen Bildern seltener beobachtet. Anhand der Skalierung ist festzustellen, dass die Vesikel ungefähr $60 \mathrm{~nm}$ $(0,06 \mu \mathrm{m})$ groß sein müssen. Das Mitochondrium $(M)$ ist ungefähr $25 \mathrm{~nm}$ groß $(0,025 \mu \mathrm{m})$ und recht mittig angeordnet. Die aktive Zone (A) ist an einem Ausläufer des Dendriten lokalisiert und besitzt eine zweite postsynaptisch dichte Stelle, die sich etwas weiter lateral befindet. 


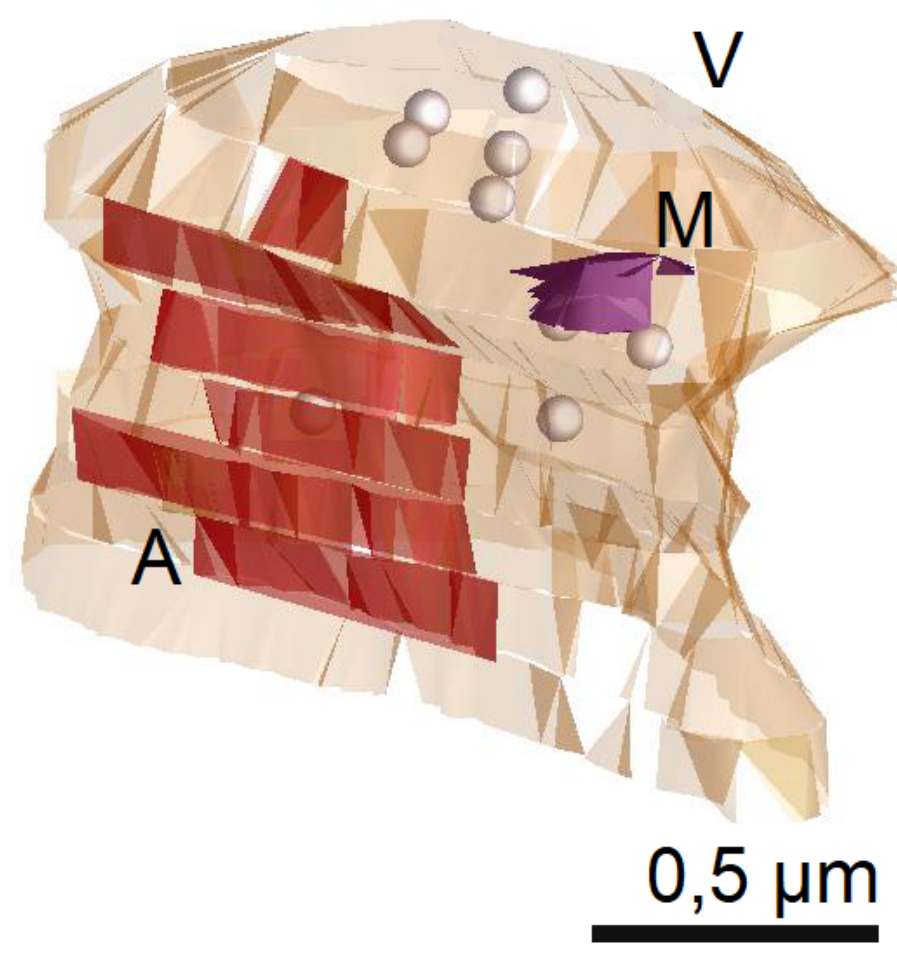

Abbildung 14: Dreidimensionale Darstellung einer pilzförmigen dendritischen Spine. Die PSD (A) verläuft in mehreren Ebenen. Ein Mitochondrium $(M)$ ist seitlich des Zellkörpers zu sehen. In dem Dornenfortsatz sind acht Vesikel (V) zu erkennen, die hauptsächlich an der Spitze des Dendriten lokalisiert sind.

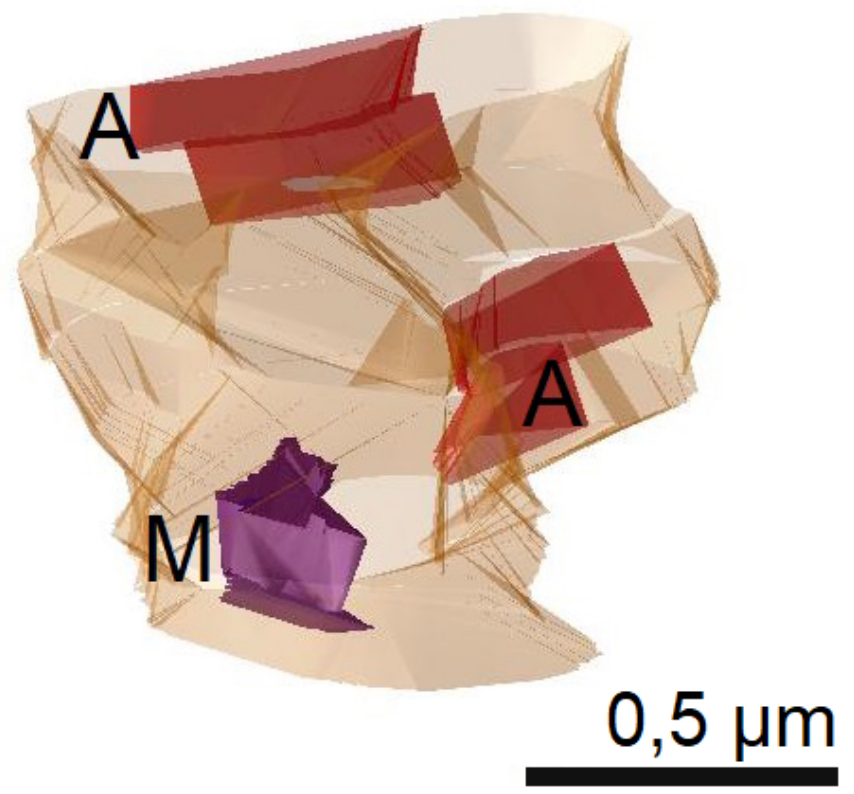

Abbildung 15: Darstellung eines Dendriten mit klassischen Charakteristika für eine pilzförmige Morphologie. Hier ist die Besonderheit, dass diese Spine zwei postsynaptisch dichte Stellen (A) 
besitzt. Das Mitochondrium (M) ist basal lokalisiert und erstreckt sich ebenfalls über mehrere Ebenen.

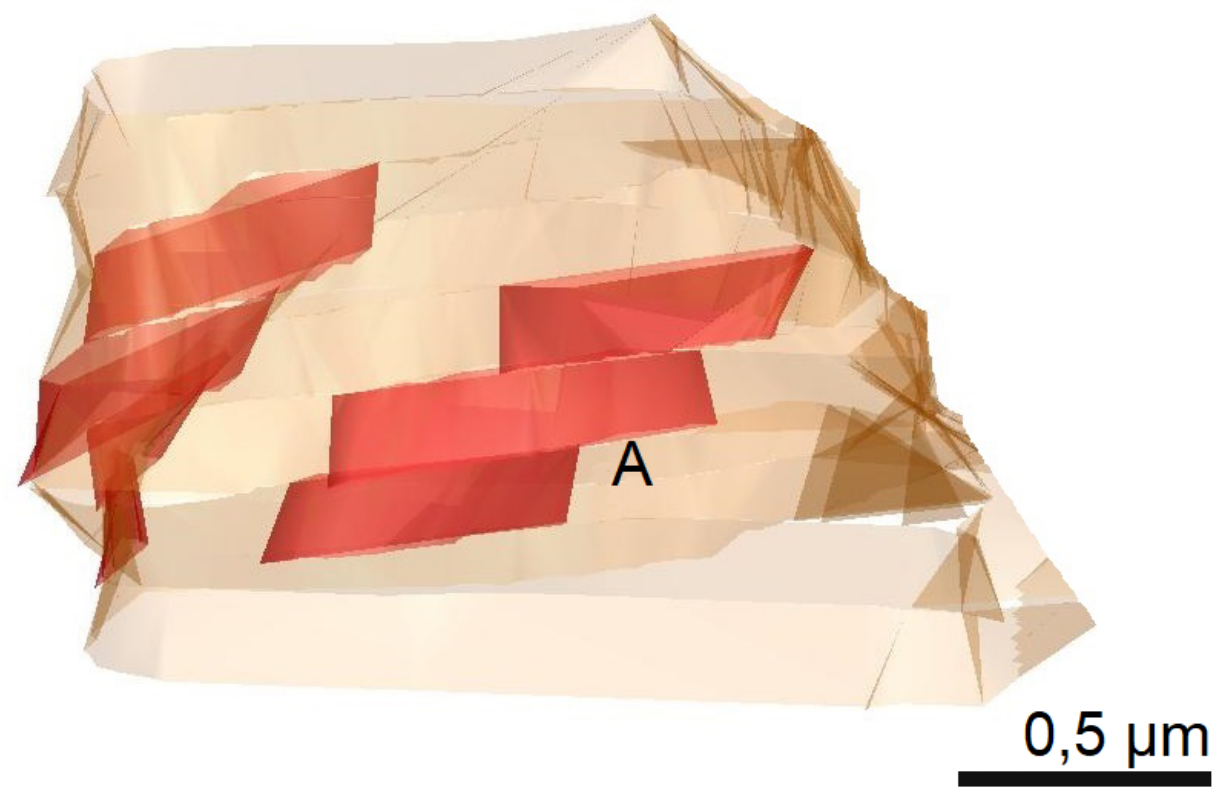

Abbildung 16: Darstellung einer stumpfförmigen Synapse nach dem Plotting mit Matlab als dreidimensionales Modell. Die zwei postsynaptisch dichten Bereiche (A) erstrecken sich über mehrere Bildebenen. Dieser dendritische Dornenfortsatz hat einen kurzen Kopf und keine Einschnürung im Halsbereich.

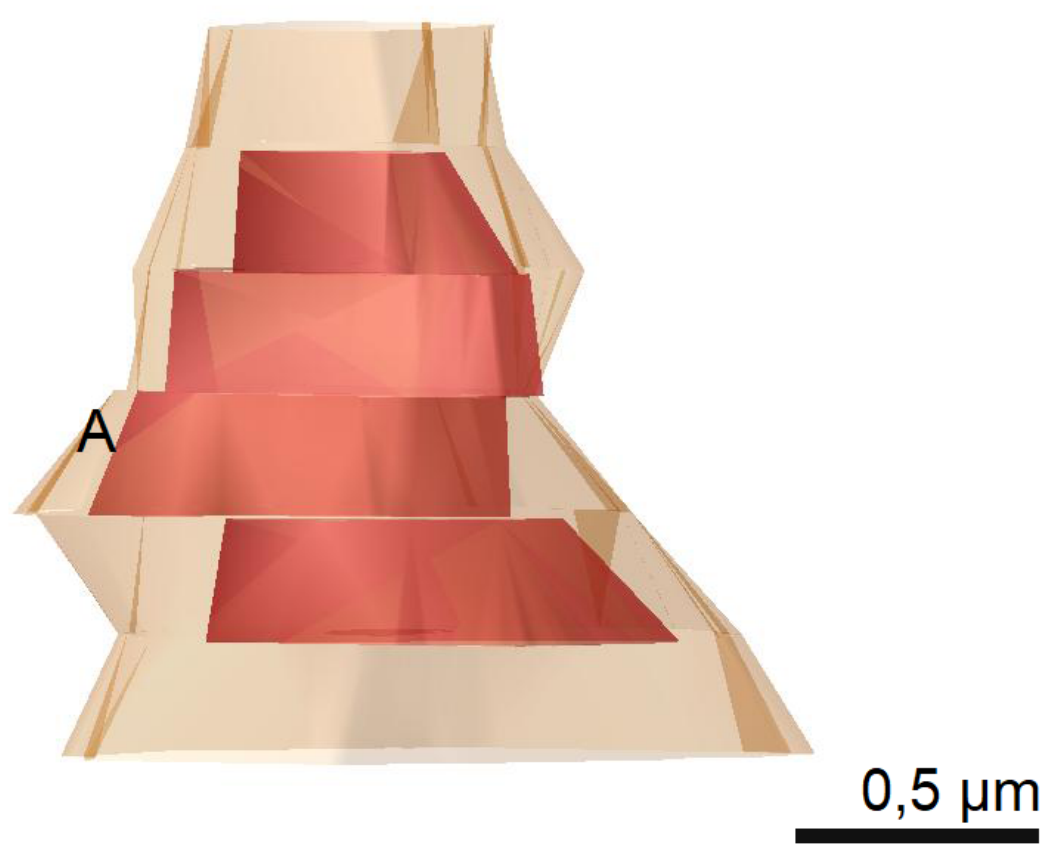

Abbildung 17: Darstellung einer stumpfförmigen Postsynapse als 3D-Modell. Bis auf die PSD (A) wurden keine Zellorganellen mit dem Elektronenmikroskop abgebildet. 


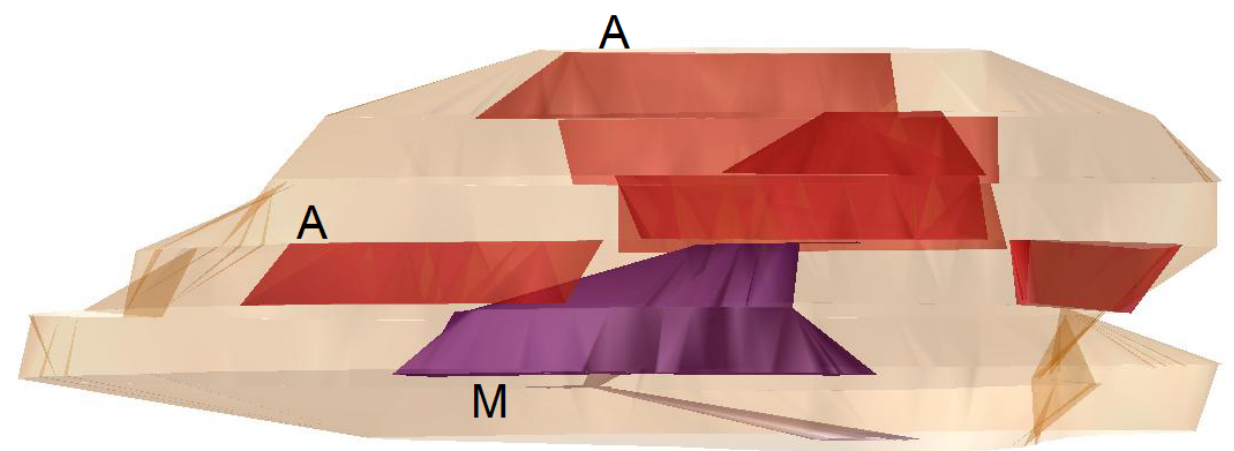

\section{$0,5 \mu \mathrm{m}$}

Abbildung 18: Diese stumpfförmige Postsynapse besitzt mehrere postsynaptisch dichte Bereiche (A), die vom Raum her fast die gesamte Seite des Dornenfortsatzes einnehmen. Das Mitochondrium (M) befindet sich annähernd basal und hat ebenfalls eine stumpfförmige Morphologie.

\subsection{Vesikel}

Vesikel sind intrazelluläre Einheiten, die bspw. Neurotransmitter durch bestimmte Transportmechanismen in die Zelle hinein- oder herausbewegen. Im Folgenden werden diese in den dendritischen Dornenfortsätzen näher untersucht und hinsichtlich ihrer Anzahl und Lokalisation miteinander verglichen. Dabei werden die Vesikel in verschiedenen Diagrammen pilzförmigen und stumpfförmigen Dendriten gegenübergestellt.

In der Präsynapse kommen Vesikel häufig vor. Sie funktionieren als Neurotransmittertransport, da die Vesikel die Transmitter im Inneren mit sich tragen. Ausgelöst durch ein Aktionspotenzial verschmilzt die Zellmembran der Vesikel mit der postsynaptischen Membran, wodurch die Neurotransmitter übertragen werden. Die präsynaptischen Vesikel variieren in ihrer Größe zwischen 30 und $50 \mathrm{~nm}$. Die Vesikel der Postsynapse haben dagegen eine Größe von ca. 60 nm (Abbildung 13).

Um zu der Quantität der Vesikel eine Aussage treffen zu können, wurde zunächst die Anzahl der Vesikel im dendritischen Dornenfortsatz erforscht. Als Säulendiagramm dargestellt, ist die Verteilung der Vesikel auf pilzförmigen und stumpfförmigen dendritischen Fortsätzen (Abbildung 19) erkennbar. Die pilzförmigen Dornenfortsätze besitzen im Durchschnitt neun Vesikel, die stumpfförmigen Postsynapsen sieben Vesikel. Somit finden sich rund $23 \%$ mehr Vesikel in pilzförmigen Postsynapsen als in 
stumpfförmigen. Der Mittelwert der pilzförmigen Dendriten beträgt zwar, wie bereits erwähnt, neun Vesikel, jedoch besteht bei beiden dendritischen Dornenfortsätzen eine Abweichung nach oben. Aufgrund der Fehlerbalken lässt sich die Aussage treffen, dass das Ergebnis bezüglich der Zählung der Vesikel in stumpfförmigen Fortsätzen einer Stichprobe maximal so hoch wird wie die durchschnittliche Anzahl der Vesikel der pilzförmigen Dendriten. Statistisch gesehen gibt es jedoch durch den t-Test keinen Unterschied zwischen stumpf- und pilzförmigen Dendriten $(\mathrm{p}=0,531)$.

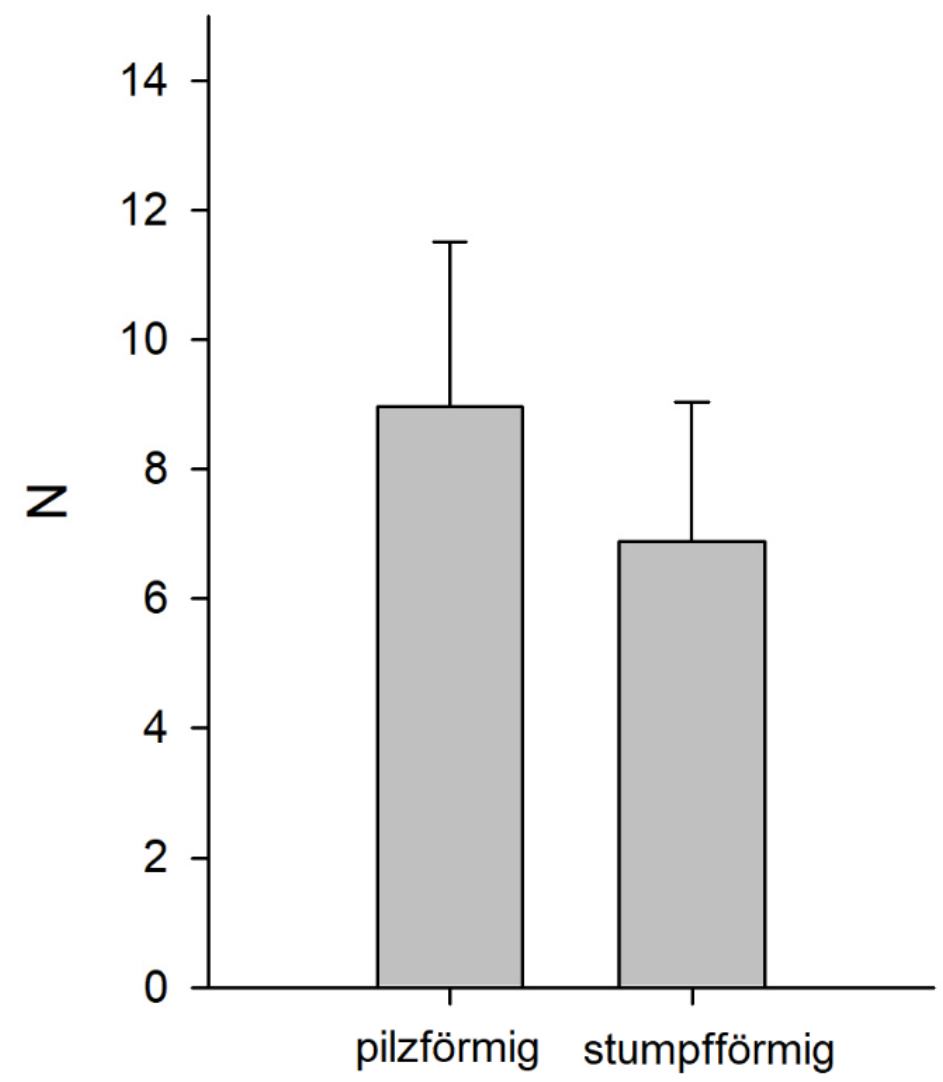

Abbildung 19: Darstellung der Vesikelanzahl in pilzförmigen und stumpfförmigen Dendriten in Form eines Säulendiagramms. Die y-Achse stellt die Anzahl der Vesikel dar, die x-Achse deren Verteilung auf pilzförmig und stumpfförmig.

Der etwas niedrigere Mittelwert der Vesikel in stumpfförmigen Dendriten könnte auch darauf zurückzuführen sein, dass zahlreiche stumpfförmige Dendriten insgesamt keine Vesikel besitzen (Abbildung 20). Insgesamt besaßen 21 stumpfförmige und 13 pilzförmige Dendriten keine Vesikel. Weiterhin waren in 12 pilzförmigen Fortsätzen vier Vesikel zu finden, wohingegen in 12 stumpfförmigen Fortsätzen drei Vesikel enthalten waren. Daraus ergaben sich Konsequenzen für den Mittelwert der Vesikel in stumpfförmigen und pilzförmigen Dendriten. Auch bei den Höchstwerten an Vesikeln, die in einem Dendriten 
gefunden wurden, ergaben sich wenige Unterschiede: In einem stumpfförmigen dendritischen Fortsatz wurden 60 Vesikel gefunden, in einem pilzförmigen waren es 54 . Dies sind die beiden höchsten Werte an Vesikeln, die in Dendriten gefunden wurden. Der dritthöchste Wert von 36 wurde ebenfalls in einem pilzförmigen Dendriten gezählt (Abbildung 20). Insgesamt lässt sich erkennen, dass sich die Peaks der Anzahlen der Vesikel von pilzförmigen und stumpfförmigen Fortsätzen wenig unterscheiden. Jedoch fällt auf, dass die pilzförmigen Synapsen immer etwas mehr Vesikel besitzen als die stumpfförmigen.

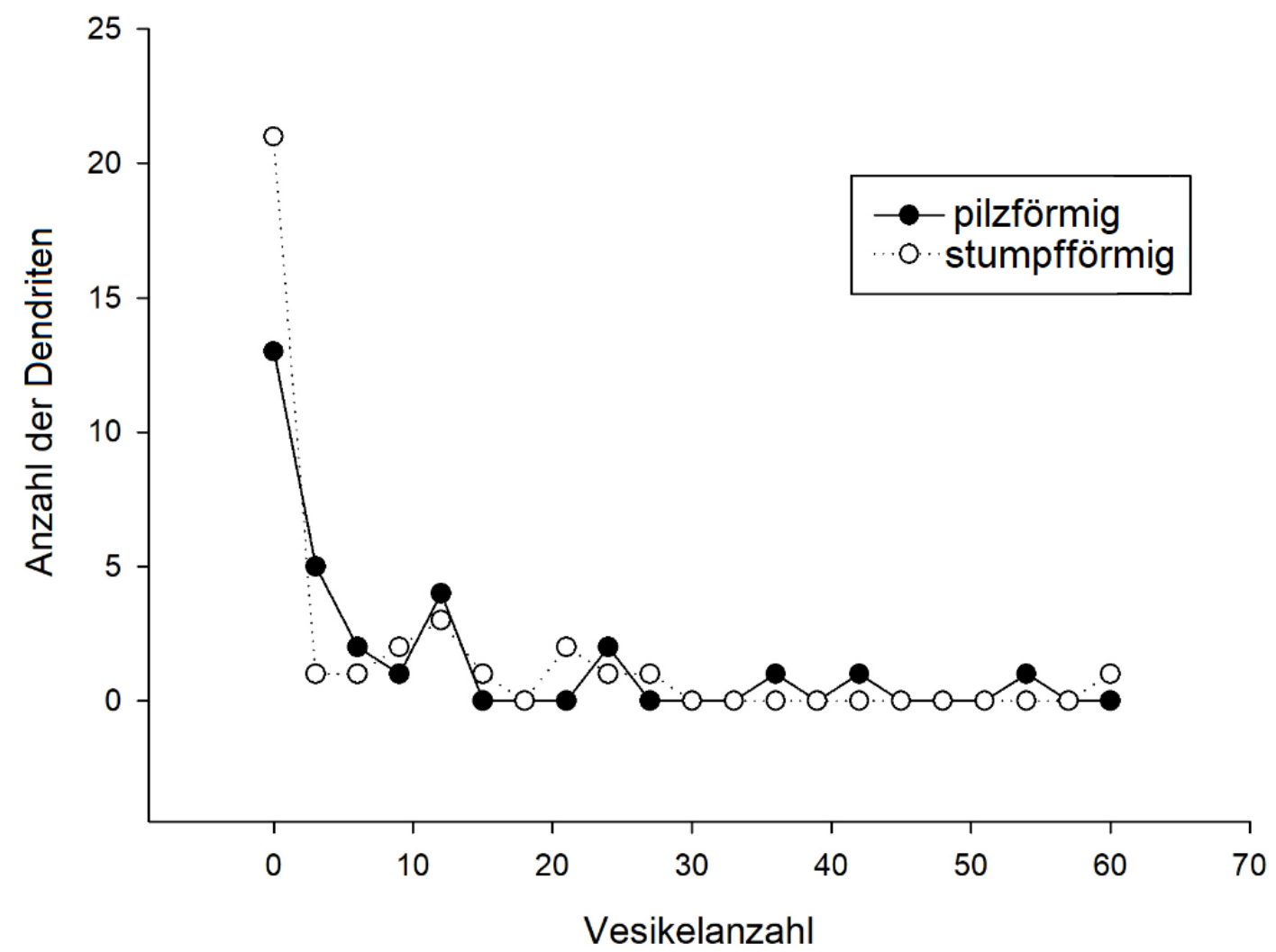

Abbildung 20: Darstellung, wie viel Dornenfortsätze eine gewisse Anzahl an Vesikeln haben. Die Anzahl der Vesikel ist auf der x-Achse angezeigt; die Anzahl der betrachteten Dornenfortsätze ist auf der y-Achse dargestellt. Es handelt sich hierbei um zwei Verteilungen. Die schwarzen Punkte stellen die pilzförmigen, die hellen Punkte die stumpfförmigen Dendriten dar. 


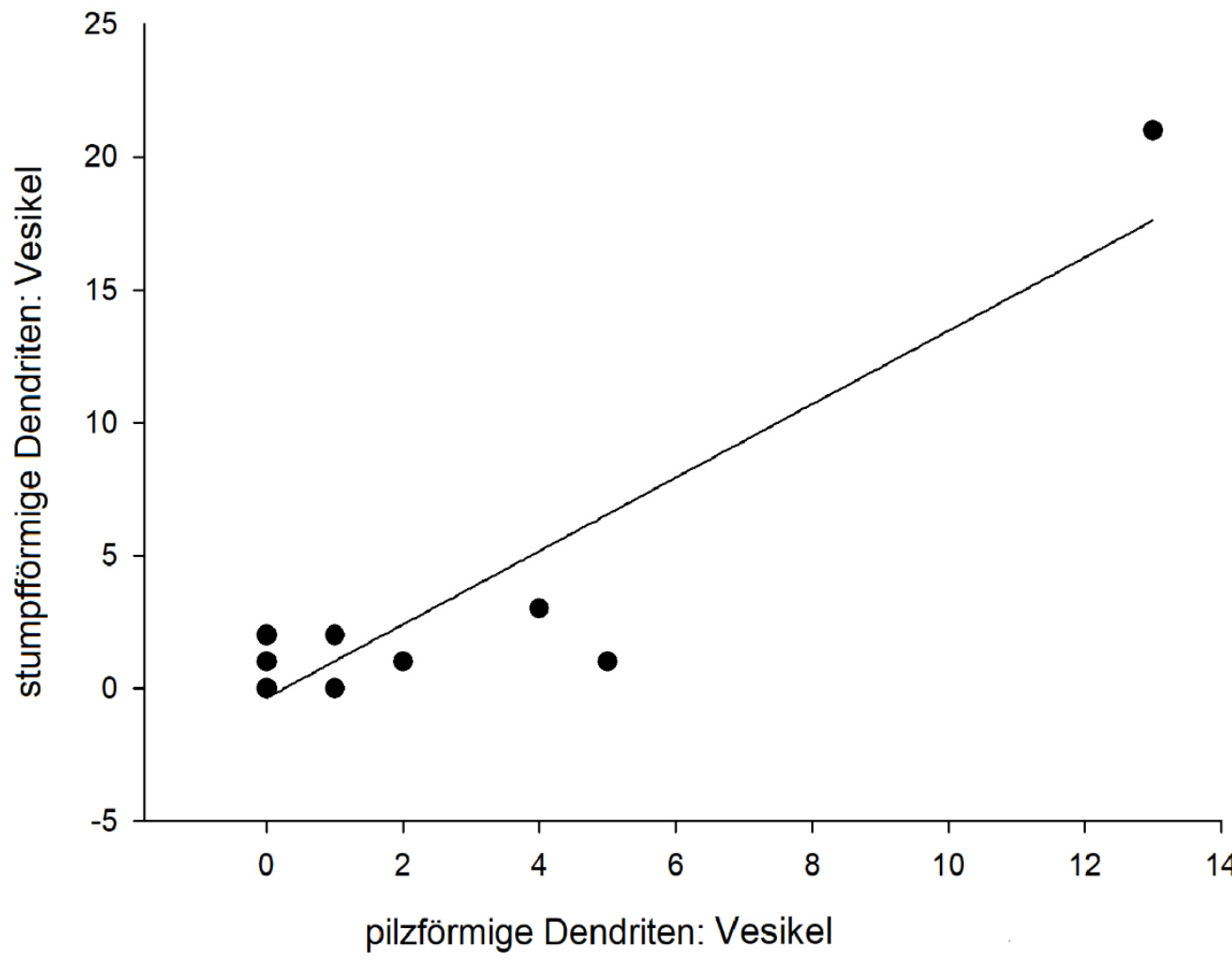

- Mushroom Vesikel vs Stumpy Vesikel FIT: stumpfförmige und pilzförmige Dendriten

Abbildung 21: Darstellung der Anzahl der Spines, die überhaupt Vesikel haben. In der Grafik ist die Regressionsgerade als schwarzer Graph dargestellt. Die gefärbten Punkte stehen für die Dendriten (sowohl stumpfförmig als auch pilzförmig). Auf der x-Achse sind die Vesikel der pilzförmigen Synapsen, auf der y-Achse die Vesikel der stumpfförmigen Dendriten ersichtlich.

Die Pearson-Korrelation (Abbildung 21) der Vesikel der stumpfförmigen Dendriten mit den Vesikeln der pilzförmigen Dendriten zeigt, dass die Vesikel beider Arten der Dornenfortsätze miteinander positiv korrelieren ( $\mathrm{r}=0,91 ; \mathrm{p}=<0,0001)$.

Zur Lokalisation lässt sich sagen, dass sich die Vesikel beider Arten an Dendriten zwischen dem Zentrum der aktiven Zone und dem Zentrum des Dendriten aufhalten müssen (Abbildung 22). Beide Regressionsgeraden weisen eine positive lineare Korrelation (stumpfförmig: $r=0,77 ; p=0,0007$; pilzförmig: $r=0,73 ; p=0,0011$ ) auf. Die Differenz zwischen beiden Werten der Korrelation ist jedoch zu vernachlässigen, da die Unterschiede gering sind. Es macht keinen Unterschied, ob die Vesikel sich in stumpfförmigen Dornenfortsätzen auffinden oder in pilzförmigen. Sind die Vesikel weit vom Zentrum der aktiven Zone entfernt, liegen sie demnach auch weitab vom Zentrum des Dendriten. Somit müssten sie dazwischenliegen und diese Tendenz vorliegen (Abbildung 14). 


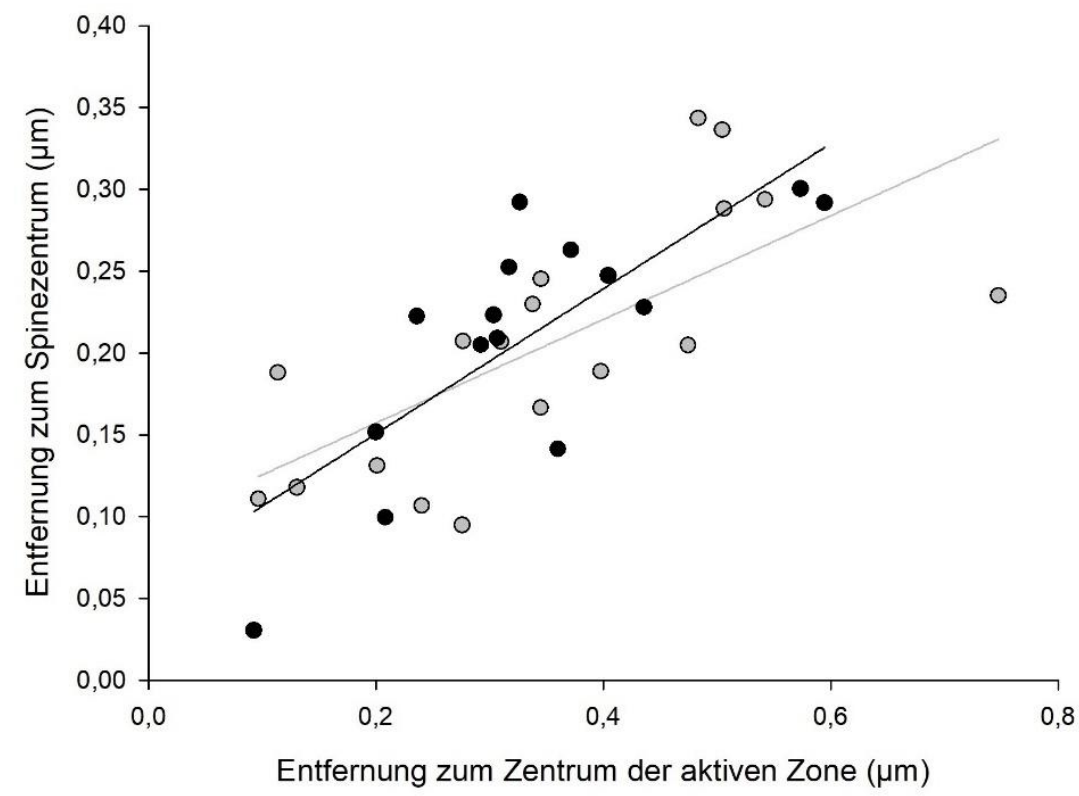

- Entfernung Zentrum der aktiven Zone vs. Entfernung Spinezentrum $(\mu \mathrm{m})$ von pilzförmige Dendriten FIT pilzförmige Dendriten

- Entfernung Zentrum der aktiven Zone vs Entfernung Spinezentrum $(\mu \mathrm{m})$ von stumpfförmigen Dendriten FIT stumpfförmige Dendriten

Abbildung 22: Dieser Graph stellt die Korrelation der Entfernung zum Spine-Zentrum (x-Achse) und die Entfernung zum Zentrum der aktiven Zone (y-Achse) in $\mu \mathrm{m}$ dar. Das Zentrum der aktiven Zone und der Spine wurde für jeden einzelnen Schnitt des EM-Bildes ermittelt.

\subsection{Vakuolen}

Vakuolen sind Zellorganellen, die mit Flüssigkeit gefüllt und von einer Membran umgeben sind. Die Anzahl der Vakuolen in pilzförmigen Dendriten beträgt im Durchschnitt eine Vakuole pro Dendrit. Bei stumpfförmigen Dendriten ist der Mittelwert mit 1,5 Vakuolen pro Dendrit etwas höher (Abbildung 23). Die Fehlerbalken verdeutlichen, dass bis zu 1,34 Vakuolen in einem pilzförmigen dendritischen Dornenfortsatz auftreten können. Auf der stumpfförmigen Seite sind es dagegen bis zu 1,97 Vakuolen pro Dendrit.

Anhand der Untersuchung wurde deutlich, dass 20 der 33 untersuchten Dendriten keine Vakuolen aufwiesen (Abbildung 24), was 60,6\% entspricht. Von den pilzförmigen dendritischen Dornenfortsätzen haben $60 \%$ keine Vakuolen (18 aus 30 Dendriten). Hier ist erkennbar, dass es kaum Unterschied zwischen der Anzahl der pilzförmigen dendritischen Dornenfortsätze und den stumpfförmigen Dendriten gibt. Auch statistisch sind keine Unterschiede zwischen stumpf- und pilzförmigen Dornenfortsätzen zu erkennen laut dem t-Test $(p=0,341)$. 


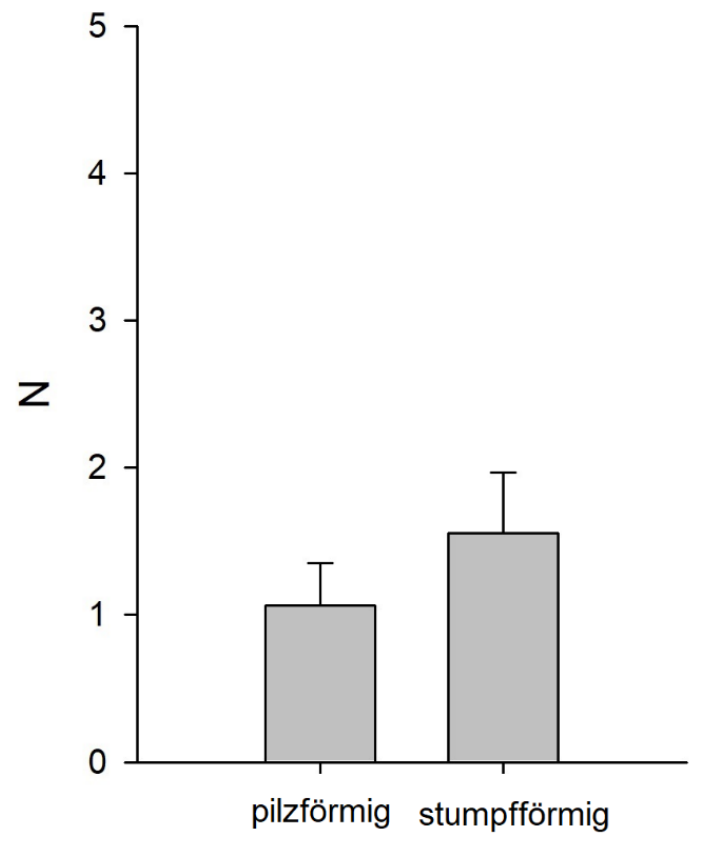

Abbildung 23: Darstellung der Anzahl der Vakuolen in pilzförmigen und stumpfförmigen Dendriten in Form eines Säulendiagramms. Die $\mathrm{x}$-Achse stellt die zwei verschiedenen Morphologien der Dendriten dar, während auf der y-Achse die Anzahl der Vakuolen gezeigt ist.

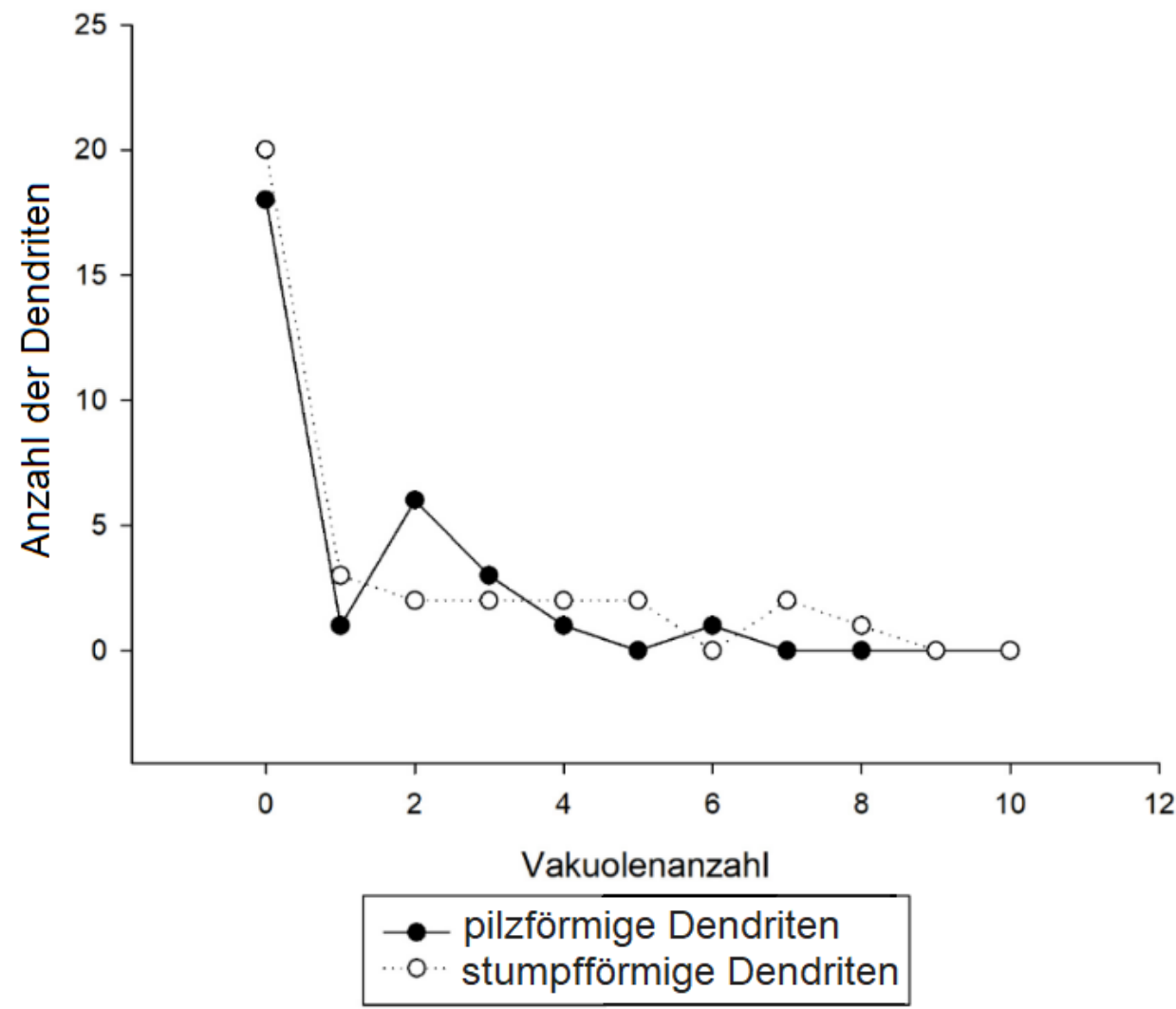

Abbildung 24: Darstellung, wie viel Dendriten mit der Morphologie pilzförmig und stumpfförmig eine gewisse Anzahl an Vakuolen haben. Auf der x-Achse ist die Anzahl der Vakuolen dargestellt; 
die y-Achse zeigt die Anzahl der betrachteten Dornenfortsätze an. Hierbei handelt es sich um zwei Verteilungen: Die schwarzen Punkte stellen die pilzförmigen Fortsätze dar, die grauen Punkte die stumpfförmigen Dornenfortsätze.

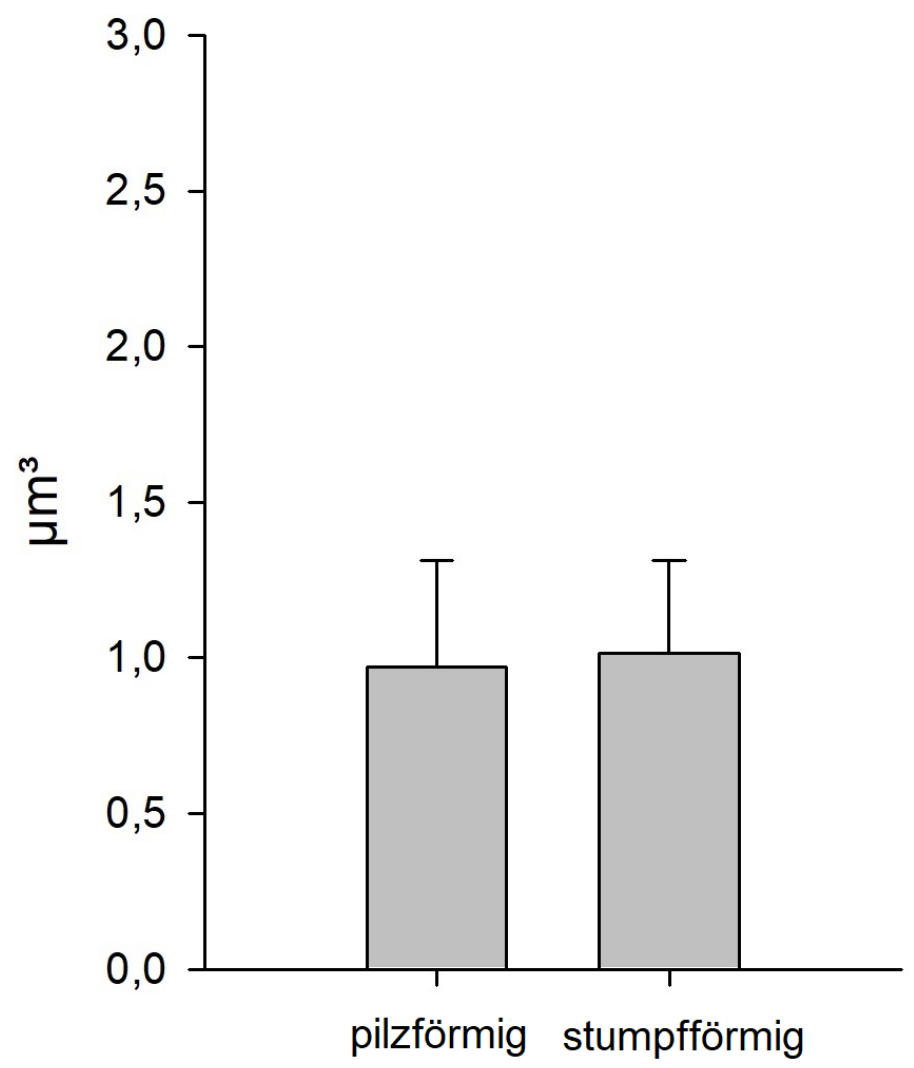

Abbildung 25: Darstellung des Volumens der Vakuolen $\left(\mu \mathrm{m}^{3}\right)$ für pilzförmige und stumpfförmige Dendriten als Säulendiagramm.

Unter Betrachtung der Dornenfortsätze, die nur eine Vakuole aufwiesen, fällt auf, dass dort ebenfalls kaum Unterschiede vorliegen: Es gab drei stumpfförmige Dendriten und einen pilzförmigen Dornenfortsatz, die eine Vakuole besaßen. Ferner wurde bei der Betrachtung von zwei Vakuolen ein etwas größerer Unterschied deutlich: Ein auffälliger Wert ist, dass zwei stumpfförmige und sechs pilzförmige Dendriten je zwei Vakuolen besitzen (Abbildung 24). Dies ist die höchste Anzahl an pilzförmigen Dornenfortsätzen, die überhaupt Vakuolen besitzen. Die höchste Anzahl an Dendriten, nämlich 60,3\%, besitzen keine Vakuolen, dies gilt sowohl für stumpf- als auch für pilzförmige Dornenfortsätze. Weiterhin ergab sich, dass 9,5\% der Dendriten vier bis sechs Vakuolen haben. Nur 4,7\% aller Dendriten besitzen mehr als sechs Vakuolen und stellen damit die Minderheit dar.

Zum Volumen der Vakuolen kann gesagt werden, dass der Mittelwert für pilzförmige Dendriten bei $0,96 \mu \mathrm{m}^{3}$ lag, während die stumpfförmigen Dendriten Vakuolen mit einem 
durchschnittlichen Volumen von $1 \mu \mathrm{m}^{3}$ besaßen. Hier unterscheiden sich die Vakuolen der pilzförmigen Dendriten nicht von denen der stumpfförmigen Fortsätze.

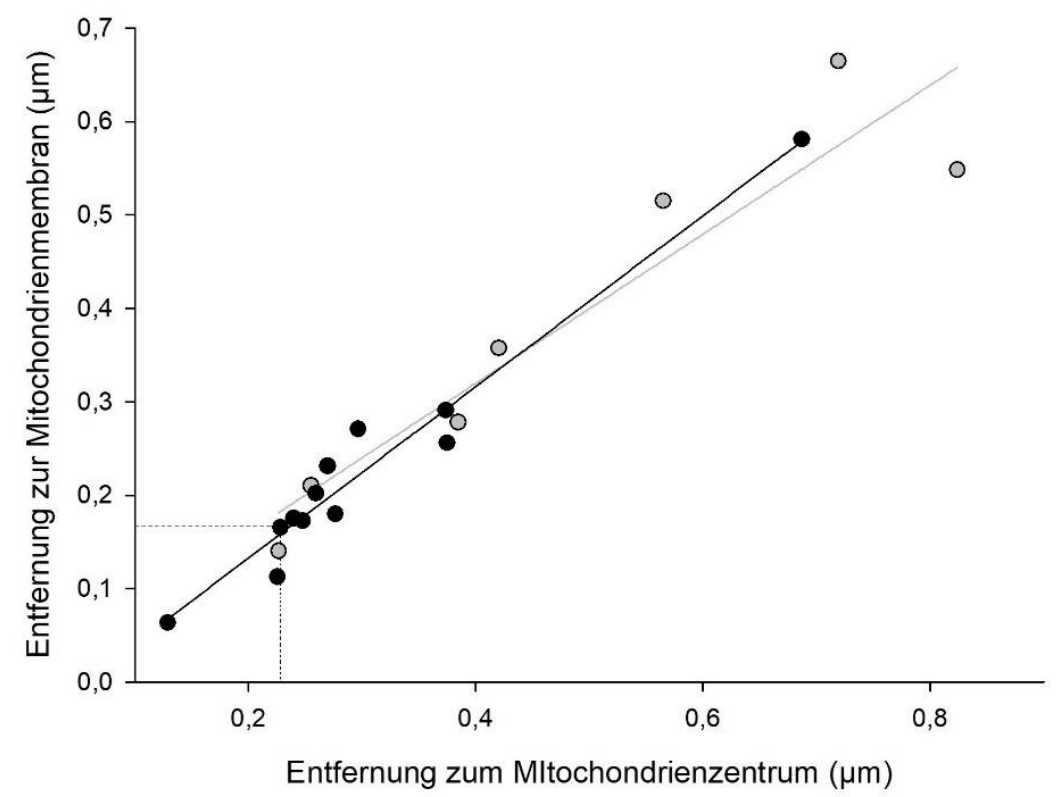

- Entfernung zum Mitochondrienentrum vs Entfernung zur Mitochondrienmembran der pilzförmigen Dendriten ( $\mu$ m) FIT pilzförmige Dendriten

- Entfernung zum Mitochondrienzentrum vs Entfernung zur Mitochondrienmembran der stumpfförmigen Dendriten ( $\mu$ m) FIT stumpfförmige Dendriten

- - - Darstellung eines Beispiels für die Entfernung von Vakuole zu Mitochondrienmembran und Mitochondrienzentrum

Abbildung 26: Darstellung der Entfernung zur Mitochondrienmembran (y-Achse) in Abhängigkeit von der Entfernung zum Zentrum der Mitochondrien (x-Achse) in $\mu \mathrm{m}$ der Vakuolen in jeweils pilzsowie stumpfförmigen Dendriten. Die hellere Regressionsgerade gehört zu den grauen Punkten und stellt die pilzförmigen Dendriten dar, die schwarze Gerade gehört zu den schwarzen Punkten und stellt die stumpfförmigen Dendriten dar.

Wird die Lokalisation der Vakuolen hinsichtlich der Mitochondrien näher beleuchtet, wird zunächst deutlich, dass beide Regressionsgeraden sich hinsichtlich ihres Winkels kaum voneinander unterscheiden (Abbildung 26). Beide Geraden zeigen eine positive lineare Korrelation nach Pearson (pilzförmig: $r=0,94 ; \quad p=0,0016$; stumpfförmig: $r=0,97$; $\mathrm{p}=<0,0001)$, was bedeutet, dass die Entfernung zur Mitochondrienmembran sowie die Entfernung zum Mitochondrienzentrum miteinander korrelieren. Besonders klein ist die Entfernung der Vakuolen zu den Mitochondrien in stumpfförmigen Dendriten. Diesbezüglich gab es einige Ausreißer der Vakuolen, die verdeutlichen, dass auch zum Teil große Distanzen zwischen ihnen und den Mitochondrien vorhanden sein können $(0,7 \mu \mathrm{m})$. Die gestrichelte Linie zeigt, dass die Entfernung von der Vakuole in diesem pilzförmigen Dornenfortsatz zur Mitochondrienmembran ungefähr 0,18 $\mu \mathrm{m}$ beträgt und zum Zentrum des Mitochondriums 0,22 $\mu \mathrm{m}$. Dies ist eine logische Konsequenz, da der Abstand von der 
Vakuole zur Membran immer kleiner sein muss als von der Vakuole zum Zentrum der Mitochondrien. Außerdem gibt diese Grafik Auskunft über die Größe der Mitochondrien: In diesem Beispiel scheint das Mitochondrium nicht besonders groß zu sein, da zwischen Membran und Zentrum eine Diskrepanz von nur 0,04 $\mu \mathrm{m}$ vorherrscht. Besonders prägnant ist die Ähnlichkeit beider Regressionsgeraden und die damit auch ähnlichen Korrelationskoeffizienten. 


\subsection{Mitochondrien}

Ein Mitochondrium ist ein Zellorganell, das von einer Doppelmembran umhüllt ist und die Funktion der Energiegewinnung trägt, indem es energiereiche Moleküle produziert. In den letzten 50 Jahren der Neurophysiologie wurde eine Vielzahl an Mitochondrien untersucht. In der Präsynapse besitzen die Mitochondrien zusätzlich zur Energiegewinnung die Funktion der Kalziumsequestrierung und Regulierung des zytosolischen Kalziums während der Neurotransmission. Im Folgenden werden einige Parameter der Mitochondrien in der Postsynapse untersucht wie z. B. ihre Anzahl, die Größe, das Volumen und ihre Lokalisation in den dendritischen Dornenfortsätzen.

Die Länge der Mitochondrien von ihrer Membran zum Zentrum variiert von 0,02 $\mu \mathrm{m}$ bis 0,28 $\mu \mathrm{m}$ (Abbildung 26). Die durchschnittliche Länge der Mitochondrienmembran bis zum Zentrum des Mitochondriums beträgt in stumpfförmigen Dendriten $0,07 \mu \mathrm{m}$. In pilzförmigen dendritischen Dornenfortsätzen beträgt dieser Wert dagegen 0,02 $\mu \mathrm{m}$ mehr, somit $0,09 \mu \mathrm{m}$.

Das Volumen der Mitochondrien beträgt in pilzförmigen Dendriten im Mittelwert 1,32 $\mu \mathrm{m}^{3}$ (Abbildung 27). Der Mittelwert der Mitochondrienvolumina in stumpfförmigen Fortsätzen liegt bei $2,29 \mu \mathrm{m}^{3}$. Dies ergibt eine Differenz von $0,97 \mu \mathrm{m}^{3}$. Die Standardabweichung der pilzförmigen Postsynapsen geht bis $1,8 \mu \mathrm{m}^{3}$, während sie in den stumpfförmigen Dendriten bis zu 3,24 $\mu \mathrm{m}^{3}$ erreicht.

Die Standardabweichung von pilzförmigen dendritischen Dornenfortsätzen beträgt $1,8 \mu \mathrm{m}^{3}$, was $78 \%$ von $2,29 \mu \mathrm{m}^{3}$ entspricht, womit also ein Unterschied von $22 \%$ zwischen der Standardabweichung der pilzförmigen Postsynapsen und dem Mittelwert der stumpfförmigen Dendriten besteht. Das Volumen der Mitochondrien sowohl in pilz- als auch in stumpfförmigen Dendriten unterschiedet sich nicht statistisch (Abbildung 27). Der t-Test ergab einen $\mathrm{p}$-Wert von 0,39. Dieser Wert deutet darauf hin, dass keine Unterschiede zwischen den Mittelwerten der Mitochondrienvolumina in pilz- und stumpfförmigen dendritischen Fortsätzen erkennbar sind.

Die Verteilung der Mitochondrienvolumina und ihr Vergleich zwischen den einzelnen Morphologien der Dendriten (Abbildung 28) zeigt, dass 22 stumpfförmige Dendriten, somit also fast ein Drittel der Gesamtmenge der dendritischen Dornenfortsätze, keine Mitochondrien besitzen. Im Gegensatz dazu ist erkennbar, dass 19 der pilzförmigen Dendriten keine Mitochondrien besitzen. 


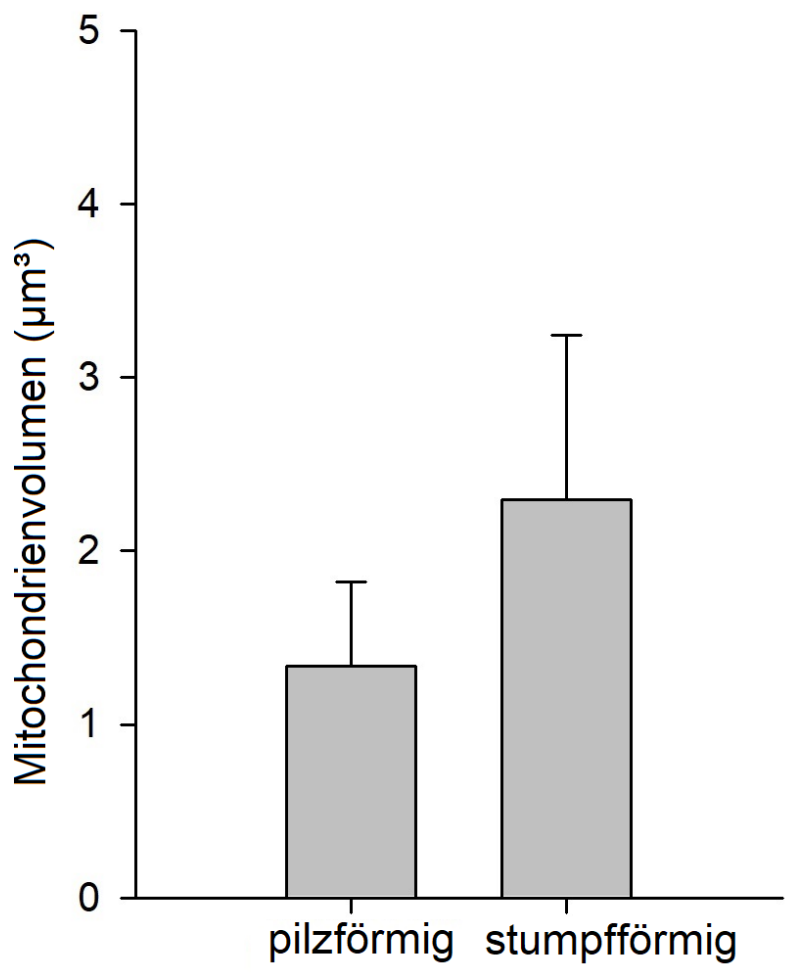

Abbildung 27: Dieses Säulendiagramm stellt das Volumen der Mitochondrien in $\mu \mathrm{m}^{3}$ dar. Die xAchse zeigt die Verteilung der pilz- und stumpfförmigen Dendriten; die y-Achse stellt das Mitochondrienvolumen in $\mu \mathrm{m}^{3}$ dar. Der t-Test ergab einen $\mathrm{p}$-Wert von 0,39 .

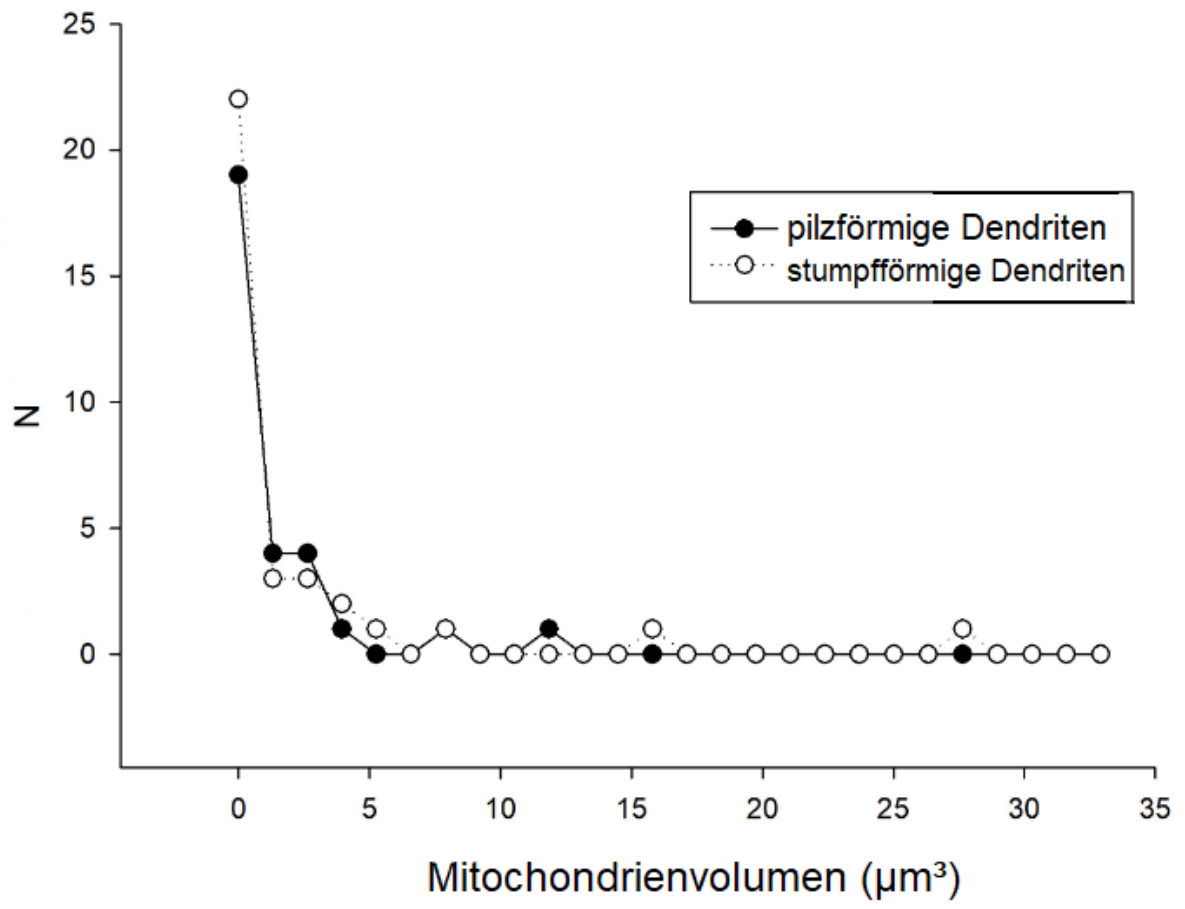

Abbildung 28: Anhand dieses Verlaufsdiagramms ist ersichtlich, wie viele Dendriten welche Anzahl an Mitochondrien besitzen und wie groß die jeweiligen Volumina sind. Auf der x-Achse ist das 
Mitochondrienvolumen in $\mu \mathrm{m}^{3}$ dargestellt; die y-Achse zeigt die Anzahl der betrachteten Dornenfortsätze. Hierbei handelt es sich um zwei Verteilungen. Die schwarzen Punkte stehen für die pilzförmigen Fortsätze, die grauen Punkte für die stumpfförmigen.

Dass eine stumpfförmige Postsynapse das größte Mitochondrienvolumen von $28 \mu \mathrm{m}^{3}$ besitzt, hebt den Mittelwert der stumpfförmigen Dendriten stark an. Dabei handelt es sich erneut um eine stumpfförmige Postsynapse, die den zweithöchsten Wert, $16 \mu \mathrm{m}^{3}$, an Mitochondrienvolumen bildet. Der hohe Mittelwert der stumpfförmigen Dendriten ist wahrscheinlich auch auf die hohen Volumina zurückzuführen, die nur bei Mitochondrien in stumpfförmigen dendritischen Dornenfortsätzen beobachtet wurden.

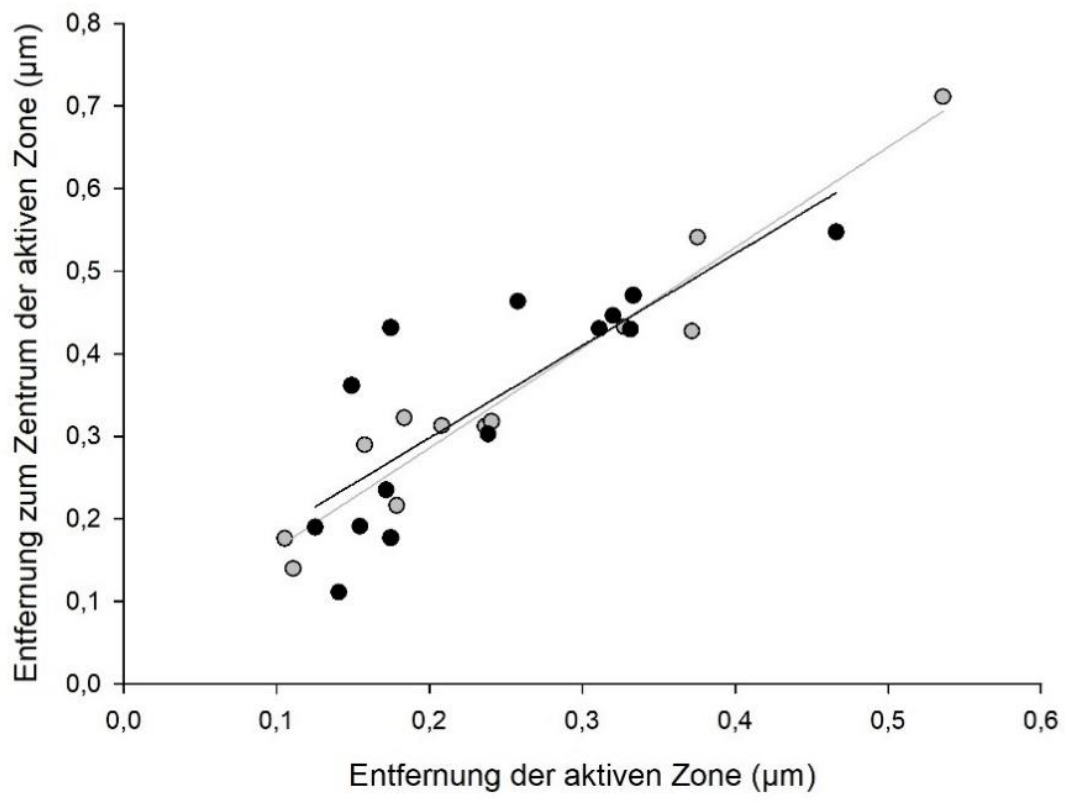

- Entfernung zur aktiven Zone vs Entfernung zum Zentrum der aktiven Zone $(\mu \mathrm{m})$ pilzförmige Dendriten FIT pilzförmige Dendriten

- Entfernung zur aktiven Zone vs Entfernung zum Zentrum der aktiven Zone $(\mu \mathrm{m})$ stumpfförmige Dendriten FIT stumpfförmige Dendriten

Abbildung 29: Darstellung der Distanz der Mitochondrien zum Zentrum der aktiven Zone in $\mu \mathrm{m}$ und zur aktiven Zone in $\mu \mathrm{m}$ als Punktdiagramm. Die hellen Punkte stehen für die pilzförmigen Dendriten, die helle Gerade zeigt die Regressionsgerade. Die dunklen Punkte zeigen die stumpfförmigen Dendriten, die dunkle Gerade steht für die Regressionsgerade der stumpfförmigen Dendriten.

Wenn nun die Mitochondrien in Bezug zur aktiven Zone betrachtet werden, fällt auf, dass die Scatterpunkte der pilzförmigen und der stumpfförmigen Dendriten zwei positive Geraden ergeben, was auf eine positive lineare Abhängigkeit hindeutet (Abbildung 29). Die 
positive lineare Relation ist auch durch den Pearson-Korrelationskoeffizienten erkennbar (stumpfförmig: $\mathrm{r}=0,81 ; \mathrm{p}=0,0004$; pilzförmig: $\mathrm{r}=0,96 ; \mathrm{p}=<0,0001$ ) und beweist, dass es eine lineare Abhängigkeit zwischen dem Zentrum der aktiven Zone und der aktiven Zone gibt. Das Zentrum der aktiven Zone wurde so definiert, dass durch jeden Schnitt durch die Zellen (70 nm Schnitttiefe) der Mittelpunkt der postsynaptischen Dichte bestimmt wurde. In dem Graphen ist eine Häufung der Punkte zwischen $0,2 \mu \mathrm{m}$ und $0,5 \mu \mathrm{m}$ zu sehen. Die beiden Geraden liegen fast übereinander, was verdeutlicht, dass hier keine 1:1-Relation der Geraden zu den beiden Achsen zutrifft. Beide sind stärker oberhalb im Feld gesetzt. Dies deutet darauf hin, dass die Mitochondrien in den Postsynapsen näher an der aktiven Zone liegen als am Zentrum ebendieser.

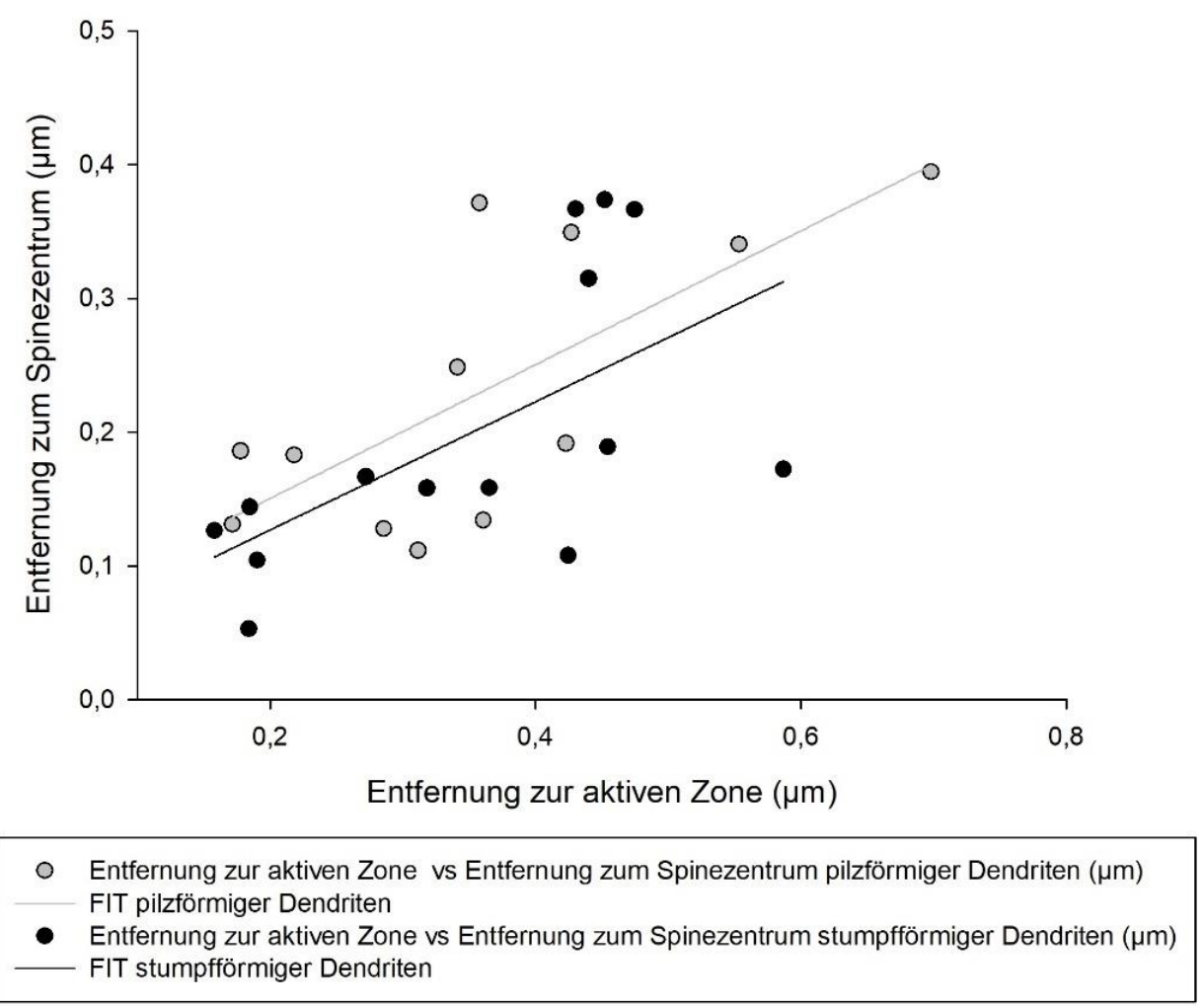

Abbildung 30: Darstellung der Entfernung von den Mitochondrien zum Spine-Zentrum in Abhängigkeit von der Entfernung der aktiven Zone in $\mu \mathrm{m}$. Die x-Achse zeigt die Entfernung zur aktiven Zone (in $\mu \mathrm{m}$ ), während die y-Achse die Distanz zum Zentrum des Dendriten darstellt. Die Regressionsgeraden der stumpf- bzw. pilzförmigen Dendriten sind in grau bzw. schwarz dargestellt und verlaufen beinahe parallel zueinander.

Werden die Mitochondrien nun im Bezug zur Entfernung zum Zentrum des Dendriten und zur Entfernung zur aktiven Zone betrachtet (Abbildung 30), so wird deutlich, dass die 
Regressionsgeraden von pilz- und stumpfförmigen Dendriten fast parallel zueinander verlaufen. Zwischen beiden Geraden liegt eine Distanz von ca. 0,02 $\mu \mathrm{m}$, die sich für alle weiteren Messwerte auf der Geraden erstreckt. Die Regressionsgeraden verlaufen beide in einer linear positiven Abhängigkeit (pilzförmig: $r=0,72 ; p=0,0078$; stumpfförmig: $r=0,59 ; p=0,023)$. Sowohl für pilz-als auch für stumpfförmige Synapsen gilt, dass sich die Mitochondrien mit zunehmender Entfernung zum Zentrum der Spine auch weiter von der aktiven Zone entfernen. Ferner besteht immer ein größerer Abstand zur aktiven Zone als zum Zentrum des Dendriten, weshalb die Mitochondrien entgegengesetzt zur aktiven Zone lokalisiert sein müssen.

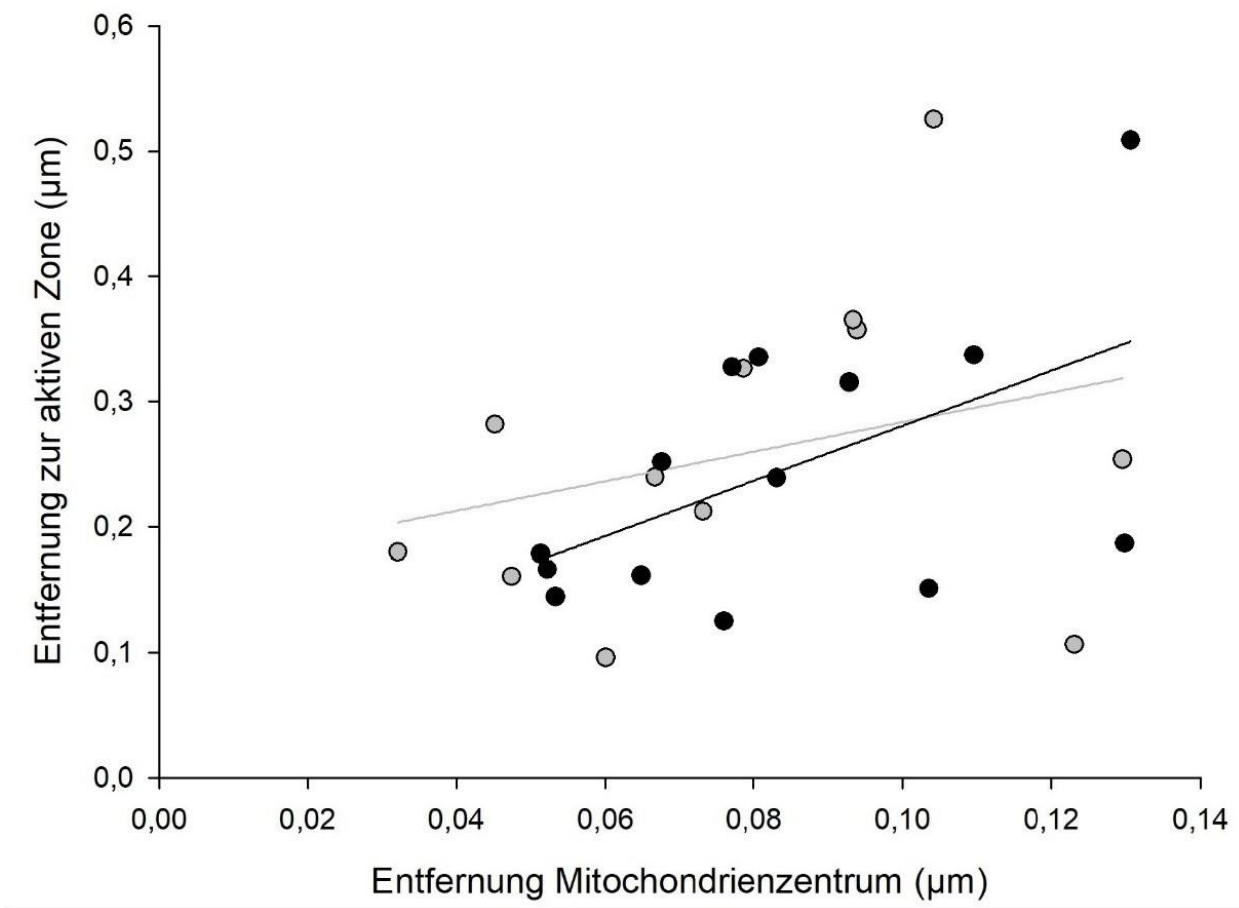

○ Entfernung zum Mitochondrienzentrum vs Entfernung zur aktiven Zone pilzförmiger Dendriten $(\mu \mathrm{m})$ FIT pilzförmiger Dendriten

- Entfernung zum Mitochondrienzentrum vs Entfernung zur aktiven Zone stumpfförmiger Dendriten $(\mu \mathrm{m})$ FIT stumpfförmiger Dendriten

Abbildung 31: Darstellung der Distanzen der Mitochondrien zur aktiven Zone auf der y-Achse $(\mu \mathrm{m})$ und zum Mitochondrienzentrum $(\mu \mathrm{m})$. Die grauen Punkte stehen für die pilzförmigen und die dunklen Punkte für die stumpfförmigen Dendriten. Die Regressionsgeraden kreuzen sich in diesem Graphen und es ist ersichtlich, dass die Steigung der grauen Regressionsgerade, die die pilzförmigen Dendriten widerspiegelt, nicht so steil ist wie die Gerade der stumpfförmigen dendritischen Dornenfortsätze. 


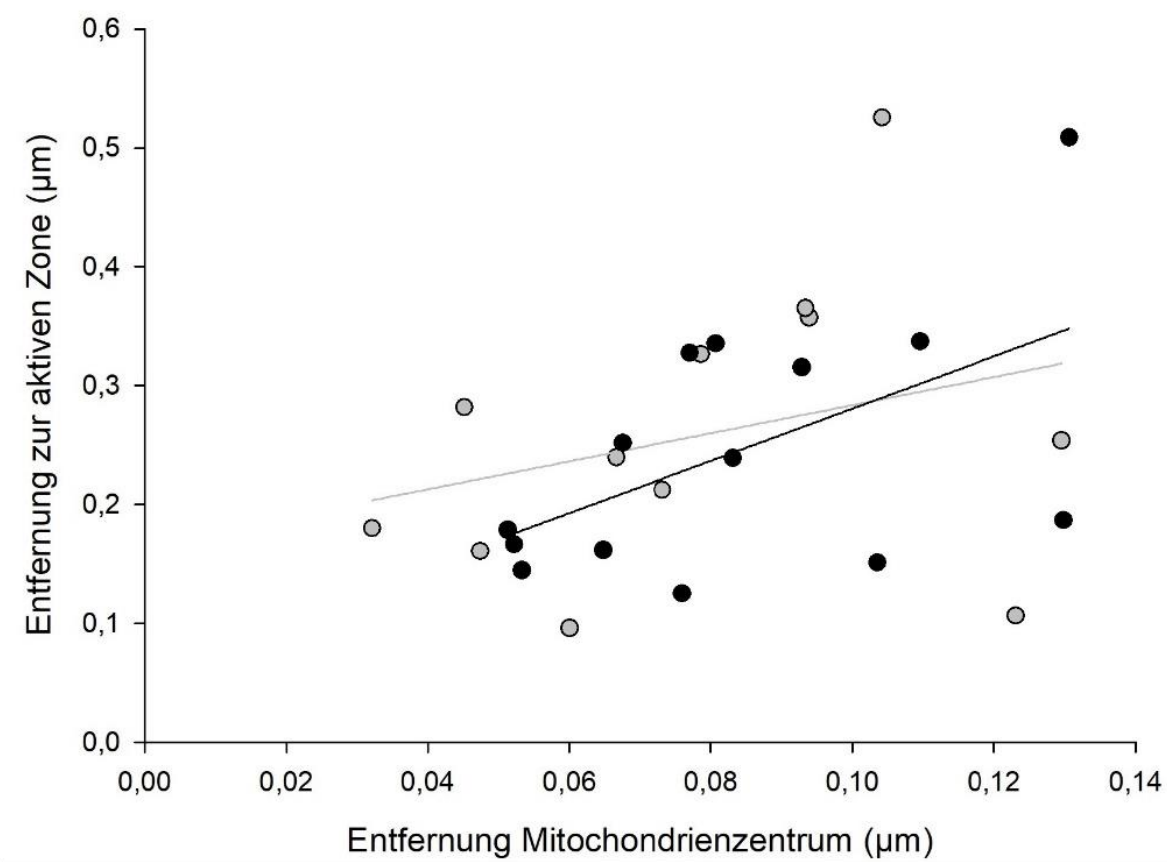

O Entfernung zum Mitochondrienzentrum vs Entfernung zur aktiven Zone pilzförmiger Dendriten ( $\mu \mathrm{m})$ FIT pilzförmiger Dendriten

- Entfernung zum Mitochondrienzentrum vs Entfernung zur aktiven Zone stumpfförmiger Dendriten ( $\mu \mathrm{m})$ FIT stumpfförmiger Dendriten

Abbildung 32: Die Graphen zeigen die Mitochondrien in Bezug zur Entfernung zur Membran (yAchse) in $\mu \mathrm{m}$ und die Entfernung zum Zentrum des Dendriten (x-Achse) in $\mu \mathrm{m}$. Die Regressionsgeraden der stumpfförmigen Verteilung fallen ab und beide Regressionsgeraden kreuzen sich auf der Höhe einer Entfernung zum Spine-Zentrum von 0,3 $\mu \mathrm{m}$. Die Verteilung von pilz- und stumpfförmigen Mitochondrien ist eher diffus.

Wird der Bezug der Mitochondrien in stumpf- sowie pilzförmigen Dendriten auf die Entfernung zur aktiven Zone und die Entfernung zum Zentrum der Mitochondrien betrachtet (Abbildung 31), so fällt auf, dass sich die Regressionsgeraden kreuzen und dass die Gerade der stumpfförmigen Dendriten steiler ist, was auf eine positive lineare Abhängigkeit hindeutet. Die helle Regressionsgerade der pilzförmigen Dendriten könnte ebenfalls eine positive Abhängigkeit darstellen, jedoch ist sie nicht so steil. Auch die Werte des Pearson-Korrelationskoeffizienten zeigen, dass die Werte der stumpfförmigen Dendriten korrelieren, die Werte der pilzförmigen jedoch nicht (pilzförmig: $r=0,296$; $\mathrm{p}=0,349$; stumpfförmig: $\mathrm{r}=0,538 ; \mathrm{p}=0,046)$. Dies bedeutet, dass die Mitochondrien bei den pilzförmigen dendritischen Dornenfortsätzen nicht organisiert angeordnet sind. Bei den stumpfförmigen Dendriten ist deutlich zu sehen, inwiefern eine Korrelation vorliegt: Die Form der stumpfförmigen dendritischen Dornenfortsätze ist durchweg ähnlich. Sie haben einen kurzen Hals, der sich kaum vom restlichen Körper abhebt und keine Verjüngung aufweist. Die Form ist wesentlich ,absehbarer ${ }^{6}$ als bei den komplexen 
Strukturen der pilzförmigen dendritischen Dornenfortsätze. Die aktive Zone kann sowohl nah als auch weit entfernt liegen, daher ist keine Konsistenz festzustellen. Die stumpfförmigen Dendriten sind konsistenter in ihrer Form, sehen größtenteils gleich aus und haben eine gleichmäßige Morphologie. Anhand dieser Aspekte lässt sich sagen, dass die stumpfförmigen Dendriten eine höhere lineare Abhängigkeit zeigen und dass ihre Morphologie und ihre bestimmten Charakteristika einer konsistenten Mitochondrienlokalisation zugutekommen.

Darüber hinaus ist ebenfalls auffällig, dass die Mitochondrien sowohl in pilz-als auch in stumpfförmigen Dendriten nicht organisiert auftreten (Abbildung 32). Die Regressionsgerade der stumpfförmigen Dendriten ist negativ und fällt ab. Die helle Gerade steigt marginal, jedoch nicht signifikant. Dies ist auf eine negative lineare Abhängigkeit nach Pearson zurückzuführen (stumpfförmig: $r=0,061 ; p=0,83$; pilzförmig: $r=0,23$; $\mathrm{p}=0,46)$.

\subsection{Morphologie der Dendriten}

Nachdem die Zellorganellen durch die verschiedenen Graphen beschrieben und analysiert wurden, wird im nachfolgenden Teil der Arbeit stärker auf die Form der Dendriten eingegangen.

Wenn die kleinere Achse der Dendriten (pilz- und stumpfförmig) und die größere Achse der Dendriten gegenübergestellt werden, so wird deutlich, dass die Regressionsgeraden beider Morphologien sich kaum unterscheiden und dicht aneinander verlaufen (Abbildung 33). Die positive lineare Abhängigkeit beschreibt ein gleichmäßiges Wachstum der Form der Spines (stumpfförmig: $r=0,668 ; p=<0,0001$; pilzförmig: $r=0,708, p=<0,0001$ ). Es muss auch erwähnt werden, dass das Achsenverhältnis immer gleichbleibt. Bei näherer Betrachtung der Skalierung ist erkennbar, dass die y-Achse immer etwas höhere Werte aufweist als die x-Achse. Demnach handelt es sich nicht um ein 1:1-Verhältnis der Achsen, sondern um eine ellipsoide Form. Zwischen Mushroom und Stumpy lässt sich somit kein signifikanter Unterschied feststellen. 


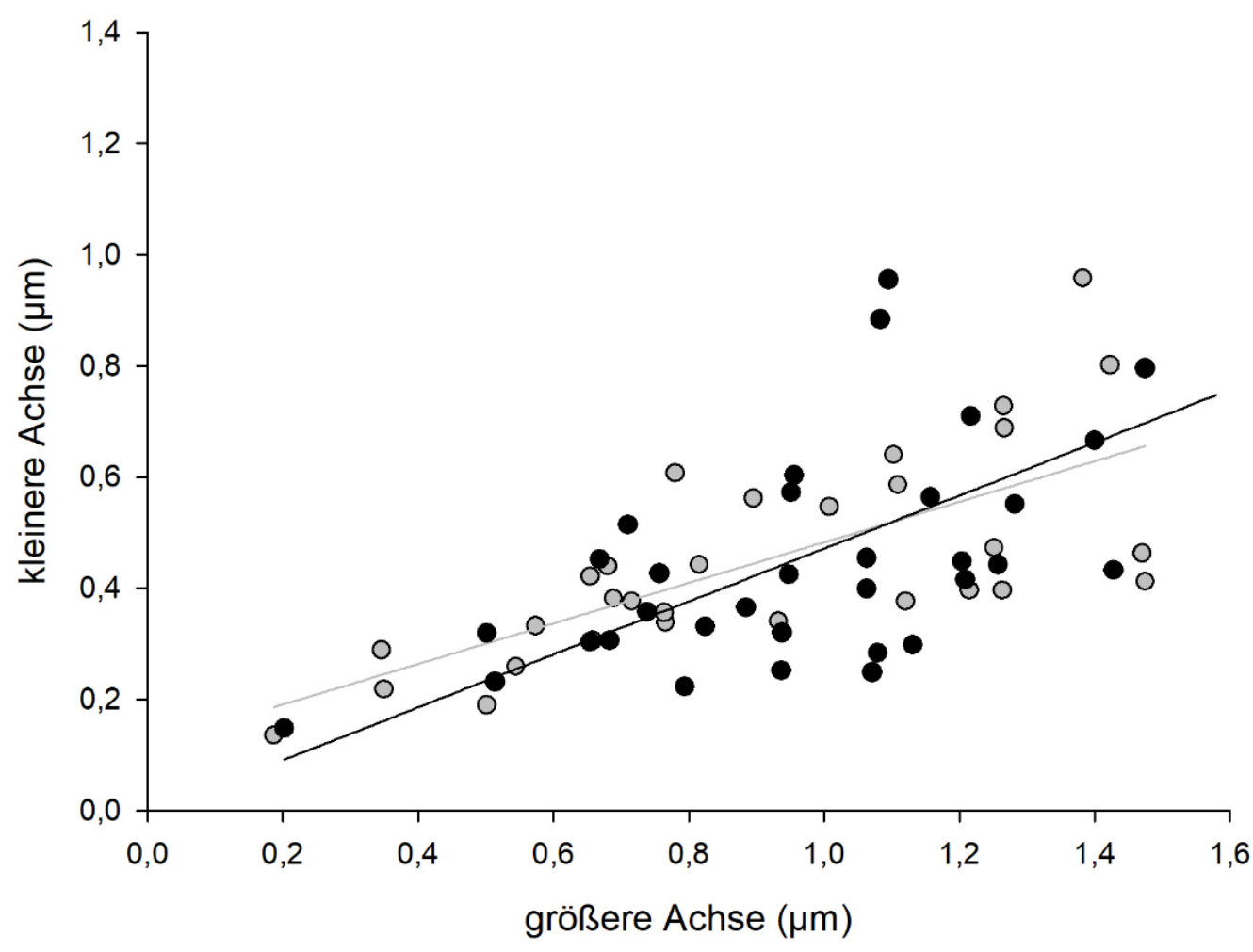

○ Größere Achse vs kleinere Achse $(\mu \mathrm{m})$ pilzförmiger Dendriten FIT pilzförmiger Dendriten

- Größere Achse vs kleinere Achse $(\mu \mathrm{m})$ stumpfförmige Dendriten FIT stumpfförmige Dendriten

Abbildung 33: Darstellung der Form der Dendriten durch Gegenüberstellung der jeweiligen Achsen. Die größere Achse ist auf der x-Achse lokalisiert, die kleinere Achse auf der y-Achse. Beide Regressionsgeraden, die den stumpf- bzw. pilzförmigen dendritischen Dornenfortsätzen zugeordnet werden können, verlaufen dicht zueinander und kreuzen sich am Punkt 1,1/0,5. Die schwarze Regressionsgerade ist den stumpfförmigen Dendriten zuzuordnen, die graue Gerade den pilzförmigen Postsynapsen. Jeder Punkt in dem Punktediagramm stellt das Verhältnis der Achsen eines Dornenfortsatzes dar. Schwarze Punkte stehen für stumpfförmige Dendriten, graue Punkte für pilzförmige dendritische Dornenfortsätze. 


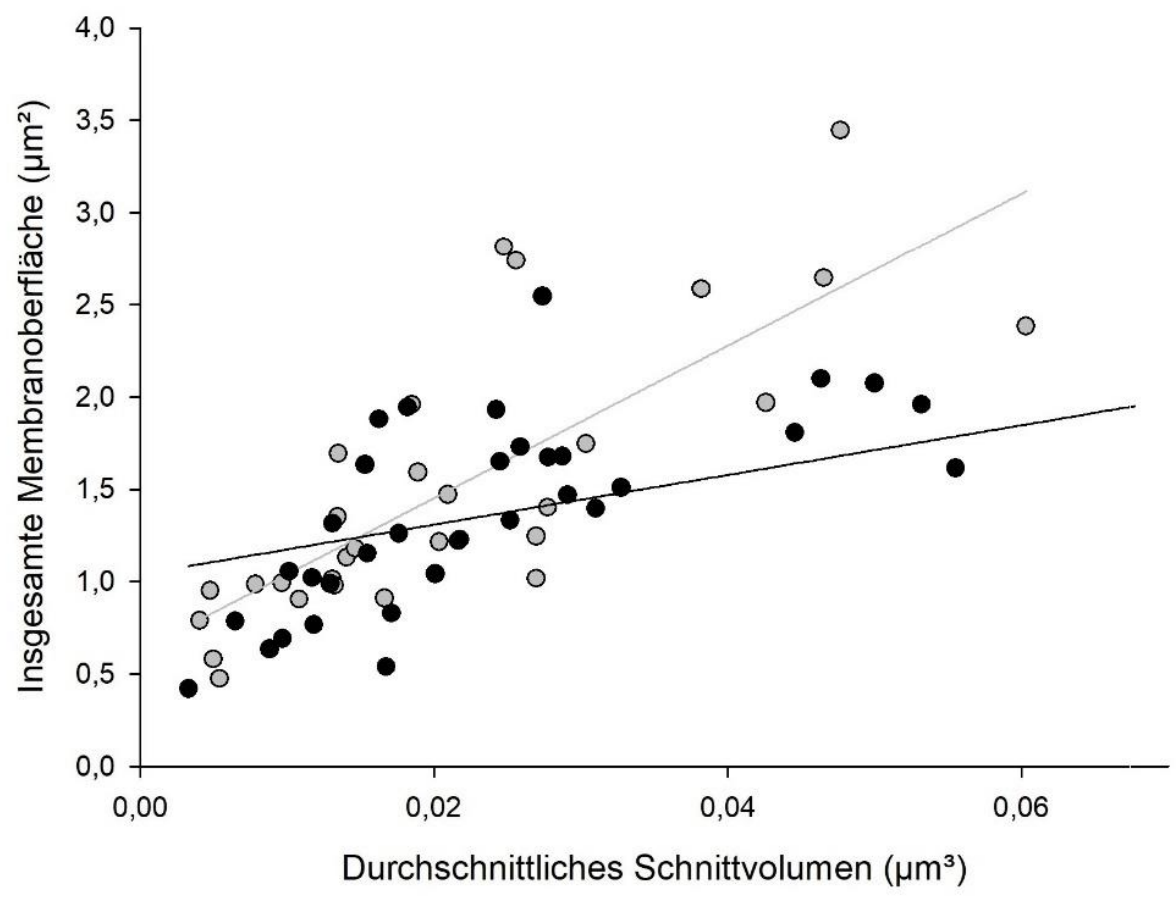

- Durchschnittliches Schnittvolumen $\left(\mu \mathrm{m}^{3}\right)$ vs insgesamte Membranoberfläche $\left(\mu \mathrm{m}^{2}\right)$ pilzförmige Dendriten FIT pilzförmige Dendriten

- Durchschnittliches Schnittvolumen $\left(\mu \mathrm{m}^{3}\right)$ vs insgesamte Membranoberfläche $\left(\mu \mathrm{m}^{2}\right)$ stumpfförmige Dendriten FIT stumpfförmige Dendriten

Abbildung 34: Darstellung eines Graphen von pilz- und stumpfförmigen Dendriten, in dem die insgesamte Membranoberfläche in $\mu \mathrm{m}^{2}$ (y-Achse) gegen das durchschnittliche Schnittvolumen in $\mu \mathrm{m}^{3}$ gestellt wurde (x-Achse). Die grauen und schwarzen Punkte, die pilz- bzw. stumpfförmige Dendriten darstellen, sind größtenteils bei einer insgesamten Membranoberfläche von $0,4 \mu \mathrm{m}^{3}$ bis $2,5 \mu \mathrm{m}^{3}$ angeordnet und zeigen in diesem Bereich eine starke Häufung.

Wird die insgesamte Membranoberfläche pilz- und stumpfförmiger Dendriten in Bezug auf ihr durchschnittliches Schnittvolumen näher untersucht (Abbildung 34), so ist zu erkennen, dass beide Regressionsgeraden eine positive Steigung aufweisen und laut dem PearsonKorrelationskoeffizienten somit eine positive lineare Abhängigkeit zeigen (stumpfförmig: $r=0,505 ; \mathrm{p}=0,0023$; pilzförmig: $\mathrm{r}=0,779 ; \mathrm{p}=<0,0001)$. Deutlich ist auch, dass die graue Regressionsgerade ein deutlich stärkeres Wachstum aufzeigt. Dass die Membranoberfläche mit dem Volumen wächst, ist bekannt, jedoch wird hier deutlich dargestellt, dass ab einer Membranoberfläche von ungefähr 1,2 $\mu \mathrm{m}^{2}$ die insgesamte Oberfläche der Membran der Mushrooms deutlich größer wird. Zudem lässt sich eine Häufung der Punkte im Diagramm feststellen, die zeigt, dass rund 74,6\% aller Dendriten im Bereich zwischen 0,4 $\mu \mathrm{m}^{2}$ und 2,5 $\mu^{2}$ lokalisiert sind. Von diesen 74,6 \% sind 40,4\% pilzförmige Dendriten und 59,6\% stumpfförmige dendritische Dornenfortsätze. Es lässt sich also auch hier sagen, dass die Verteilung pilz- und stumpfförmiger Dendriten relativ ausgeglichen ist. 


\section{Diskussion}

Durch Untersuchungen an hippocampalen Zellen konventioneller Neuronenkulturen wurden die Zellorganellen der dendritischen Dornenfortsätze erforscht. Das Hauptziel dieser Studie war die quantitative Analyse der Zellorganellen in Dendriten. Aus den Ergebnissen (Kapitel 3) können mehrere Schlussfolgerungen gezogen werden. Ein ausschlaggebendes Resultat allerdings zieht sich durch nahezu alle Grafiken und Statistiken: Die verschiedenen Morphologien der Dendriten, in diesem Fall pilzförmige und stumpfförmige Fortsätze, weisen kaum Unterschiede zueinander auf hinsichtlich ihrer Zellorganellen. Daher kann vermutet werden, dass zwischen den pilz- und stumpfförmigen dendritischen Fortsätzen ebenfalls keine Unterschiede bezüglich ihrer Funktion vorliegen bis auf die Verjüngung im Halsbereich der pilzförmigen Dendriten und ihre komplexere Form. Im Folgenden werden die Ergebnisse in einen wissenschaftlichen Kontext gebracht und diskutiert. Zunächst muss jedoch hervorgehoben werden, dass in dieser Studie mit hippocampalen Neuronenkulturen geforscht wurde anstelle, wie bisher, mit Gehirnschnitten.

Obwohl das glatte endoplasmatische Retikulum meistens in Dendriten lokalisiert ist, extendiert es gelegentlich auch in die dendritischen Fortsätze. Das glatte endoplasmatische Retikulum wurde in $15 \%$ der Fälle im Hals der Dendriten gefunden. Der Spine-Apparat, eine Spezialisierung des glatten endoplasmatischen Retikulums, wurde in großen Dendriten gefunden (Spacek und Harris 1997; Gray 1959). In dieser Forschung wurden Vakuolen näher beleuchtet, die flüssigkeitsgefüllte Zellorganellen sind. Da nur die Zellmorphologie und nicht auf molekularer Ebene erforscht wurde, ist es möglich, dass einige Vakuolen glatte endoplasmatische Retikula sind. Dadurch, dass manche Vakuolen eine tubuläre Struktur in den durch MATLAB erstellten Modellen besitzen, könnte auch vermutet werden, dass diese die Natur eines endoplasmatischen Retikulums besitzen. Obwohl das neuronale endoplasmatische Retikulum, wie in den meisten nichtneuronalen Zellen, eine Hauptrolle des inneren Membransystems spielt (Spacek und Harris 1997), wurde keines in den dendritischen Spines gefunden. Die gefundenen Vakuolen können eventuell dem glatten endoplasmatischen Retikulum zugeordnet werden, jedoch fehlt hierfür die molekulare Ebene ebendieser Zellen. 


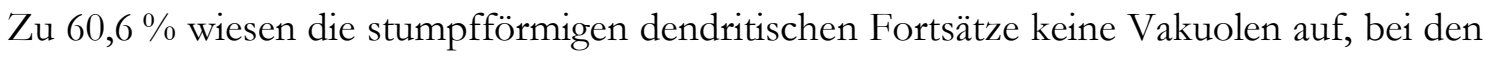
pilzförmigen Fortsätzen waren es $60 \%$. Der Mittelwert des Volumens für Vakuolen lag bei pilzförmigen Dendriten bei $0,96 \mu \mathrm{m}^{3}$, während die stumpfförmigen Dendriten Vakuolen mit einem durchschnittlichen Volumen von $1 \mu \mathrm{m}^{3}$ besaßen. Hier unterscheiden sich die Vakuolen der pilzförmigen Dendriten nicht von den Vakuolen der stumpfförmigen Fortsätze.

Die Lagebeziehung zu den Mitochondrien stellte ebenfalls keine Unterschiede dar. Die Entfernung von den Vakuolen zu den Mitochondrien in stumpfförmigen Dendriten war besonders klein. In den pilzförmigen Dendriten gab es einige Vakuolen, die verdeutlichten, dass zwischen ihnen und den Mitochondrien auch zum Teil große Distanzen von bis zu $0,7 \mu \mathrm{m}$ herrschen können.

In anderen Studien waren die meistgefundenen Organellen in Dendriten, die nicht zum endoplasmatischen Retikulum gehören, Mitochondrien und Vesikel. Am häufigsten waren die Mitochondrien im zentralen Teil des Halses der Dendriten lokalisiert. Ferner wurden die Vesikel unterteilt in große ellipsoide Vesikel und kleinere, runde Vesikel, die einen Durchmesser von $50 \mathrm{~nm}$ besaßen (Cooney et al. 2002). In dieser Studie wurden die Vesikel bezüglich ihrer Anzahl und Größe erforscht sowie in Bezug auf ihre Lokalisation. Die Größe von $60 \mathrm{~nm}$ passt also ebenfalls zu anderen Studien. Die Anzahl der Vesikel war in pilz- und stumpfförmigen Dendriten annähernd ähnlich und wies keine statistischen Unterschiede zwischen den beiden Morphologien auf ( $\mathrm{t}-$ Test: $\mathrm{p}=0,53)$. Diese Erkenntnis stützt die Vermutung, dass es statistisch kaum Unterschiede zwischen stumpf- und pilzförmigen Synapsen gibt. Die Diagramme, die die Anzahl der Vesikel verteilt auf die einzelnen Morphologien von Dendriten darstellen, verdeutlichen, dass pilz- und stumpfförmige dendritische Fortsätze beide zu einem hohen Anteil, nämlich 21 von 33, keine Vesikel besitzen (Abbildung 20). Bei den pilzförmigen Dendriten besaßen 13 von 30 Fortsätze keine Vesikel. Darüber hinaus wurde durch den PearsonKorrelationskoeffzienten herausgestellt, dass die Vesikel beider Arten der Dornenfortsätze eine positive lineare Abhängigkeit zeigen ( $r=0,91 ; \mathrm{p}=<0,0001)$.

In anderen Studien wird diskutiert, ob Mitochondrien einen großen Einfluss auf die Neurotransmission haben, indem sie $85 \%$ der synaptischen Vesikel mobilisieren (Rizzoli und Betz 2005). Darüber hinaus wurde ebenfalls in weiteren Studien untersucht, ob die Form der dendritischen Dornenfortsätze wirklich einen Einfluss auf ihre Funktion hat und 
ob die meisten Veränderungen ihrer Morphologie während des Wachstums entstehen. Dendriten werden demnach konstant geformt und wieder eliminiert (Chen et al. 2014)

Die Vesikel, die in dieser Studie untersucht wurden, wurden quantitativ sowohl in pilz- als auch in stumpfförmigen dendritischen Fortsätzen zu fast gleicher Zahl gefunden. Ihre Größe betrug ungefähr $60 \mathrm{~nm}$, was nur einen geringen Unterschied zu präsynaptischen Vesikeln (ca. 30 bis $50 \mathrm{~nm}$ ) bedeutet.

Die Vesikel waren vermutlich zwischen dem Zentrum der aktiven Zone und dem Zentrum des Dendriten lokalisiert. Durch das Auftreten der positiven linearen Abhängigkeit war erkennbar, dass, wenn die Vesikel sich gleichermaßen vom Zentrum der Spine wegbewegen, sie sich auch vom Zentrum der aktiven Zone entfernen. Dies ergab auch hinsichtlich ihrer Funktion Sinn, da sie nahe der aktiven Zone liegen müssen, um die Neurotransmitter zu transportieren.

Mitochondrien kamen selten in den dendritischen Dornenfortsätzen vor. Meistens sind sie an komplexe oder große dendritische Dornenfortsätze gebunden, wie sie normalerweise im zerebralem Kortex, in den verzweigten Ästen der hippocampalen Bereiche oder in Spines in olfaktorischen Gebieten gefunden werden (K M Harris und S B Kater 1994). Dies geht auch aus dieser Studie hervor, da insgesamt nur wenige Mitochondrien in dendritischen Spines gefunden wurden (Abbildung 28). Stumpfförmige Synapsen besaßen zu einem Drittel der Gesamtmenge keine Mitochondrien. Zur Lokalisation der Mitochondrien lässt sich des Weiteren sagen, dass diese eher entgegengesetzt zur aktiven Zone angeordnet waren (Abbildung 30). Auch zur Konsistenz der Lokalisation der Mitochondrien war keine Korrelation nach Pearson bei den pilzförmigen Synapsen zu erkennen (pilzförmig: $\mathrm{r}=0,296 ; \mathrm{p}=0,349 ;$ stumpfförmig: $\mathrm{r}=0,538 ; \mathrm{p}=0,046)$. Die stumpfförmigen Spines zeigten dagegen eine lineare Abhängigkeit. Dass die Entfernung der Mitochondrien zur postsynaptischen Dichte so inkonsistent war, liegt an der komplexen Form und Morphologie der Mushroom spines (Abbildung 35). Stumpfförmige Dendriten sehen sich vorwiegend ähnlich, mit ihrer kurzen, breiten Form und dem fehlenden Hals. Deshalb ist es einleuchtend, dass die Distanzen von den Mitochondrien zur postsynaptischen Dichte konsistent sind. 


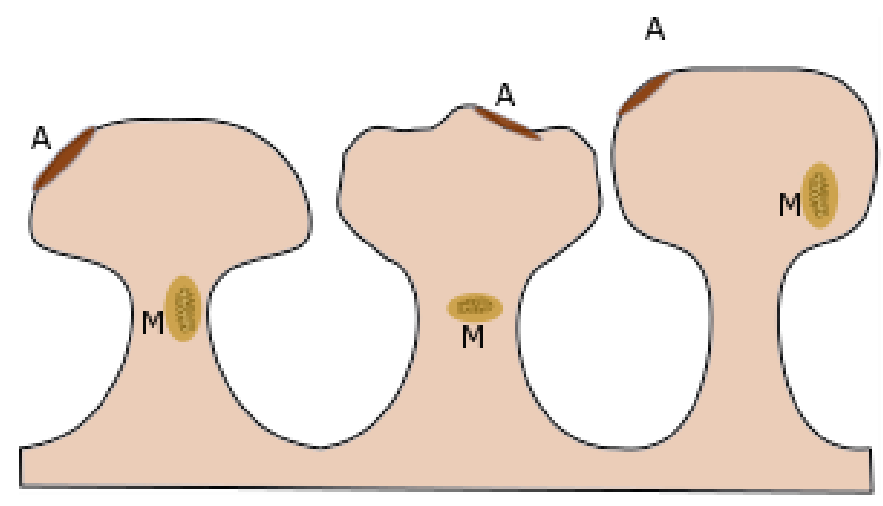

Abbildung 35: Stark vereinfachte Skizze dreier pilzförmiger Synapsen, die verdeutlichen soll, dass die Distanzen von der aktiven Zone (A) zu den Mitochondrien (M) aufgrund der komplexen und teils unterschiedlichen Form der Dendriten inkonsistent sind.

Der Radius der Mitochondrien variierte von $0,02 \mu \mathrm{m}$ bis hin zu 0,28 $\mu \mathrm{m}$. Die Länge der Distanz von der Mitochondrienmembran bis hin $\mathrm{zu}$ ihrem Zentrum betrug im Durchschnitt in stumpfförmigen Dendriten $0,07 \mu \mathrm{m}$, in pilzförmigen Mitochondrien dagegen $0,09 \mu \mathrm{m}$.

Ferner unterschied sich das Volumen der Mitochondrien sowohl in pilz-als auch in stumpfförmigen dendritischen Dornenfortsätzen statistisch nicht (t-Test: $p=0,39)$. In nahezu allen Gehirnregionen sind zahlreiche Mitochondrien rundlich und in allen Größen vertreten; andere sind länglich geformte Organellen mit einer Breite von 0,1 $\mu \mathrm{m}$. Wiederum weitere sind länglich mit einem Durchmesser von $0,1 \mu \mathrm{m}$. In Pyramidenzellen beträgt der Durchmesser von Mitochondrien im Durchschnitt 0,42 $\mu$ m. (Pysh und Khan 1972).

Beim genaueren Betrachten der Form der Dendriten fiel auf, dass die stumpfförmigen und pilzförmigen Dendriten in ihrer Morphologie ebenfalls kaum Unterschiede zwischen sich selbst aufwiesen (Abbildung 33). Die positive lineare Abhängigkeit beschrieb ein gleichmäßiges Wachstum der Form der Spines (stumpfförmig: $r=0,668 ; p=<0,0001$; pilzförmig: $\mathrm{r}=0,708, \mathrm{p}=<0,0001)$. Auf der $\mathrm{x}$-Achse kam es sowohl bei pilz- als auch bei stumpfförmigen Dendriten zu immer etwas höheren Werten als auf der y-Achse. Daher kann von einem ellipsoiden Wachstum der dendritischen Dornenfortsätze ausgegangen werden (Abbildung 36). Dass beide Arten fast dasselbe Wachstum aufwiesen, ist ebenfalls ein Indiz für die Theorie, dass stumpfförmige und pilzförmige Dendriten sich ähnlich sind. Die stumpfförmigen Dendriten verschwinden fast mit der Reifung, was vermuten lässt, dass sie eine Übergangsfunktion haben (Harris et al. 1992). Die traditionelle Klassifikation der Spines in verschiedene Gestalten (wie z. B. pilzförmig, stumpfförmig etc.) überträgt 
verschiedene Aufgaben zu ebendiesen. Eine neue Studie, die hochauflösende STEDMikroskopie (Stimulated Emission Depletion) verwendete, suggeriert, dass die stumpfförmigen dendritischen Dornenfortsätze in Wirklichkeit pilzförmig sind und dass die Klassifizierung in verschiedene Morphologien obsolet ist (Tønnesen et al. 2014).

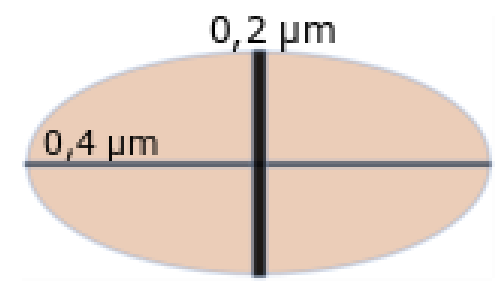

Abbildung 36: Skizze einer Ellipse mit Werten, um das Verhältnis der kleineren Achse gegen die größere Achse zu verdeutlichen.

Auch zeigte die insgesamte Membranoberfläche in Bezug auf das Schnittvolumen der Dendriten keine Auffälligkeiten und Unterschiede zwischen beiden Morphologien (Abbildung 34). Die Geraden wiesen laut dem Korrelationskoeffizienten eine positive lineare Abhängigkeit auf (stumpfförmig: $r=0,505 ; \mathrm{p}=0,0023$; pilzförmig: $r=0,779$; $\mathrm{p}=<0,0001)$. Die Membranoberfläche der pilzförmigen Dendriten wächst ab einer Größe von $1,2 \mu \mathrm{m}^{2}$ stärker an als die Membranoberfläche der stumpfförmigen Dendriten, was damit zusammenhängen kann, dass die pilzförmigen Dendriten eine Verjüngung im Halsbereich aufweisen, die eine Oberfläche bis maximal $1,2 \mu \mathrm{m}^{2}$ hat. Danach könnte der Kopf der Dendriten schneller wachsen als bei stumpfförmigen Synapsen, die ein konsistentes Wachstum haben. 


\section{$5 \quad$ Zusammenfassung}

Diese Arbeit endet mit einer kurzen Zusammenfassung, in der die zentralen Erkenntnisse genannt werden. Darüber hinaus werden Einschränkungen der Arbeit herausgearbeitet sowie weitere Ausblicke für folgende Studien zu dieser Thematik genannt.

Da die Organellen der Präsynapse bekannt sind, ist es unumgänglich, mehr Wissen über die Postsynapse zu erlangen. Die konventionelle hippocampale Neuronenkultur ist das Standardmodell für die synaptische Forschung. Die angelegten hippocampalen Zellen wurden mithilfe eines Diamantmessers in $70 \mathrm{~nm}$ dünne Scheiben geschnitten, die anschließend mittels Elektronenmikroskopie (ZESS EM 902 A Mikroskop) abgebildet und mithilfe von Photoshop Adobe CS6 übereinandergelegt und gedreht wurden. Dies erfolgte als Vorarbeit für die Herstellung eines 3D-Modells durch die Software MATLAB. Durch manuelles Einzeichnen der einzelnen Bestandteile der Synapse wurden mithilfe von MATLAB 3D-Bilder gefertigt, die nach der jeweiligen Morphologie und den typischen Charakteristika in zwei große Gruppen eingeteilt wurden: pilzförmige und stumpfförmige Dendriten. Anschließend wurden die Daten der einzelnen dendritischen Fortsätze mithilfe von SigmaPlot in Grafiken visualisiert und die Ergebnisse durch statistische Hilfsmittel konkretisiert.

Hinsichtlich der Form der dendritischen Fortsätze wurde klar, dass diese ellipsoid sein muss. Außerdem wächst die Oberfläche der pilzförmigen Spines schneller als die der stumpfförmigen Synapsen, was auf die Verjüngung im Halsbereich zurückgeführt werden konnte. Sowohl in stumpf- als auch in pilzförmigen dendritischen Dornenfortsätzen waren kaum Vesikel zu finden, und auch die Anzahl der Vesikel, wenn sie vorhanden sind, verhielt sich in beiden Morphologien ähnlich. Die Vesikel waren zwischen der aktiven Zone und dem Zentrum des Dendriten lokalisiert. Auch Vakuolen waren eher selten zu finden in dendritischen Fortsätzen und traten nur zu $40 \%$ auf. Darüber hinaus waren, wenn vorhanden, selten mehr als sechs Vakuolen pro Dendrit zu sehen. Auch die Volumina beider Dendritenmorphologien waren sich ähnlich. Die Größe der Vesikel der Postsynapse ist wie erwartet ein wenig größer als die der Vesikel in der Präsynapse, und sie sind vorwiegend zwischen dem Zentrum der Postsynapse und dem Bereich der 
postsynaptischen

Dichte

lokalisiert.

Insgesamt fällt bei näherer Betrachtung der Zellorganellen auf, dass weder bei der Anzahl der Vesikel noch bei der Anzahl der Vakuolen und Mitochondrien ein großer Unterschied zwischen den pilzförmigen und den stumpfförmigen Synapsen besteht. Auch die Volumina der Vakuolen und Mitochondrien weisen keine statistischen Unterschiede auf.

$\mathrm{Zu}$ Beginn dieser Arbeit wurde davon ausgegangen, dass die zwei unterschiedlichen Morphologien der Dendriten auch Unterschiede in der Anordnung und Anzahl der Zellorganellen mit sich bringen würden. Diese Vermutung konnte jedoch nicht bestätigt werden.

Diese Erkenntnisse basieren auf den MATLAB-Analysen sowie auf der verfügbaren Literatur.

\subsection{Limitationen der wissenschaftlichen Arbeit}

Der Forschungsgegenstand bezog sich auf ein Gebiet, das bisher wenig erforscht ist. Umso bedeutender sind weitere Untersuchungen für die Validität der Forschung. Auf diesem Sektor finden sich nur wenige wissenschaftliche Arbeiten und insbesondere zur Lokalisation der Organellen lassen sich kaum Vergleiche finden. Ferner war die Bearbeitung mit Photoshop nicht vollkommen präzise, da beim Rotieren der einzelnen Bilddateien nicht sicher war, ob die Synapsen aufgrund der EM-Aufnahme verdreht waren oder ob dies deren tatsächliche Form war. Da die Methodik dieser Arbeit sich im Wesentlichen von anderen bisherigen Forschungen unterscheidet (hier wurde eine hippocampale Neuronenkultur verwendet anstelle von Gewebsschnitten), sollte weitere Forschung auf diesem Gebiet betrieben werden, um Werte adäquat miteinander vergleichen zu können.

\subsection{Weitere Ausblicke für wissenschaftliche Arbeiten}

Da diese Studie größtenteils die Morphologien der Zellorganellen beleuchtete, wäre es interessant, einen Schritt weiterzugehen und die Zellorganellen auf molekularer Ebene zu untersuchen, gerade um Gewissheit über das glatte endoplasmatische Retikulum zu erhalten. Darüber hinaus könnten auch andere Morphologien der Dendriten einander gegenübergestellt werden, um zu sehen, ob diese sich ebenfalls ähneln. 


\section{$6 \quad$ Literaturverzeichnis}

Azevedo FAC, Carvalho LRB, Grinberg LT, Farfel JM, Ferretti REL, Leite REP, Jacob Filho W, Lent R, Herculano-Houzel S (2009): Equal numbers of neuronal and nonneuronal cells make the human brain an isometrically scaled-up primate brain. J Comp Neurol $\underline{513}, 532-541$

Berlucchi G, Buchtel HA (2009): Neuronal plasticity: Historical roots and evolution of meaning. Exp Brain Res 192, 307-319

Bolshakov VY, Siegelbaum SA (1994): Postsynaptic Induction and Presynaptic Expression of Hippocampal Long-Term Depression. Science, New Series, 1148-1152

Bourne JN, Harris KM (2008): Balancing structure and function at hippocampal dendritic spines. Annu Rev Neurosci 31, 47-67

Chang FL, Greenough W'T (1984): Transient and enduring morphological correlates of synaptic activity and efficacy change in the rat hippocampal slice. Brain Res $\underline{309}$, 35-46

Chicurel ME, Harris KM (1992): Three-dimensional analysis of the structure and composition of CA3 branched dendritic spines and their synaptic relationships with mossy fiber boutons in the rat hippocampus. J Comp Neurol $\underline{325}, 169-182$

Cho KO, Hunt CA, Kennedy MB (1992): The rat brain postsynaptic density fraction contains a homolog of the drosophila discs-large tumor suppressor protein. Neuron $\underline{9}$, 929-942

Choquet D, Triller A (2013): The dynamic synapse. Neuron $\underline{80}$, 691-703

Cooney JR, Hurlburt, Jamie L, Selig, DK., Harris KM, Fiala JC (2002): Endosomal Compartments Serve Multiple Hippocampal Dendritic Spines from a Widespread Rather Than a Local Store of Recycling Membrane. J Neurosci 22 (6), 2215-2224

Dudek SM, Bear MF (1992): Homosynaptic long-term depression in area CA1 of hippocampus and effects of N-methyl-D-aspartate receptor blockade. Proc Natl Acad Sci USA $\underline{89}, 4363-4367$

Dunaevsky A, Tashiro A, Majewska A, Mason C, Yuste R (1999): Developmental regulation of spine motility in the mammalian central nervous system. Proc Natl Acad Sci USA 무, 13438-13443

Engert F, Bonhoeffer T (1999): Dendritic spine changes associated with hippocampal longterm synaptic plasticity. Nature $\underline{399}, 66-70$ 
Ferrer I, Gullotta F (1990): Down's dyndrome and Alzheimer's disease: dendritic spine counts in the hippocampus. Acta Neuropathol 79(6), 680-685

Fifkova E, Anderson CL (1981): Stimulation-Induced Changes in Dimensions of Stalks of Dendritic Spines in the Dentate Molecular Layer. Exp Neurol 74(2), 621-627

Gray EG (1959): Axo-somatic and axo-dendritic synapses of the cerebral cortex. J Anat $\underline{93}$, $420-433$

Harris KM, Jensen FE, Tsao B (1992): Three-dimensional structure of dendritic spines and synapses in rat hippocampus (CA1) at postnatal day 15. J Neurosci 12(7), 2685-2705

Harris KM, Kater SB (1994): Dendritic Spines: Cellular Specializations Imparting Both Stability and Flexibility to Synaptic Function. Annu Rev Neurosci 17, 341-371

Hering H, Sheng M (2001): Dendritic Spines: Structure, Dynamics and Regulation. Nat Rev Neurosci $\underline{2,880-888}$

Jones EG, Powell T (1969): Morphological variations in the dendritiv spines of the neocortex. J Cell Sci $\underline{\text { (2) }), 509-529}$

Lisman JE, Goldring MA (1988): Feasibility of long-term storage of graded information by the $\mathrm{Ca} 2+$ /calmodulin-dependent protein kinase molecules of the postsynaptic

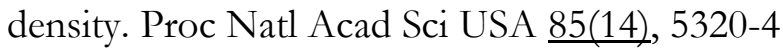

Lorincz A, Nusser Z (2010): Molecular identity of dendritic voltage-gated sodium channels. Science $\underline{328}$, 906-909

Majewska A, Brown E, Ross J, Yuste R (2000): Mechanisms of calcium decay kinetics in hippocampal spines: role of spine calcium pumps and calcium diffusion through the spine neck in biochemical compartmentalization. J Neurosci 20(5), 1722-1734

Murk, JL, Humbel BM, Ziese U, Griffith JM, Posthuma G, Slot JW, Koster AJ, Verkleij AJ, Greuze HJ, Kleijmeer MJ (2003): Endosomal compartmentalization in three dimensions: Implications for membrane fusion. Proc Natl Acad Sci USA $\underline{100,13332-}$ 13337

Nakanishi S, Masu M (1994): Molecular Diversity and Functions of Glutamate Receptors. Annu Rev Biophys Biomol Struct. 23, 319-348

Nikolaev MV, Magazanik LG, Tikhonov DB (2012): Influence of external magnesium ions on the NMDA receptor channel block by different types of organic cations. Neuropharmacology $\underline{62}$, 2078-2085

Pysh JJ, Khan T (1972): Variations in mitochondrial structure and content of neurons and neuroglia in rat brain: An electron microscopic study. Brain Res. $\underline{36}, 1-18$

Rizzoli SO, Betz WJ (2005): Synaptic Vesicle Pools. Synaptic Neurosci 6(1), 57-69 
Sabatini BL, Maravall M, Svoboda K (2001): Ca2+ signaling in dedritic spines. Curr Opin Neurobiol 11, 349-356

Segal M (2016): Dendritic spines: Morphological building blocks of memory. Neurobiol Learn Mem 138, 3-9

Siekevitz P (1985): The postsynaptic density: A possible role in long-lasting effects in the

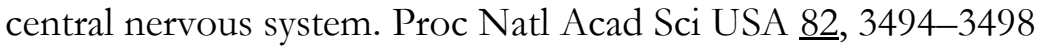

Sorra KE, Harris KM (1998): Stability in Synapse Number and Size at $2 \mathrm{Hr}$ after LongTermin Potentiation in Hippocampal Area CA1. J Neurosci 18,658-671

Sorra KE, Harris KM (2000): Overview on the structure, composition, function, development, and plasticity of hippocampal dendritic spines. Hippocampus $\underline{10}, 501-$ 511

Sotelo C (2003): Viewing the brain through the master hand of Ramon y Cajal. Nat Rev Neurosci $\underline{4}, 71-77$

Spacek J, Harris KM (1997): Three-Dimensional Organization of Smooth Endoplasmic Reticulum in Hippocampal CA1 Dendrites and Dendritic Spines of the Immature and Mature Rat. J Neurosci 17, 190-203

Stewart MG, Popov VI, Kraev IV, Medvedev N, Davies HA: Structure and Complexity of the Synapse and dendritic Spine. In: Pickel V, Segal M (Hrsg.): The Synapse: Structure and Function (Neuroscience-Net Reference Book Series). Elsevier/Academic Press, Oxford 2014, 1-18

Toni N, Buchs PA, Nikonenko I, Povilaitite P, Parisi L, Muller D (2001): Remodeling of Synaptic Membranes after Induction of Long-Term Potentiation. J Neurosci 21(6), 6245-6251

Tønnesen J, Katona G, Rózsa B, Nägerl V (2014): Spine neck plasticity regulates compartmentalization of synapses. Nat Neurosci 17(5), 678-685

Wu K, Aoki C, Elste A, Rogalski-Wilk AA, Siekevitz P (1997): The synthesis of ATP by glycolytic enzymes in the postsynaptic density and the effect of endogenously generated nitric oxide. Proc Natl Acad Sci USA 94, 13273-13278

Yuste R (2015): The discovery of dendritic spines by Cajal. Front Neuroanat $\underline{9}, 18$ 


\section{Danksagung}

Hiermit möchte ich mich herzlich bei Herrn Prof. Dr. Silvio O. Rizzoli, Leiter des Instituts für Neuro- und Sinnesphysiologie, für die Möglichkeit bedanken, diese Arbeit unter seiner Leitung durchzuführen. Besonders danke ich für die hervorragende Betreuung und seine ständige Hilfsbereitschaft. Auch für das Überprüfen der Arbeit e möchte ich ihm herzlich danken. Jederzeit war er auf geduldige Art bereit, mir Denkanstöße und Feedback zu geben. Herrn Prof. Dr. Paul Lingor danke ich ebenfalls für seine Bereitschaft, diese Arbeit als Ko-Referent zu prüfen.

Mein Dank geht auch an die gesamte Arbeitsgruppe, besonders Martin Helm und Christina Schäfer, für die konstante Hilfsbereitschaft und die wertvollen Anregungen, die besonders zum Gelingen dieser Arbeit beigetragen haben.

Christina Koerbs möchte ich ebenfalls meinen Dank aussprechen - es ist schön zu sehen, welche Freundschaft sich entwickelt hat und wie wir uns gegenseitig unterstützen konnten.

Ich möchte ebenfalls Britta Wilde für das Korrekturlesen und ihre Motivation danken. 


\section{Lebenslauf}

\section{Persönliche Daten}

Mein Name ist Vanessa Salimi, ich wurde am 26. April 1993 in Sydney geboren und bin deutsche Staatsbürgerin.

\section{Bildungsweg}

Ich habe das Abitur im Jahr 2011 am Gymnasium Bad Nenndorf mit sehr guten Leistungen absolviert, sodass ich anschließend das Studium der Zahnmedizin an der Georg-August-Universität in Göttingen aufnehmen konnte und im Juni 2018 mit Erfolg abgeschlossen habe.Des Weiteren habe ich die Promotion über das Thema „Die prärise Ultrastruktur der Organellen der dendritischen Spines” bei Prof. Dr. Silvio O. Rizzoli im Februar 2016 begonnen. Mein Einstieg in das Berufsleben erfolgt ab dem 01.09.2018 in einer Gemeinschaftspraxis in Mannheim, in welcher ich meine Assistenzzeit absolvieren werde.

\section{Praktische Erfahrungen}

Mein persönliches Interesse, internationale Erfahrungen zu sammeln, konnte ich mit praktischen Erfahrungen der Zahnmedizin kombinieren. So habe ich von September bis Oktober 2017 eine Famulatur bei Mini Molars e. V. in Pnomh Penh, Kambodscha, absolviert. Hierbei habe ich gemeinsam mit einem Team von Zahnärzten Kinder in der Hauptstadt Kambodschas zahnmedizinisch behandelt, auch außerhalb der Stadt in Slums. Darüber hinaus habe ich im August 2016 ein Praktikum in einer privaten Kieferchirurgiepraxis in Johannesburg, Südafrika absolviert. Sowohl die Praktika in Kambodscha, Südafrika als auch die praktischen Erfahrungen im Laufe des Studiums haben mir geholfen, von unterschiedlichen Ärzten zu lernen, meine praktischen Fähigkeiten zu vertiefen und mir geholfen, mich auf meine Zeit als Assistenzzahnärztin vorzubereiten. Abschließend hat das Implantologie-Seminar in Maishofen, Österreich mein Interesse für die Chirurgie geweckt. 